\title{
AN INTEGRATED MODELING APPROACH FOR DESIGN AND OPTIMIZATION OF EJECTOR PUMPS CARRYING TWO-PHASE FLUID
}

\author{
A Dissertation \\ Presented to \\ the Faculty of Mechanical and Aerospace Engineering and Graduate School \\ at the University of Missouri-Columbia
}

In Partial Fulfillment

of the Requirement for the Degree

Doctor of Philosophy

By
KHALID SARHAN ALMUTAIRI

Professor El-Gizawy, Ahamed. Sherif, Dissertation Supervisor

DECEMBER 2017 
The undersigned, appointed by the dean of the Graduate School, have examined the dissertation entitled

\section{AN INTEGRATED MODELING APPROACH FOR DESIGN AND OPTIMIZATION OF EJECTOR PUMPS CARRYING TWO PHASE FLUID}

presented by KHALID SARHAN ALMUTAIRI, a candidate for the degree of doctor of philosophy, and hereby certify that, in their opinion, it is worthy of acceptance.

Professor El-Gizawy, A. Sherif

Professor Salim, Hani

Professor Zhang, Yuwen

Professor Fales, Roger

Professor Awwad, Mohamed 


\section{ACKNOWLEDGEMENTS}

This work would not have been possible without the financial support of the Saudi Arabia government via King Abdullah, the Custodian of the Two Holy Mosques Scholarship program. In addition, I would thank the Boeing Company for their generous funding for this work. I am especially indebted to Dr. El-Gizawy, who has been supportive of my career goals and who worked actively to provide me with the protected academic time to pursue those goals.

I am grateful to all of those with whom I have had the pleasure to work during this project. Each of the members of my dissertation committee has provided me with extensive personal and professional guidance and taught me a great deal about both scientific research and life in general. I would especially like to thank Dr. Zhang, Yuwen, the chairman of Mechanical and Aerospace Engineering department. As my teacher, he has taught me more than I could ever give him credit for here. He has shown me, by his example, what a good scientist (and person) should be. Nobody has been more important to me in the pursuit of this project than the members of my family have. I would like to thank my parents, whose love, guidance, and prayers are with me in whatever I pursue. They are the ultimate role models. Most importantly, I wish to thank my loving and supportive wives, Nouf and Modhi, and my five wonderful children, Sarhan, Tala, Nour, Fahad and Diala who provide unending inspiration. 


\section{TABLE OF CONTENTS}

\section{LIST OF FIGURES}

\section{CHAPTER I}

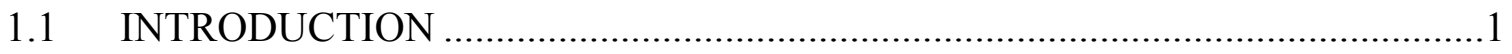

2 CHAPTER II

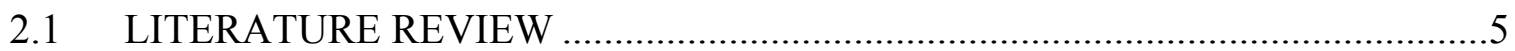

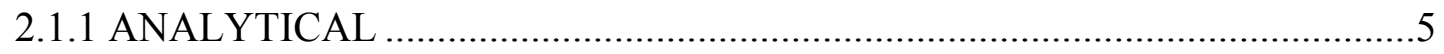

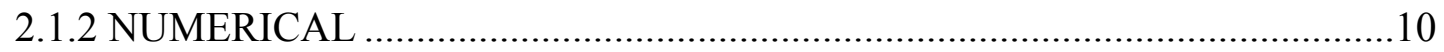

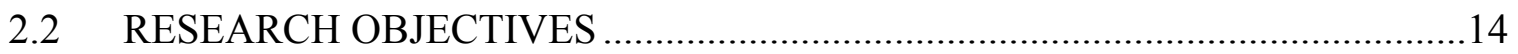

3 CHAPTER III

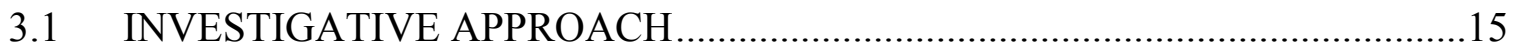

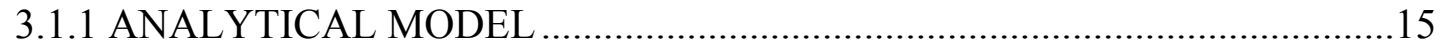

3.1.2 EVALUATION OF UNCERTAINTY .........................................................25

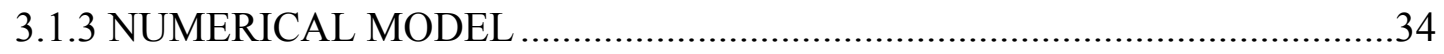

3.1.4 EXPERIMENTAL INVESTIGATION .................................................... 37

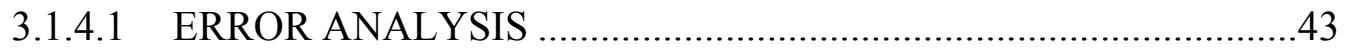

3.1.4.2 MATRIX EXPERIMENT FOR VARIOUS GEOMETRIC

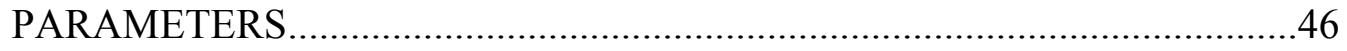

4 CHAPTER IV

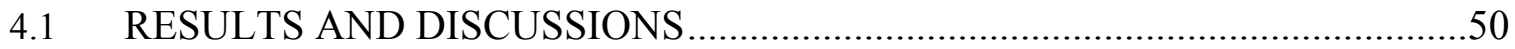

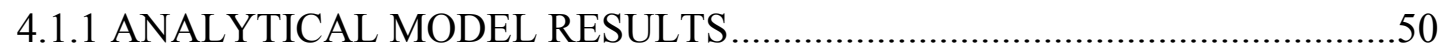


4.1.1.1 MODEL VERIFICATION

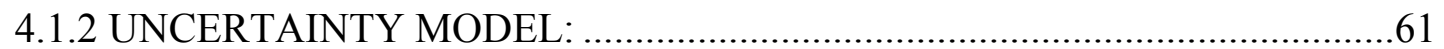

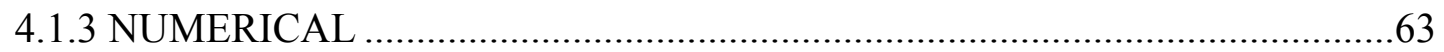

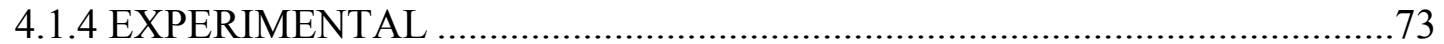

5 CHAPTER V

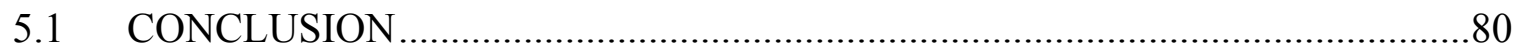

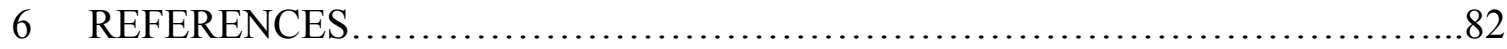

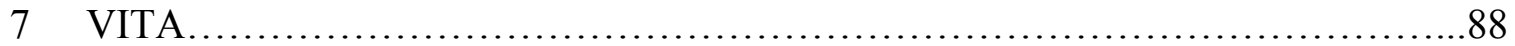




\section{LIST OF FIGURES}

Figure Page

Figure 1 Cross section view of a typical liquid ejector.................................................... 1

Figure 2 Characteristic pressure distribution within a liquid ejector [1] ......................... 2

Figure 3 Characteristic curve of ejector performance over complete operating range [1] . 4

Figure 4 Reference planes and notations as applied to ejector analysis .......................... 17

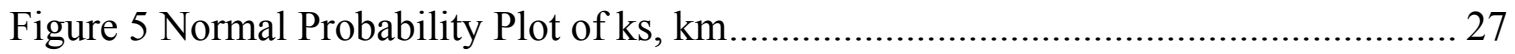

Figure 6 Lognormal Probability Plot of ks, km ......................................................... 27

Figure 7 Exponential Probability Plot of ks, km........................................................ 28

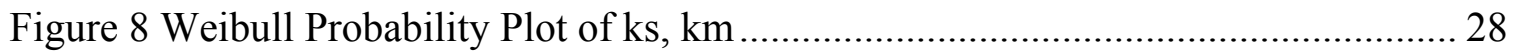

Figure 9 Probability density function for $\mathrm{Km}$............................................................ 30

Figure 10 Cumulative density function for $\mathrm{Km}$.......................................................... 30

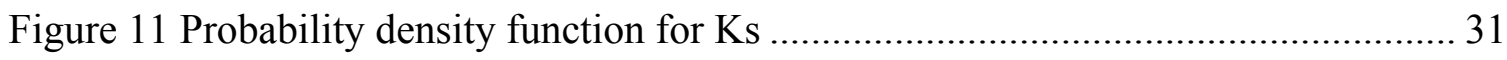

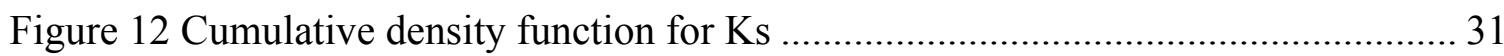

Figure $13 \mathrm{~A}$ schematic diagram of the test rig and A 3-D rendering of the test rig ......... 38

Figure 14 Visual of left empty and right full trash bag for airflow measurement ............ 43

Figure 15 geometric parameters for group A................................................................ 48

Figure 16 geometric parameters for group B .......................................................... 48

Figure 17 geometric parameters for group C .......................................................... 49

Figure 18 Analytical model characteristic curves for single-phase experiments ............. 52

Figure 19 Analytical model prediction of pressure ratio ................................................ 55

Figure 20 Analytical model prediction of efficiency ..................................................... 56

Figure 21 Analytical model prediction of flow ratio ...................................................... 57

Figure 22 Analytical model prediction of secondary pressure ……................................. 58 
Figure 23 Cumulative probability for the pressure ratio $\mathrm{N}$

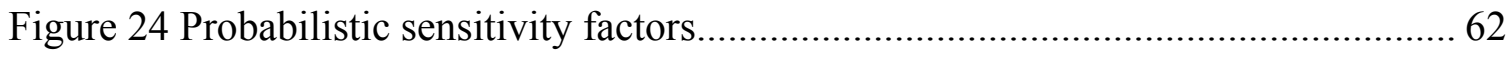

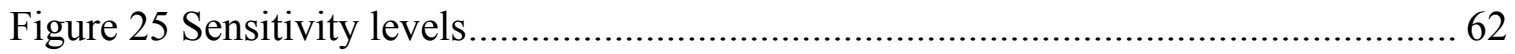

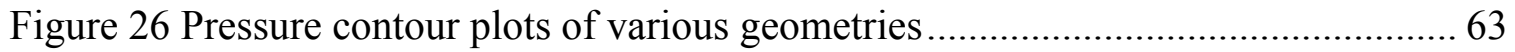

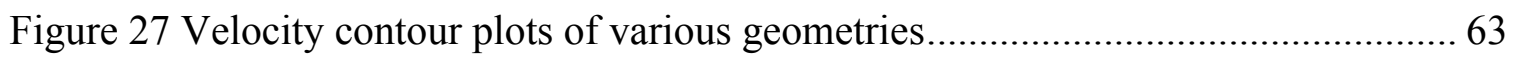

Figure 28 Volume fractions of the primary phase contour plots of various geometries... 64

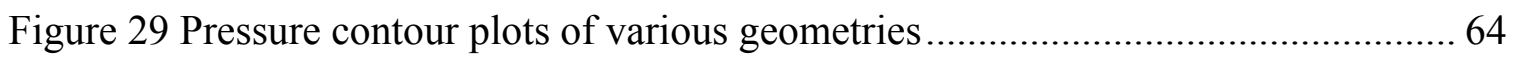

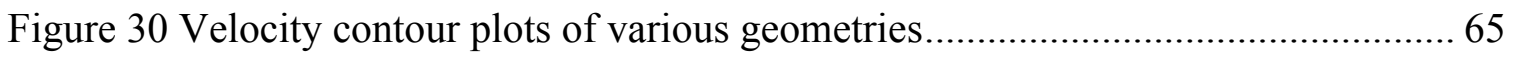

Figure 31 Volume fractions of the primary phase contour plots of various geometries... 65

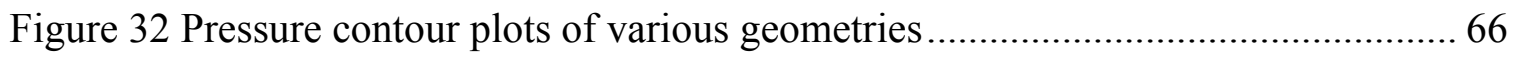

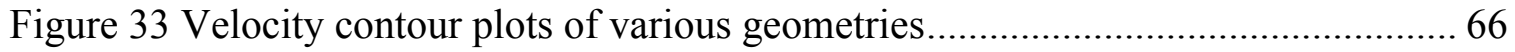

Figure 34 Volume fractions of the primary phase contour plots of various geometries... 67

Figure 35 the impact of the mixing chamber length, L, and the nozzle diameter, d. ....... 68 Figure 36 Group A; Variation of $\alpha$ with different Mixing tube length and constant nozzle

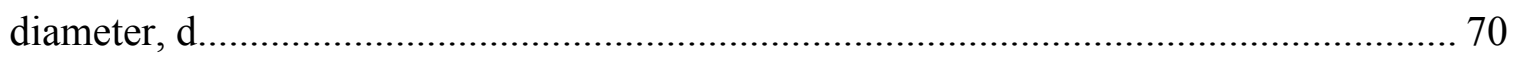

Figure 37 Group B; Variation of $\alpha$ with different Mixing tube length and constant nozzle

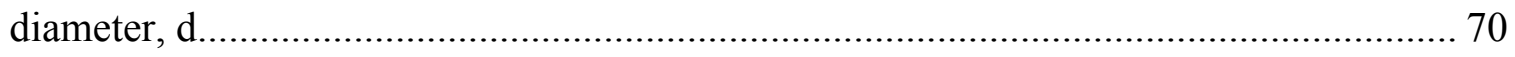

Figure 38 Group C; Variation of $\alpha$ with different Mixing tube length and constant nozzle

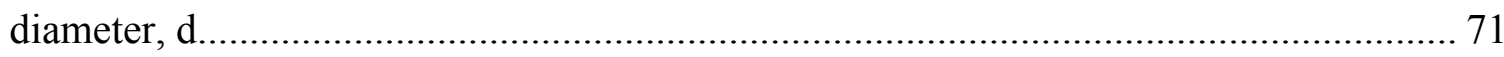

Figure 39 Group L1; Variation of gas induction with different nozzle diameter, $\mathrm{d}$ and

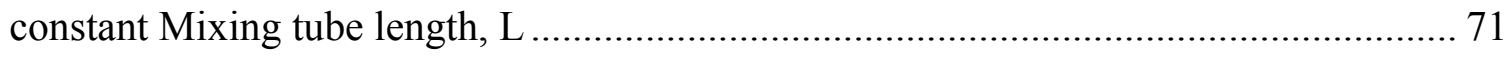

Figure 40 Group L2; Variation of gas induction with different nozzle diameter, $\mathrm{d}$ and

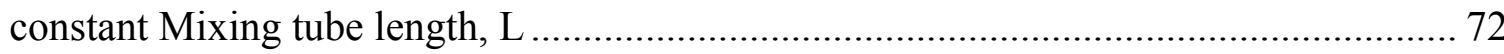


Figure 41 Group L3; Variation of gas induction with different nozzle diameter, $\mathrm{d}$ and

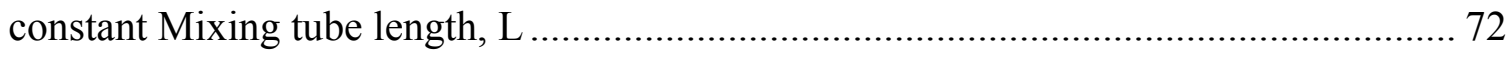

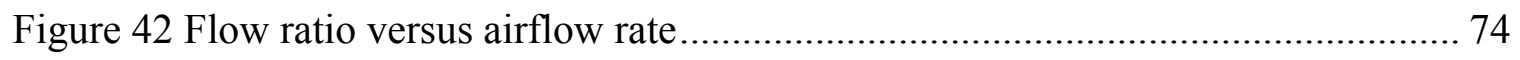

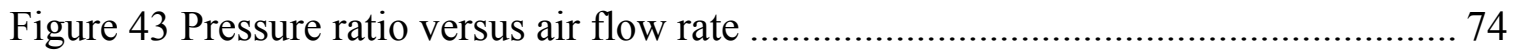

Figure 44 Pressure versus primary flow rate ..................................................... 75

Figure 45 Secondary pressure as a function of primary flow rate and inlet barrel fluid

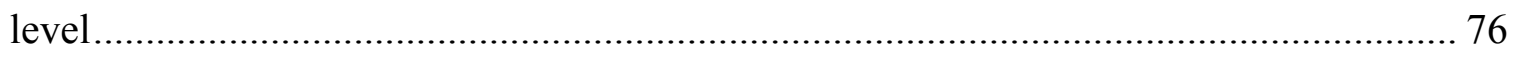

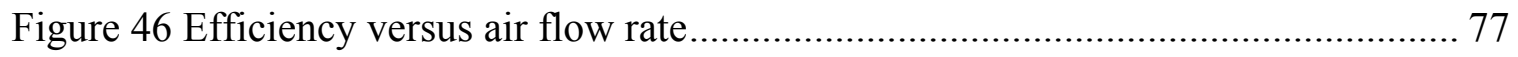

Figure 47 Empirical relationship for $\Delta \mathrm{H}$ as a function of Qp................................... 78

Figure 48 Empirical model for volumetric flow rate of induced air............................. 79 


\section{NOMENCLATURE}

\begin{tabular}{|c|c|}
\hline$C$ & fluid density ratio, dimensionless \\
\hline$d$ & diameter of primary nozzle exit, in \\
\hline$D$ & diameter of mixing chamber, in \\
\hline$f$ & friction factor, dimensionless \\
\hline$K$ & component loss coefficient, dimensionless \\
\hline$L$ & length of mixing chamber, in \\
\hline$l$ & characteristic length, in \\
\hline$M$ & volume flow ratio, dimensionles \\
\hline$N$ & pressure ratio, dimensionless \\
\hline$Q$ & volume flow rate, GPM \\
\hline$R$ & area ratio, dimensionless \\
\hline $\operatorname{Re}$ & Reynolds number, dimensionless \\
\hline$s$ & distance from primary nozzle exit to mixing chamber entrance, in \\
\hline$V$ & velocity, in/s \\
\hline$x$ & quality, dimensionless \\
\hline$\beta$ & coefficient for nozzle placement 'jet loss' term, dimensionless \\
\hline$\varepsilon$ & effective roughness height of mixing chamber surface, $\mathrm{mm}$ \\
\hline$\eta$ & ejector efficiency, dimensionless \\
\hline$\varphi$ & diffuser half angle, degrees \\
\hline$\rho$ & density, $\mathrm{kg} / \mathrm{m}^{3}$ \\
\hline$\sigma$ & cavitation number, dimensionless \\
\hline$\alpha$ & fitting parameters \\
\hline
\end{tabular}




\begin{tabular}{|c|c|}
\hline Subscripts & \\
\hline $1,2,3,4,5$ & planes within ejector, as defined in Figure 4 \\
\hline$d$ & diffuser or discharge flow \\
\hline$m$ & mixing chamber \\
\hline$n$ & primary nozzle exit \\
\hline$p$ & primary flow \\
\hline$s$ & secondary or induced flow \\
\hline
\end{tabular}




\title{
AN INTEGRATED MODELING APPROACH FOR DESIGN AND OPTIMIZATION OF EJECTOR PUMPS CARRYING TWO-PHASE FLUID
}

\author{
KHALID SARHAN ALMUTAIRI \\ Professor El-Gizawy, A. Sherif, Dissertation Supervisor
}

ABSTRACT

An ejector pump uses a primary flow as a motive fluid to entrain another fluid, and can work with both incompressible flow and compressible flow, in either as a singlephase or two-phase mixture. Determining the behavior of the two-phase flow inside the ejector with different geometric parameters was the objective of this research. Three approaches were used to predict the performance and the capture the flow behavior inside it. An analytical model used the geometric parameters to calculate the loss factors for the first time and work as a basis for the two-phase flow ejectors. A fluid transportation system was built to verify analytical and numerical predictions and to explore optimum. Using a fitting parameter to capture the flow behavior inside the ejector was crucial for the accuracy of the numerical model. The fitting parameter is a new technique that uses an arbitrary fluid to match the induced air measurements numerically with the ones founded experimentally. To apply the three approaches, nine ejectors were built with different geometric parameters. The nozzle exit diameters are tested at three levels while the length mixing tube are tested at three levels as well. The results reveal that the diffuser angle of $5^{\circ}$, the smallest nozzle exit diameter, and the longest mixing tube result on maximum efficiency and highest induced air. More investigation of two-phase ejectors is important to fully understand flow behavior and to increase efficiency. There are many improvements needed to this work in future 


\section{CHAPTER I}

\subsection{INTRODUCTION}

An ejector uses a primary flow as a motive fluid to entrain another fluid, and can work with both incompressible flow and compressible flow, either as single-phase or two-phase mixture. An ejector is illustrated in Figure 1which has four main parts: a primary nozzle, secondary chamber, a mixing chamber and a diffuser.

Ejector is based upon Bernoulli's Principle that states that when a motive fluid at high pressure is accelerated through a nozzle, it exits the nozzle at high velocity as its kinetic energy increases and its pressure reduces.

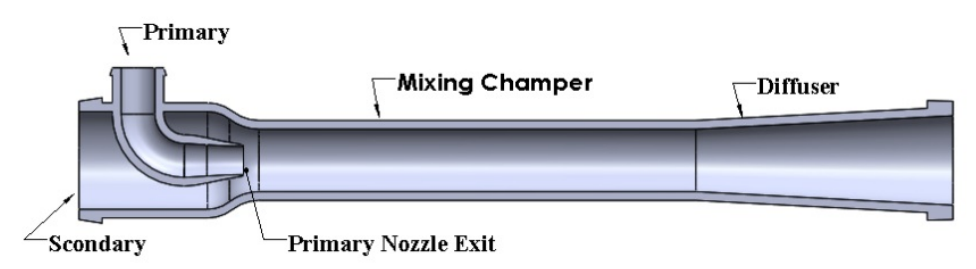

Figure 1 Cross section view of a typical liquid ejector

The low-pressure and low-velocity secondary fluid induces since the motive fluid creates a vacuum at the nozzle exit due to the pressure drop. 
Both the motive fluid, which in this case is water, and secondary fluid, which is air, combines in the mixing chamber to create a mixture flow. Since there are two different pressures and velocities, the energy and momentum will transfer from high to low, and turbulence may occur in the mixing chamber. For simplicity, we assume that the mixture will be fully developed at the end of the mixing chamber due to some pressure recovery and decelerated flow. Since most of the energy is lost in mixing chamber, we also assume that the mixture will be homogenous, no slip velocity. In the last part of the ejector, the diffuser, the mixture decelerates further and gains more pressure due to conversion that happens as kinetic energy is converted into potential energy.

This pressure distribution is depicted in Figure 2.

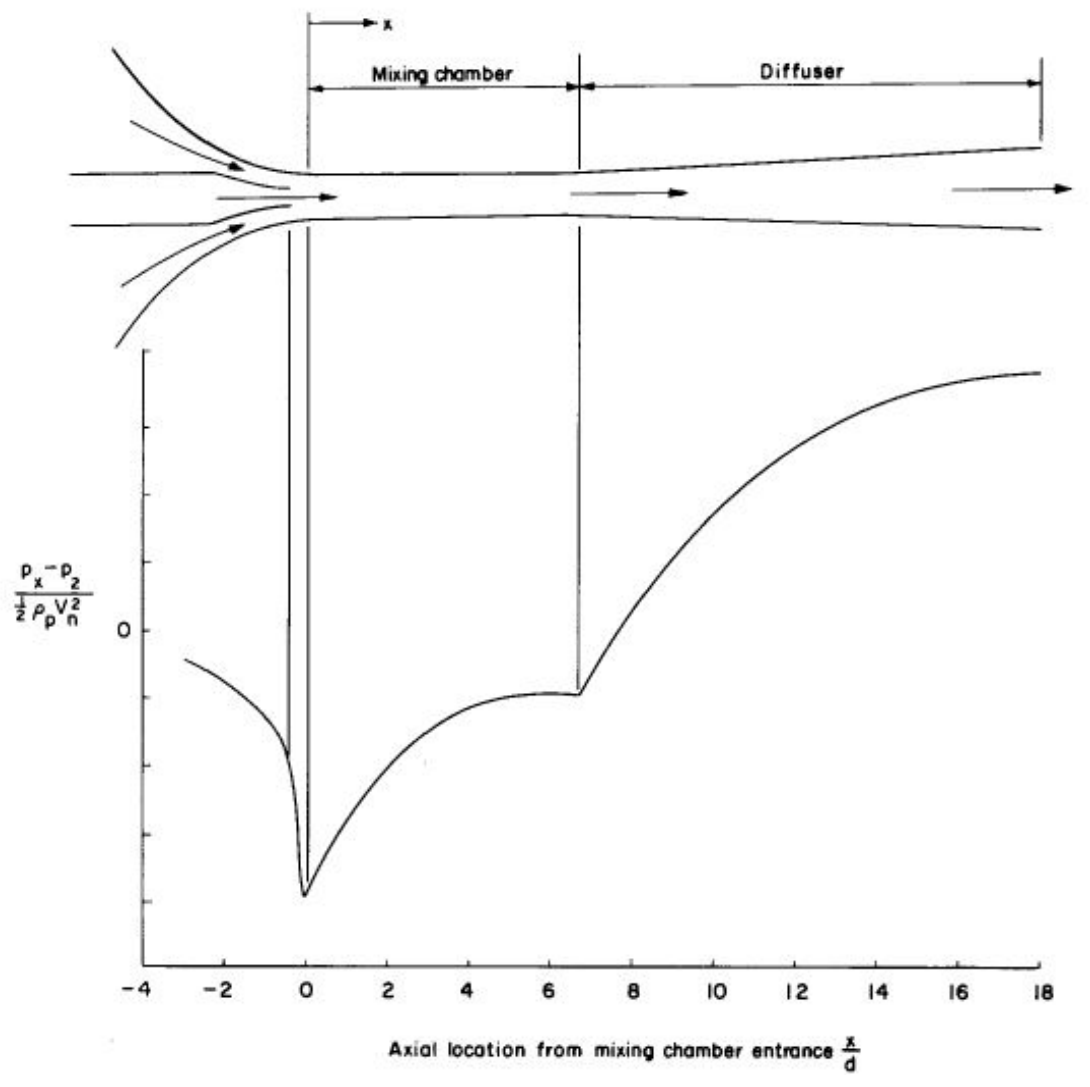

Figure 2 Characteristic pressure distribution within a liquid ejector [1] 
There are two most important parameters used to describe the performance of an ejector as the 'flow ratio' and the 'pressure ratio' [2]

Multiplying the ratios describes the ejector performance and overall efficiency. The flow ratio is the secondary flow rate compared to the primary flow rate and the pressure ratio is the secondary pressure rise compared to the primary pressure drop. Equations 1-1 to 1-3 show the ejector performance and its parameters.

$$
\begin{gathered}
M=\frac{Q_{s}}{Q_{p}} \\
N=\frac{P_{d}-P_{s}}{P_{p}-P_{d}} \\
\eta=M \times N
\end{gathered}
$$

A typical characteristic curve as shown in Figure 3 describes the ejector performance and its parameters. The efficiency, $\eta$, and pressure ratio, $N$, is plotted versus flow ratio, M. As we see in the typical characteristic curve, there are two lines. The slope which is the area ratio, $\mathrm{R}$, is describing the pressure ratio, N. It has two intercept points with the $\mathrm{Y}$-axis, pressure ratio, and $\mathrm{X}$-axis, $\mathrm{M}$, flow ratio. The one intercept with the $\mathrm{Y}$ axis describes the secondary reverse flow point that we do not want the flow to reach because it will affect the ability of the ejector to entrain more air in the system. The other intercepts with the efficiency curve and describes the cavitation point. Both are critical points that we are trying to avoid when we design the system. In addition, the slope shows that when the flow ratio, $M$, increases the pressure ratio, $N$, decreases. When $M=0$, 
the secondary flow is 0 and only the primary fluid is running. Therefore, the best point to design the ejector is at the mid-point which has the highest efficiency.

The efficiency curve is describing the efficiency of the ejector and it is plotted using equation 1-3. The characteristic curve of an ejector pump is important to understand because it explains the parameters that affect the ejector efficiency, which is the flow ratio, $\mathrm{M}$, the pressure ratio, $\mathrm{N}$, and the geometry of the ejector, $\mathrm{R}$.

Ejector performance will be studied in two cases as a single-phase liquid (water) and a two-phase liquid/gas mixture (water/air).

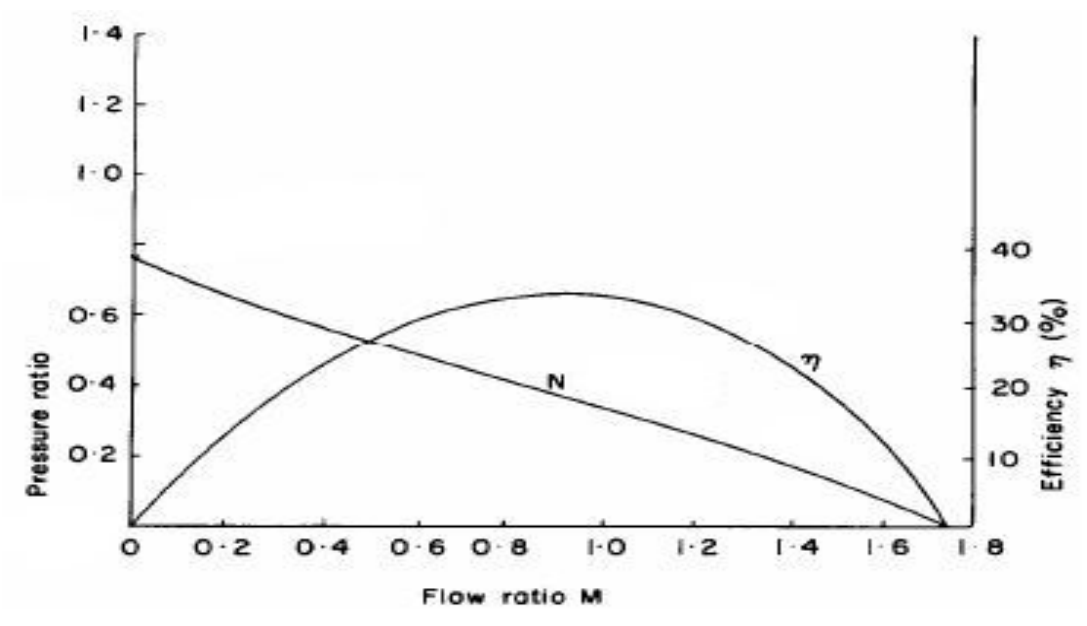

Figure 3 Characteristic curve of ejector performance over its complete operating range [1] 


\section{CHAPTER II}

\subsection{LITERATURE REVIEW}

\subsubsection{ANALYTICAL}

Since the introduction of single phase ejectors in the mid-twentieth century, ejectors have been studied and analyzed for improvements in design and performance. In 1934, Gosline and O'Brien [3] published the first comprehensive theoretical analysis of water ejectors verified with empirical data. While Gosline and O'Brien did not focus on improved capabilities, their work has since served as the basis of ejector design and performance analysis. Hundreds of papers have been published based on one-dimensional analysis of liquid jet pumps. Ejectors were the focus of two symposiums in the 1970s sponsored and organized by the British Hydraulic Research Association of Fluid Engineering in conjunction with the Institution of Chemical Engineers [4, 5]. In bibliographic reviews by Seddon and Dyke of the Royal Aircraft Establishment [6] and Bonnington and King [7], over 500 references were cited relating to ejectors prior to 1964. Approximately half of these articles referred to liquid ejectors while only two articles referred to liquid ejectors with two-phase entrained flow.

Gosline and O'Brien's combination of theory and experiment provided notable agreement and introduced the concepts of area ratio, the dimensionless geometry factor impacting the $\mathrm{N}$ and $\eta$ characteristic curves of an ejector, and loss factors accounting for friction losses in the different sections of the ejector assembly [3]. Cunningham researched both optimal geometries of ejectors and appropriate loss factors [8]. Performance models were considerably enhanced by direct measurement of all four loss coefficients, but because that is not always feasible, estimations must be made. 
Additionally, it was determined that in addition to area ratio, there are two geometrical parameters required for adequate design: spacing of the primary nozzle away from the throat entrance and the length of the throat. Cunningham performed an energy balance to determine the impact of primary nozzle placement on the pressure ratio, N. The analytical equation for N, as determined by Cunningham [8], is shown in Eq.(3 45) where the final term in the denominator accounts for the 'jet loss' or the additional energy loss from the withdrawn primary nozzle unaccounted for in basic one-dimensional analysis [8]. If the primary nozzle tip is in the same plane as the entrance to the mixing chamber, $\beta$ $=0$, and the equation simplifies to the standard analytical equation for $\mathrm{N}$, which will be derived later in this work. Mixing throat length is critical to the one-dimensional assumptions of performance prediction. If the mixing throat length is inadequate, mixing will not be complete at the entrance to the diffuser. Diffuser loss coefficients for performance predictions are not adequate to account for this. Sanger's experiments involving mixing throat lengths validated this theory and looked at optimum mixing throat lengths [9]. While short mixing throat lengths extend mixing into the diffuser, lengths that are too long have increased friction losses, thus impeding pump performance.

Cunningham et al. continued their investigation into optimal placement of the primary nozzle away from the throat entrance and determined that retraction of the primary nozzle aids the delay of the onset of cavitation [10]. Use of a cavitation index, $\sigma$, and equal to 1.35 is generally recommended for prediction of the onset of cavitation. Marini et al.'s investigation into prediction of cavitation agrees with Cunningham et al., but Marini et al. also show that for low area ratio ejectors, the mixing chamber and diffuser loss 
coefficients vary significantly with discharge flow rate [11]. Inclusion of this factor improves performance prediction over previous models. Kentfield and Barnes determined the diffuser loss coefficient to be the most significant factor in the effectiveness of performance prediction [12].

As the design and performance predictions have improved for ejector operation with similar fluids, attention has shifted to ejectors with streams of different phases. Developments in these areas are not as advanced and leave many questions unanswered. Mikhail and Abdou investigated liquid ejectors where the primary and induced liquid streams have different viscosity and density, resulting in an empirical determination of the mixing chamber loss coefficient based on the Reynolds number of the unique homogeneous mixture [13]. Liquid ejectors entraining gas flows studied by Cunningham [14] and Cunningham and Dopkin [14, 15], employ similar loss coefficients to the four required for liquid-liquid ejectors, but the overall efficiency is increased by including the compression of the induced flow stream into the parameter.

$$
\eta=\eta_{l}+\eta_{g}=M N+\frac{P_{s} \phi_{s} \ln \frac{P_{d}}{P_{s}}}{P_{p}-P_{d}}
$$

where $\phi s$ is the ratio of gas flow to the primary flow stream shows that the efficiency of pumping the liquid remains the same, but the overall efficiency considered for the application increases by the work done by compressing the gas divided by the energy rate input to the system. Hongqi provides additional investigation into deriving governing equations for the operation of liquid ejectors entraining gas flow [16]. Based on flow ratio and pressure ratio, an ejector can be designed with the highest possible entrainment 
and the highest possible discharged pressure, when operating at given conditions. Many studies were made to understand not only fundamental ejector fluid dynamics and heat transfer but also ejector operational behavior $[17,18,19]$.

Most relevant to this work, research into ejectors with a single two-phase stream, primary or induced, is preliminary and not validated. Jiao et al. employ the same analysis for a two-phase induced flow as has been used for one-dimensional analysis of ejector performance [20]. However, Jiao et al. utilize an empirical expression for the loss coefficient associated with the throat and the diffuser. This factor was determined by applying data regression to empirical data. The resultant model predicts two-phase ejector performance with a mean square error equal to 0.065 of the experimental data. An important notation in this work is that the properties of the gas phase are at standard conditions - that which are known outside of the ejector. The most accurate temperature and pressure which should be used to model the gas phase would be those properties insitu. However, it is unlikely these would be known during operation.

Noronha et al. presented another two-phase model covering the same experimental data used by Jiao et al. $[21,22]$. This work utilized linear regression to determine all of the loss coefficients, including primary nozzle, secondary nozzle, throat, and diffuser, to improve Jiao's model. Noronha et al. also improved Jiao's model by disregarding data points that correlate poorly, citing possible experimental error or transcription mistakes. The results used 118 of the original 269 data points, reducing the mean square error to 0.050. All of the data points considered by Jiao et al. and Noronha et al. neglected low 
pressure tests [20-22] and the primary fluid was $2,000-3,000$ psi $(13,800-27,600 \mathrm{kPa})$, significantly higher than pressure obtained in aircraft fuel barrel applications.

Cunningham extended his study of ejectors to two-phase flow inn 1995, when he proposed theoretical governing equations for an ejector with a liquid primary flow and a liquid-vapor secondary flow [23]. This model encompasses both liquid/liquid and liquid/gas operations of ejectors. With the correct input flow parameters, the model would predict performance of a liquid/liquid or a liquid/gas counterpart. Unlike other models, it provides a method for predicting the overall efficiency, from which the pressure ratio can be determined. This method is not validated, however, and the author states, "no experimental data are known to be available at this time for comparison with the gas-in-liquid two-phase secondary-flow predictions [23]." Additional review of the citations for this article also provides no experimental validation.

Another way to evaluate existing research is to consider the ability of the model to predict the properties of the flow stream. All of the previous references declare the properties of the entrained flow streams to be known a priori, thus the entrained flow streams are considered inputs into the model [24]. Balamurugan et al. summarize the literature for determining the entrainment rate by providing a semi-empirical determination of the liquid entrainment rate for an ejector with air as the primary stream and water as the induced stream within $20 \%$ [25]. This work will include a similar prediction of the quality of a water-air stream entrained by a water primary stream, enhancing the novel model with the ability to predict the induced flow stream properties and the overall system performance. 
In 1985, the Engineering Sciences Data Unit, an advisory organization in the United Kingdom, published a document summarizing the one-dimensional theory generally adopted for design and performance of ejector pumps [3, 4, 8, 13, 20, 26, 27]. Published as ESDU 85032, the document covers ejectors operating with incompressible liquid flow [1]. This document serves as the basis of the existing single-phase analytical ejector model employed by industry, and thus serves as the basis for the extended twophase analytical ejector model devised in this work. Integrating the works in the reported analytical models will enable industry to enhance their current models to handle the full range of ejector operation within the examined application.

\subsubsection{NUMERICAL}

In recent years, numerical and empirical modeling approaches for understanding flow behavior inside ejectors produced good but scattered efforts, particularly for twophase flow. Kumar et al. [28] investigated the two-phase flow in terms of the variant geometrical parameters. Their study was for a desalination system. An optimization was applied on the parameters to find out the maximum performance along variant geometrical parameters. Neto and Porto [29] applied area ratios on ejector to find out the optimum design. They had $0.25,0.35$, and 0.53 for the area ratios. Their observation was that 0.35 gives the highest performance. Chamlong et al. [30] improved a way to gain the prime mixing tube length for a nozzle position. They found that the prime ratio of mixing tube length to nozzle diameter. Mikhail et al. [31] improved a theory for ejector performance. The theory was a one-dimension. Their focus was spent on the mixing with two methods, analytical, experimental. In addition, they introduced the pressure loss 
coefficient empirically. Samad and Nizamuddin [32] were investigating the effect of geometry numerically and they found that the longer mixing tube gives the best performance. $(\mathrm{Lm} / \mathrm{Dn})$ is 2-3.5. Afzal Husain and his coworkers [33] introduced an improved numerical modeling and optimization approach using fluid dynamics to design energy efficient ejector pumps. In their work, optimization was conducted by applying geometrical variables by using LHS, Latin Hypercube Sampling, and method. The jet pump was optimized numerically and the highest efficiency detected. Nevertheless, there was no experimental or industrial data supporting or verifying Husain et al. [33] claims.

It has been shown that when liquid is pumped through a nozzle to create a highvelocity jet, if the velocity of the jet is increased, the velocity of surrounding fluid also increases, causing higher gas induction Bin [34]. Any obstruction downstream of the jet like the throat of a venture tube will adversely affect the fluid induction as more energy is required to overcome the pressure drop of the obstruction Bhutada and Pangarkar [35]; Fadavi and Chisti [36]; Havelka et al. [37]. Thus, besides liquid flow rate, the rate of gas induction is dependent upon the geometry of the ejector. Studies have shown that the mass transfer rates closely relate to gas induction rates, making it imperative to study gas induction in ejectors for safe design Havelka et al. [36]. Many different studies have developed methods for correlating gas induction in ejectors, most dealing with down flow ejectors Acharjee et al. [38]; Bhutada and Pangarkar [39]; Dutta and Raghavan [40]. They correlate the ratio of area of nozzle and throat $\left(\mathrm{A}_{\mathrm{r}} / \mathrm{A}_{\mathrm{t}}\right)$. While the correlations have considerably different exponents and constants, the general theme is the same. Bhutada [41] presents a very detailed experiment on gas-liquid ejectors of varying geometric 
parameters. Ben Brahim et al. [42] shows a definite correlation for motive and entrained fluid Reynolds number for different motive and entrained fluids. All these studies are correlative in their approach and are reasonably successful in matching the observed gas induction with the experimental parameters and fluid parameters Bhat et al. [43]. There also have been attempts to model the gas-liquid ejectors, where the study of flow characteristics of the jet is crucial to predicting gas induction. Several efforts have been made to develop computational fluid dynamics (CFD) based models for simulating gas induction in gas-liquid ejectors. Yadav et al. [44]; Kim et al. [45] have used the Eulerian-Eulerian (EE) and mixture model approach to model gas induction Kim et al. [45], [46]; Utomo et al. [47]; Yadav and Patwardhan [44]. Kandakure et al. [48] have developed CFD methodology for estimating gas induction using the two-phase mixture model framework. In the mixture model, simulations of algebraic expressions for slip velocity were used for modelling the interaction between gas and liquid instead of modelling the drag force between the phases. Notwithstanding, some of the uncertainties associated with the mixture model, they have reported much success in estimating gas induction. The experimental studies have shown how different aspects of gas induction, like gas inlet Reynolds number and gas Euler number, correlate to different jet parameters and jet Reynolds numbers Kandakure et al. [48]. The differences in the fitting parameters of the correlations reflect different ejector geometries. However, no explicit relationship between the different geometric parameters and gas induction was established. Even very detailed induction studies like Bhutada and Pangarkar [35], [39] and Bhutada [41] develop separate correlations for different geometries instead of developing a single correlation using various geometric parameters. While all the 
experimental studies explain the driving force for induction as a suction force, no measurements of pressure were presented in the experimental data. Even for the calculations for gas Euler number, there is no experimental data provided. The reaction engineering models developed have too many unknowns, like mass transfer coefficient, bubble diameter, gas hold up, etc.; hence, correlative studies do not explain the phenomenon of gas induction and the impact of various geometric parameters on it. An adjustable parameter was introduced in Sharma et al [49] to ensure a fully mixed fluid for the two-phase.

The above literature survey for both analytical and numerical studies clearly indicates that very little work was reported considering two-phase flow behavior in ejector pumps. No reliable numerical simulation or empirical models are available for understanding the flow behavior in ejector pumps.

The present work is a continuation of a project started 5 years ago with support from Boeing Company for improving the efficiency of ejectors used in the Fuel System for large aircraft [50]. The results of the presented research are expected to address many of the deficiencies in our original work. Improvements would include refining the analytical model with more accurate parameters estimations, including uncertainties that were never included in any previous models, and consideration of the cost and time efficient numerical simulation of the flow behavior inside the ejectors. Both analytical and numerical models will be verified experimentally in the present work. 


\subsection{RESEARCH OBJECTIVES}

The present research aims at:

1- Developing an integrated modeling approach for understanding two-phase flow inside ejector pumps using analytical, experimental, and numerical modeling methods.

2- Optimal performance of ejectors in terms of energy use, delivered flow rate, and manufacturing cost.

3- Predicting flow behavior inside ejectors carrying two-phase fluids.

4- Introducing uncertainty in the developed analytical model to increase its prediction accuracy.

5- Developing a numerical simulation modeling method using computational fluid dynamics based on an ANSYS platform to facilitate effective design of experiments needed for exploring optimal ejector design.

6- Introducing a comprehensive experimental investigation using a specifically built fluid transportation system to verify analytical and numerical predictions.

7- Developing digital design and manufacturing techniques for the construction of quality and cost-effective ejectors. 


\section{CHAPTER III}

\subsection{INVESTIGATIVE APPROACH}

The present research uses three different techniques to ensure accurate predictions that will help in development of optimal ejector design for different applications.

\subsubsection{ANALYTICAL MODEL}

The objective of the analytical model is to design an ejector theoretically with the main parameter being the pressure ratio, $\mathrm{N}$, because secondary pressure, Ps, is dependent. Other parameters, such as primary volumetric flow rate, Qp, primary pressure, Pp, discharge pressure, Pd, flow ratio, and initial fluid height, $\mathrm{H}$, are independent and they are known experimentally.

The analytical model of a liquid ejector derives a dimensionless equation for $N$ based on a continuity equation, conservation of energy equations, and a momentum equation, and uses loss factors for the four main parts of the ejector. Literature shows research that uses constants empirically determined in other publications. Since there is an abundance of information about loss factors for two-phase ejectors, it makes sense to determine them analytically and compare them to ones that have been determined empirically.

To determine the loss factors for a two-phase ejector, begin with the governing equations for the loss factors for a single-phase ejector, and then add terms to be valid for the two-phase ejector.

In order to make a reliable model, we should note assumptions such as: 
1. Ejector operates isothermally and under steady-state conditions

2. Flow is one-dimensional except within the mixing chamber

3. Nozzle wall thickness at the exit is zero

4. Nozzle spacing from the throat entrance is zero $(s=0)$

5. Mixing (momentum transfer) is completed within the constant cross-sectional area mixing chamber

6. The primary and secondary streams enter the mixing chamber with uniform velocity profiles, and the produced fluid exits the mixing chamber with a uniform velocity profile

7. Frictional losses in the nozzle, secondary inlet, mixing chamber, and diffuser are accounted for by four loss coefficients

8. Primary fluid is a single-phase incompressible liquid

9. Secondary fluid behaves as an incompressible liquid (liquid mass flow rate $>>$ gas mass flow rate)

10. Any two-phase mixture is homogeneous

11. There is no mass transfer between the phases

12. Temperatures of primary and secondary fluids are equal

13. Gas phase, if present, undergoes ideal-gas isothermal compression

14. Fluid velocities are less than the speed of sound

We made some modifications to the reference plane to make it easy to follow up. So, the letter notations have been replaced by numbers. Figure 4 shows the modifications. 


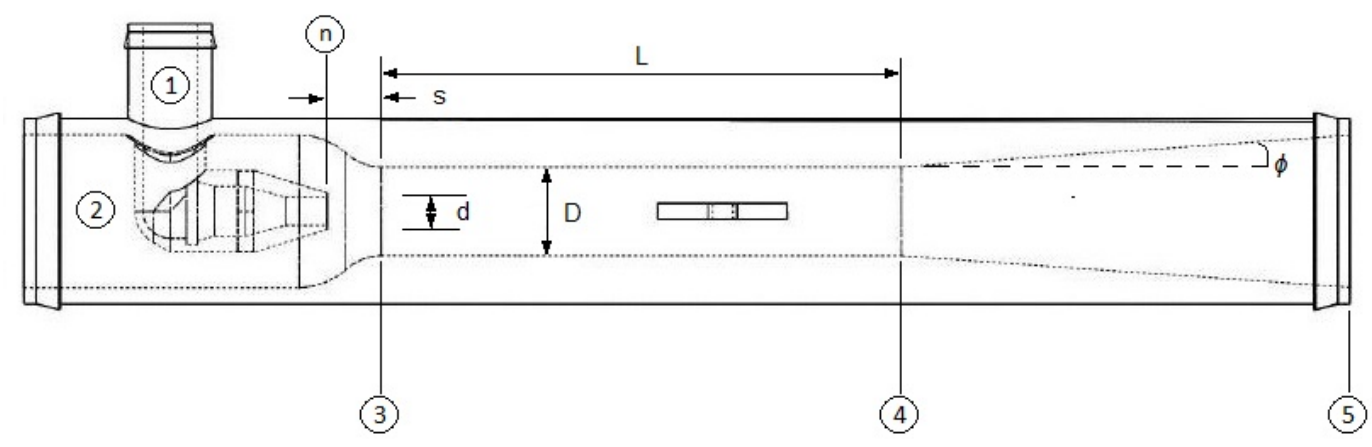

Figure 4 Reference planes and notations as applied to ejector analysis

All the equations have been updated based on Figure 4

Thus, the pressure ratio is also shown by Eq.3-1:

$$
N=\frac{P_{d}-P_{s}}{P_{p}-P_{d}}=\frac{P_{5}-P_{2}}{P_{1}-P_{5}}
$$

This equation is the goal of the analytical model but in extended form to cover all the cases as shown in Eq. 3-28.

Eqs 3-2 \& 3-4 show how loss factors are determined analytically: 


$$
\begin{aligned}
& K_{p}=\frac{P_{1}-p_{n}}{\frac{1}{2} \rho_{p} V_{n}^{2}}-1 \\
& K_{s}=\frac{P_{2}-p_{s}}{\frac{1}{2} \rho_{s} V_{3}^{2}}-1 \\
& K_{d}=\frac{P_{4}-P_{5}}{\frac{1}{2} \rho_{d} V_{4}^{2}}
\end{aligned}
$$

The only equation that is different is the mixing chamber loss coefficient. It has a friction factor because the turbulent flow occurs in it.

Thus, $K_{m}$ is shown by Eq. 3-5:

$$
K_{m}=4 f \frac{L}{D}
$$

where

$$
f=\frac{\Delta p}{4 \frac{L}{D} \frac{1}{2} \rho_{m} V_{4}^{2}}
$$

The velocity at the exit of the mixing chamber, $\mathrm{V}_{4}$, is used to get the pipe friction factor because it is lower than the average velocity in the mixing chamber. It gives us accurate results since the friction loss inside the mixing chamber has been found to be much less than in conventional pipe flow [9].

Conservation of energy is used to find the total pressure at the primary nozzle, secondary inlet, and diffuser, as shown in Eqs.3-7 \& 3-9: 


$$
\begin{aligned}
& P_{1}=p_{3}+\frac{1}{2} \rho_{p} V_{n}^{2}+K_{p}\left(\frac{1}{2} \rho_{p} V_{n}^{2}\right) \\
& P_{2}=p_{3}+\frac{1}{2} \rho_{s} V_{3}^{2}+K_{s}\left(\frac{1}{2} \rho_{s} V_{3}^{2}\right) \\
& P_{5}=p_{4}+\frac{1}{2} \rho_{d} V_{4}^{2}-K_{d}\left(\frac{1}{2} \rho_{d} V_{4}^{2}\right)
\end{aligned}
$$

where

$$
\begin{aligned}
& K_{p}\left(\frac{1}{2} \rho_{p} V_{n}^{2}\right)=\text { primary nozzle pressure loss } \\
& K_{s}\left(\frac{1}{2} \rho_{s} V_{3}^{2}\right)=\text { secondary flow inlet pressure loss } \\
& K_{d}\left(\frac{1}{2} \rho_{d} V_{4}^{2}\right)=\text { diffuser pressure loss }
\end{aligned}
$$

Thus,

$$
\begin{aligned}
& P_{1}=p_{3}+\frac{1}{2} \rho_{p} V_{n}^{2}\left(1+K_{p}\right) \\
& P_{2}=p_{3}+\frac{1}{2} \rho_{s} V_{3}^{2}\left(1+K_{s}\right) \\
& P_{5}=p_{4}+\frac{1}{2} \rho_{d} V_{4}^{2}\left(1-K_{d}\right)
\end{aligned}
$$

The conservation of mass, the continuity equation for the ejector at steady-state conditions, is shown by Eq.3-16: 


$$
\rho_{p} Q_{p}+\rho_{s} Q_{s}=\rho_{d} Q_{d}
$$

The velocity at the entrance to the mixing chamber, $V_{3}$ and the velocity at the exit of the mixing chamber, $\mathrm{V}_{4}$ can be used as functions of the primary nozzle exit velocity, $V_{n}$ by applying Eq. 1-1 for the flow ratio as shown in Eqs. 3-17 and 3-18, respectively.

$$
\begin{aligned}
& V_{3}=\frac{M R}{1-R} V_{n} \\
& V_{4}=R(1+M) V_{n}
\end{aligned}
$$

Lastly, conservation of momentum in the mixing chamber:

$$
p_{3} A_{3}+\rho_{p} Q_{p} V_{n}+\rho_{s} Q_{s} V_{3}=p_{4} A_{4}+\rho_{m} Q_{m} V_{4}+\rho_{d} A_{4} K_{m} R^{2}(1+M)^{2} \frac{V_{n}^{2}}{2}
$$

where

$$
\rho_{d} A_{4} K_{m} R^{2}(1+M)^{2} \frac{V_{n}^{2}}{2}=\text { mixing chamber friction loss }
$$

Substituting Eqs.3-17, 3-18, and 3-20, and replacing the volumetric flow terms by an equivalent area multiplied by velocity representation, Eq. 3-21becomes:

$$
\left(p_{4}-p_{3}\right) A_{4}=\rho_{p} A_{n} V_{n}^{2}+\rho_{s}\left(A_{3}-A_{n}\right)\left(\frac{M R}{1-R}\right)^{2} V_{n}^{2}-\rho_{d} A_{4} R^{2}(1+M)^{2} V_{n}^{2}-\rho_{d} K_{m} R^{2}(1+M)^{2} \frac{V_{n}^{2}}{2}
$$

The pressure increase of the secondary stream, also the numerator of Eq.3-1, can be found by subtracting Eq. 3-14 from Eq. 3-15:

$$
P_{5}-P_{2}=p_{4}-p_{3}+\left(1-K_{d}\right) \frac{1}{2} \rho_{d} V_{4}^{2}-\left(1+K_{s}\right) \frac{1}{2} \rho_{s} V_{3}^{2}
$$

Applying Eq. 3-21to Eq. 3-22 and simplifying, the pressure increase becomes: 


$$
P_{5}-P_{2}=\frac{1}{2} \rho_{p} V_{n}^{2}\left[2 R+\frac{2 C M^{2} R^{2}}{1-R}-R^{2}\left(1+K_{m}+K_{d}\right)(1+C M)(1+M)-C\left(1+K_{s}\right)\left(\frac{M R}{1-R}\right)^{2}\right]
$$

where

$$
\begin{aligned}
& C=\frac{\rho_{s}}{\rho_{p}} \\
& R=\frac{A_{n}}{A_{m}}=\frac{A_{n}}{A_{4}}
\end{aligned}
$$

Doing the same thing for the pressure drop of the primary stream, the denominator of Eq. 3-1, can be found by subtracting Eq. 3-13 from Eq. 3-15

$$
P_{1}-P_{5}=p_{3}-p_{4}+\left(1+K_{p}\right) \frac{1}{2} \rho_{p} V_{n}^{2}-\left(1-K_{d}\right) R^{2}(1+M)(1+C M) \frac{1}{2} \rho_{p} V_{n}^{2}
$$

Applying Eq. 3-21to Eq. 3-26 and simplifying, the pressure decrease becomes:

$$
P_{1}-P_{5}=\frac{1}{2} \rho_{p} V_{n}^{2}\left[-2 R-\frac{2 C M^{2} R^{2}}{1-R}+R^{2}(1+M)(1+C M)\left(1+K_{m}+K_{d}\right)+\left(1+K_{p}\right)\right]
$$

Lastly, dividing Eq. 3-23 by Eq. 3-27, the analytical equation for $N$ is determined by Eq. 3-28:

$$
=\frac{2 R+\frac{2 C M^{2} R^{2}}{1-R}-R^{2}(1+C M)(1+M)\left(1+K_{m}+K_{d}\right)-\frac{C M^{2} R^{2}}{(1-R)^{2}}\left(1+K_{s}\right)}{\left(1+K_{p}\right)-2 R-\frac{2 C M^{2} R^{2}}{1-R}+R^{2}(1+C M)(1+M)\left(1+K_{m}+K_{d}\right)}
$$

If the air is induced into the ejector, the densities will not be the same, $\mathrm{C}=1$. the flow ratio is approximated by Eq. 3-29 [9]: 


$$
M=\frac{M_{C=1.0}}{\sqrt{C}}
$$

As we assumed, it can be seen that Eq. (3-43) is for the case of $s=0$ only. Cunningham enhanced this equation when using a withdrawn primary nozzle by adding an additional "jet loss" term in the denominator, as discussed in Chapter II [51]. Applying this term to Eq. 3-28, the pressure ratio becomes:

$$
N=\frac{2 R+\frac{2 C M^{2} R^{2}}{1-R}-R^{2}(1+C M)(1+M)\left(1+K_{m}+K_{d}\right)-\frac{C M^{2} R^{2}}{(1-R)^{2}}\left(1+K_{s}\right)}{\left(1+K_{p}\right)-2 R-\frac{2 C M^{2} R^{2}}{1-R}+R^{2}(1+C M)(1+M)\left(1+K_{m}+K_{d}\right)+\beta \frac{C M^{2} R^{2}}{(1-R)^{2}}\left(1+K_{s}\right)}
$$

where

$$
\begin{aligned}
& \beta=0 \text { for } s=0 \\
& \beta=1 \text { for } s>0
\end{aligned}
$$

Eq.3-30 matches the equation derived by Cunningham, who assumes that the nozzle tip is withdrawn from the entrance of the mixing chamber. Eq.3-30 depends on very few parameters. $\mathrm{R}$, is ratio, is known for a given ejector. $\mathrm{C}$ is a determination term which comes from the properties of the primary and secondary flow streams, and $\mathrm{M}$ is an input into the model from the experiments. The four loss coefficients are needed to solve for $\mathrm{N}$. Literature shows that model performance is considerably enhanced when direct measurements are taken of the four loss coefficients [51]. Pressure measurements along the ejector are hard to make due to the design of the ejector used in this experiment. so, measurement of the loss factors are also not easy to determine. Instead, empirical data can be used to determine the loss factors. The goal is to calculate loss factors based on the geometry of the ejector and find the associated pressure drops using the ability to account 
for the two-phase flow conditions. The ejector primary nozzle is a converging nozzle. The motive fluid is a liquid, so two-phase flow does not occur in the primary nozzle. Thus, the calculation for the gradual contraction [1] is shown in Eq. 3-33:

$$
K_{p}=0.8 \sin \frac{\theta}{2}\left(1-\frac{d_{1}^{2}}{d_{2}^{2}}\right)
$$

where $\theta$ is the angle of the convergence. The last term, ratio of diameters, for contraction is small to large.

The secondary inlet has a gradual contraction too. Thus, the calculation for the secondary inlet loss coefficient is similar to 3-33, with the addition of a frictional loss term:

$$
K_{s}=0.8 \sin \frac{\theta}{2}\left(1-\frac{d_{1}^{2}}{d_{2}^{2}}\right)+4 f \frac{l}{d} \Phi_{0}^{2}
$$

Friedel's correlation, $\Phi_{L O}^{2}$, is an empirical coefficient which scales the frictional losses [52]. In single-phase flow conditions, $\Phi_{L O}^{2}=1$. In two-phase flow conditions in vertical upward and horizontal flow, we should solve the Eq. 3-25. Friedel's correlation works best in the case of air in water, which is seen in Table 1.

Friedel's correlation:

Table 1 Two-phase correlation recommendations

\begin{tabular}{|c|c|c|}
\hline$\mu / \mu_{g}$ & $\mathrm{~m}$ & $\begin{array}{c}\text { Recommended } \\
\text { Correlation }\end{array}$ \\
\hline$<1,000$ & -- & Friedel \\
\hline$>1,000$ & $>100$ & Chisholm \\
\hline$>1,000$ & $<100$ & Martinelli \\
\hline
\end{tabular}




$$
\Phi_{0}^{2}=C_{1}+\frac{3.24 C_{2}}{F r^{0.045} W e^{0.035}}
$$

where

$$
\begin{gathered}
C_{1}=(1-x)^{2}+x^{2} \frac{\rho f_{g 0}}{\rho_{g} f_{0}} \\
C_{2}=x^{0.78}(1-x)^{0.24}\left(\frac{\rho}{\rho_{g}}\right)^{0.91}\left(\frac{\mu_{g}}{\mu}\right)^{0.19}\left(1-\frac{\mu_{g}}{\mu}\right)^{0.7} \\
F r=\frac{\mathrm{m}^{2}}{g D \rho_{T P}^{2}} \\
W e=\frac{\mathrm{m}^{2} D}{\rho_{T P} \sigma}
\end{gathered}
$$

and $f_{G O}$ and $f_{L O}$ are the friction factors for gas and liquid properties. For the Friedel correlation, $\rho_{T P}$ is given by:

$$
\rho_{T P}=\left(\frac{x}{\rho_{G}}+\frac{1-x}{\rho_{L}}\right)^{-1}
$$

Also, The Friedel correlation has been adding to the mixing chamber loss coefficient [9]:

$$
K_{m}=4 f \frac{L}{D} \Phi_{L O}^{2}
$$

Finally, the diffuser loss coefficient is a similar to Eq. 3-33 and 3-34 Crane 410 [53]. The diffuser loss coefficient:

$$
K_{d}=\frac{2.6 \sin \frac{\theta}{2}\left(1-\beta^{2}\right)^{2}}{\beta}
$$

Where $\beta$ is the ratio of smaller diameter to larger diameter: 


$$
\beta=\frac{d_{1}}{d_{2}}
$$

The $\beta$ in the denominator is included for the tailpipe at the exit of the diffuser.

Miller indicates that the loss coefficients and head recoveries are determined for diffusers with inlet Reynolds numbers above $10^{5}$ [54]. For Reynolds numbers less than $10^{5}$, these values may not hold true. This correlates to the experimental data obtained, such that:

$$
\begin{aligned}
0< & \operatorname{Re}_{m}<50,000: K_{d a}=0 \\
50,000 \leq & \operatorname{Re}_{m}<100,000: K_{d a}=\left(\frac{\mathrm{Re}_{m}}{50,000}-1\right) K_{d} \\
& \operatorname{Re}_{m} \geq 100,000: K_{d a}=K_{d}
\end{aligned}
$$

where $K_{d a}$ is the actual loss applied in the model and $K_{d}$ is from Eq. 3-42 Neve investigated the two-phase effects on diffuser performance, but for the low entrainment ratios experienced when air is merely sucked into the secondary inlet with the induced water, the effect is negligible so no adjustment is necessary for this application [55].

\subsubsection{EVALUATION OF UNCERTAINTY}

The NASA developed program called Numerical Evaluation for Stochastic Structures under Stress (NESSUS) [56], can perform reliability-based analysis to predict the pressure ratio, $\mathrm{N}$. The system is examined for the probability that the flow rate through it is above a minimum acceptable value to give an acceptable pressure ratio and for sensitivity of the model to the loss coefficients.

The Advanced Mean Value plus iteration (AMV+) method has been conducted for the analysis. The efficiency has a method to make it more reliable. The accuracy for the Standard Monte Carlo simulation is high, but consuming the time is a matter, and it needs only few runs to validate the results. 
Probability density function or PDF is used to define the probability that a certain value occurs in a certain domain. Density functions will be different depending on how the variables are changing over a domain. Normal, Lognormal, and Weibull are some of the PDF functions used in analysis.

$$
P(a \leq X \leq b)=\int_{a}^{b} f_{X}(x) d X
$$

where $\mathrm{x}$ is the desired value in the domain. CFD or cumulative density function describes the probability that a certain value is smaller than a certain known value.

$$
F_{X}(x)=P(X \leq x)=\int_{-\infty}^{x} f_{x}(x) d x
$$

Since there are many types of distribution, choosing one of them must be done carefully. In this way, the probability plot is established for the chosen variables of $\mathrm{Km}$ and $\mathrm{Ks}$ with four types of distributions. The probability distribution has been conducted for normal, lognormal, exponential and Weibull as shown in Figure 5-Figure 8 respectively. 


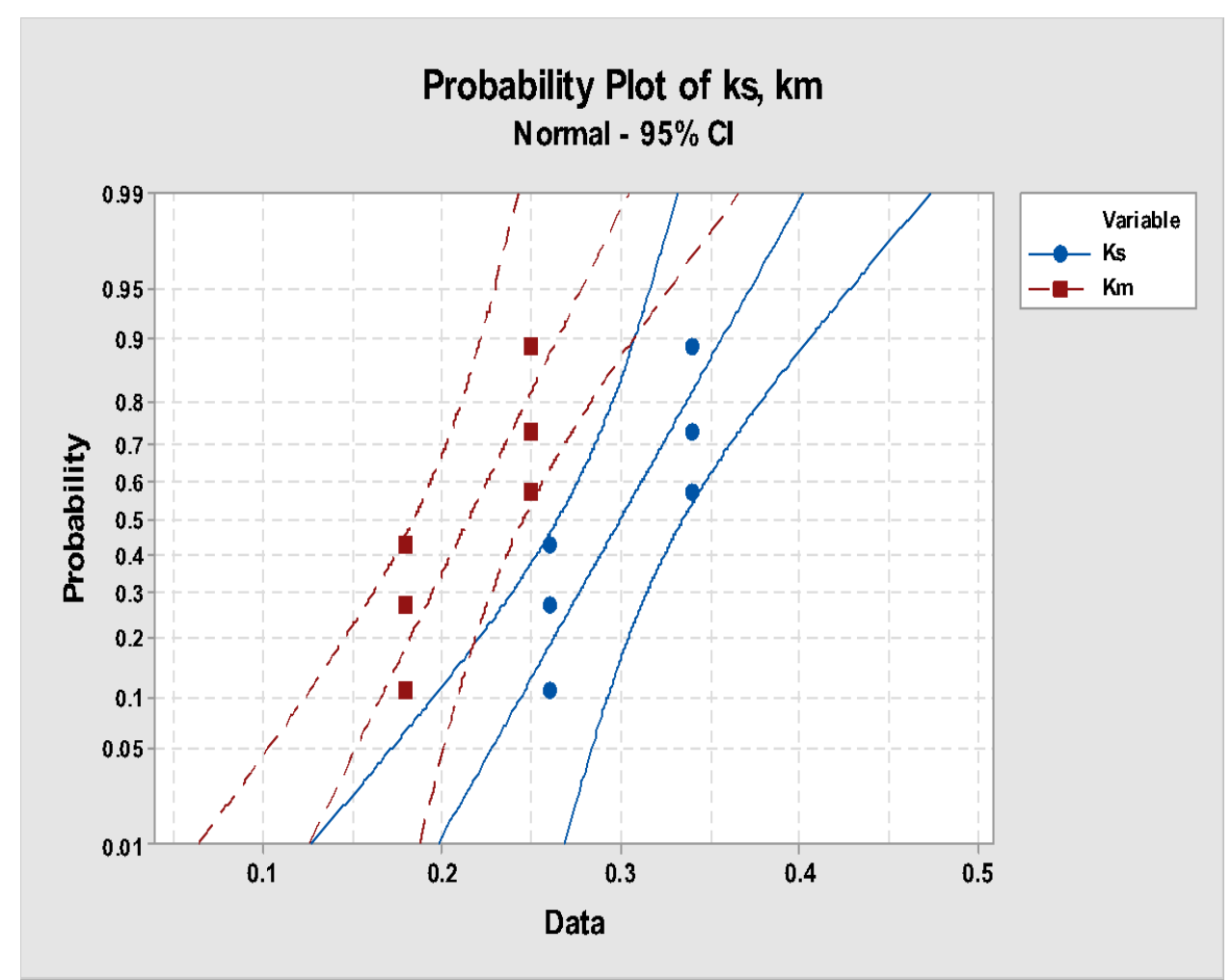

Figure 5 Normal Probability Plot of ks, km

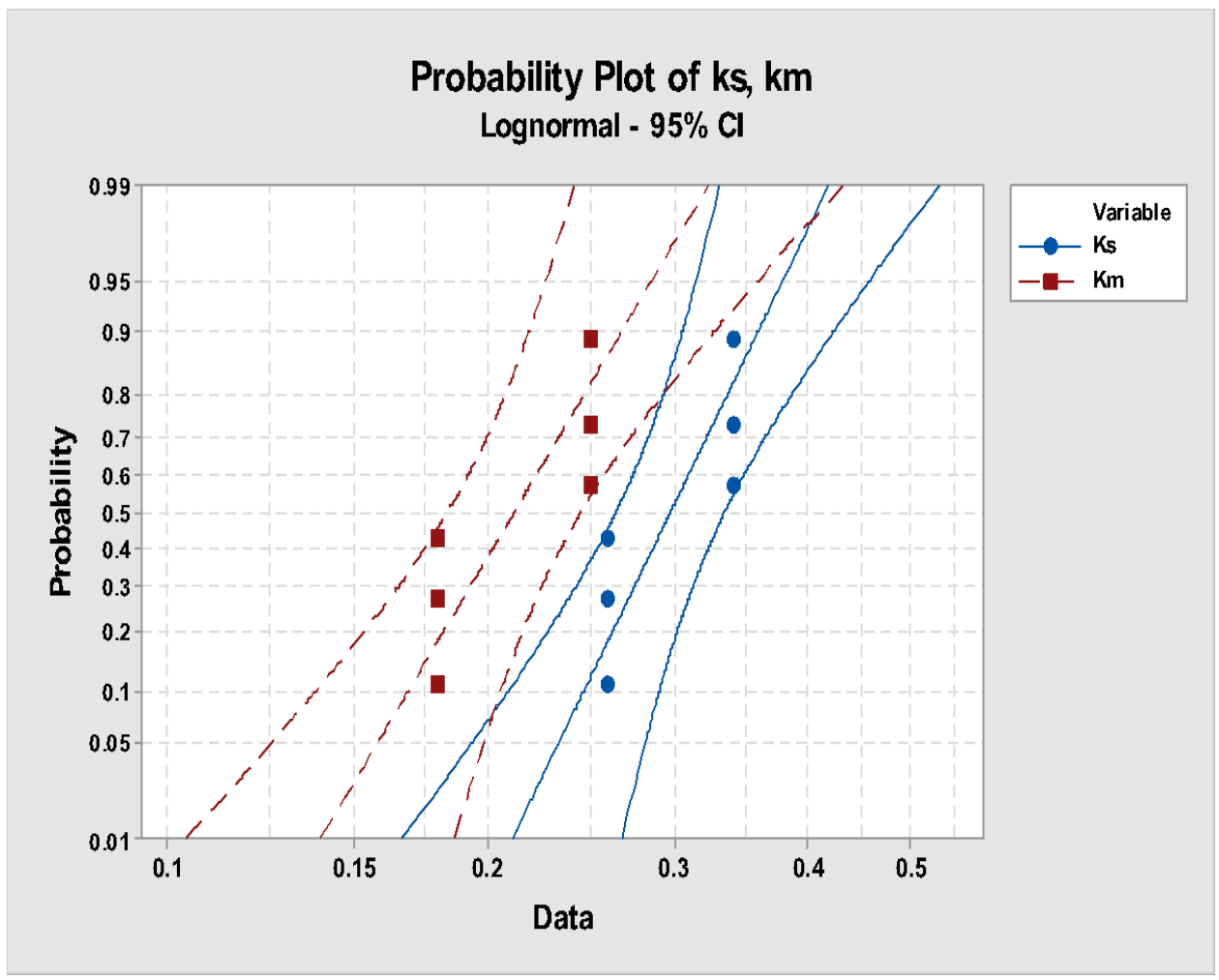

Figure 6 Lognormal Probability Plot of ks, km 


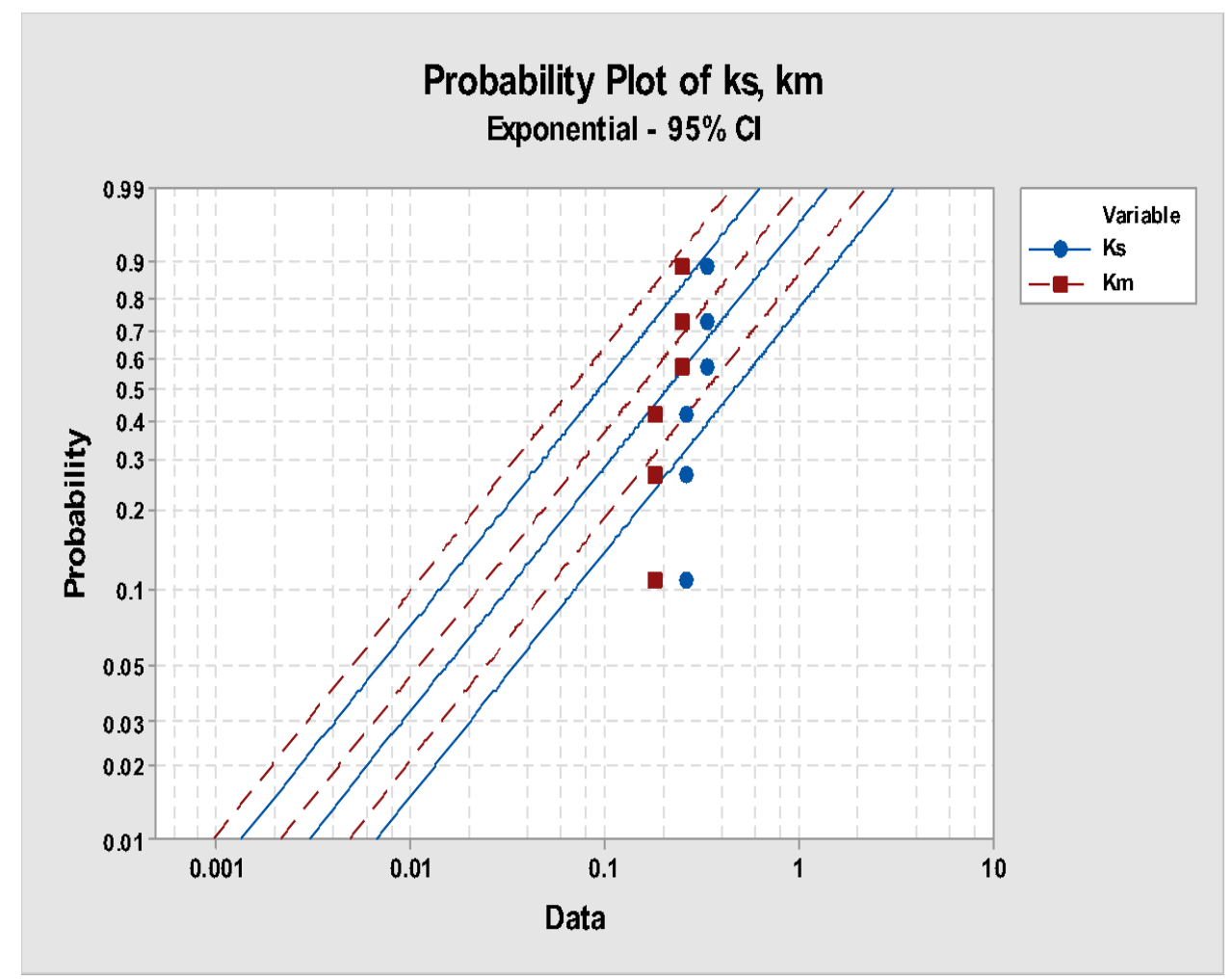

Figure 7 Exponential Probability Plot of ks, km

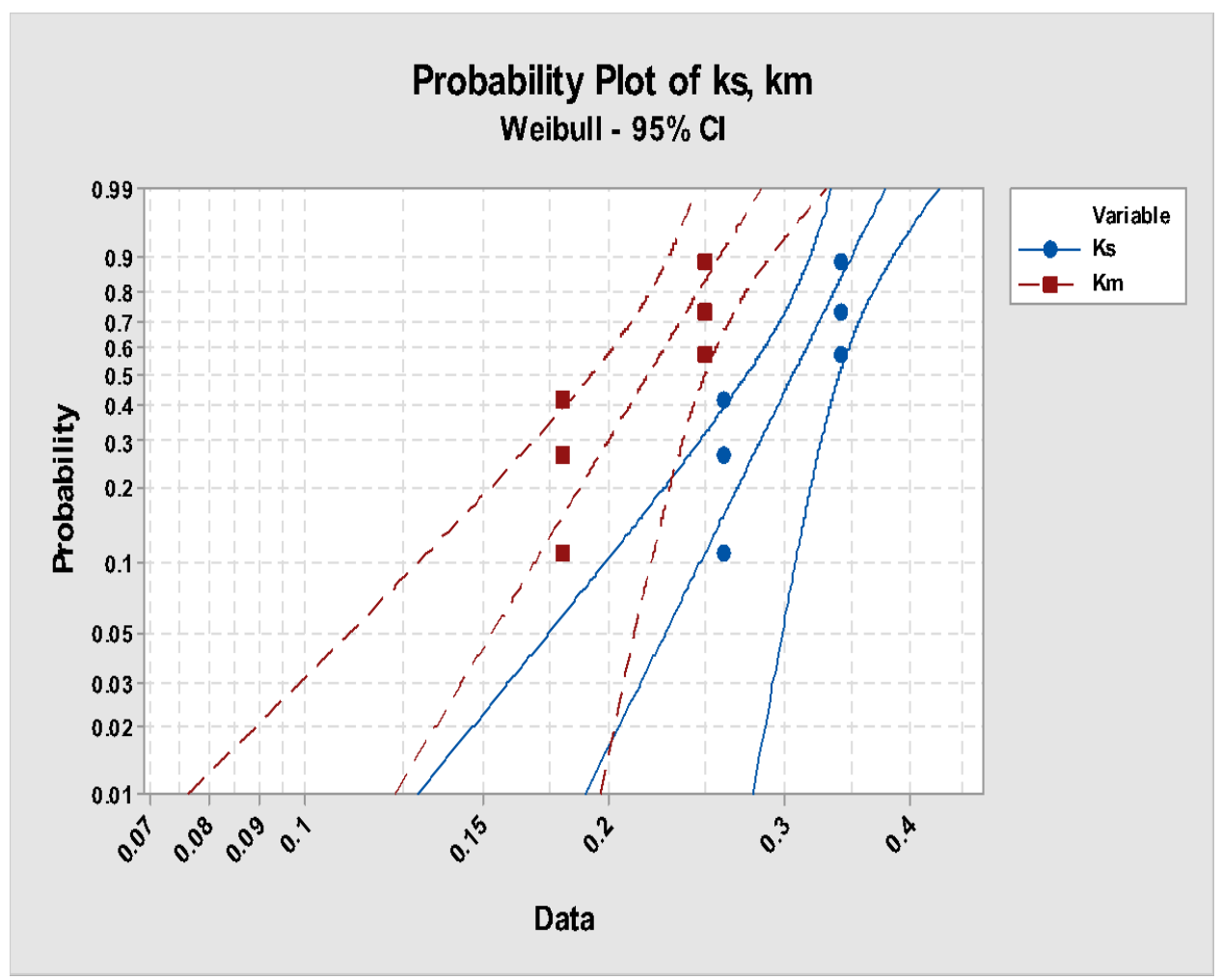

Figure 8 Weibull Probability Plot of ks, km 
Looking at them to see which distribution lines is the best match for our data. Immediately we can rule out the Exponential and Weibull distribution, where some of our data points out of the best-fit lines. The other two look better, so that the normal or lognormal distribution would be a good choice for running subsequent reliability analyses.

Normal distribution is the most common distribution used to describe how the variables are changing. It is also called Bell curve or Gaussian distribution. Normal distribution uses the average (mean) of the data and the standard deviation.

Eq. 3-47 describes the probability density function for the normal distribution.

$$
f_{x}(x)=\frac{1}{\sigma \sqrt{2 \pi}} e^{-\frac{1}{2}\left(\frac{x-\mu}{\sigma}\right)^{2}} d x,-\infty<x<\infty
$$

where $\mathrm{f}$ is the probability density function for the normal distribution, $\mu$ is the average and $\sigma$ is the standard deviation. Eq. 3-48 shows the cumulative density function for the normal distribution.

$$
F(x)=\frac{1}{\sigma \sqrt{2 \pi}} \int_{-\infty}^{x} e^{-\frac{1}{2}\left(\frac{x-\mu}{\sigma}\right)^{2}} d x
$$

The loss coefficients for Km, Ks are considered in this probabilistic model. They are assumed to have a normal distribution as shown in Figure 9 to Figure 12 based on the mean $\mu$ and standard deviation $\sigma$, which were calculated by the analytical model. 


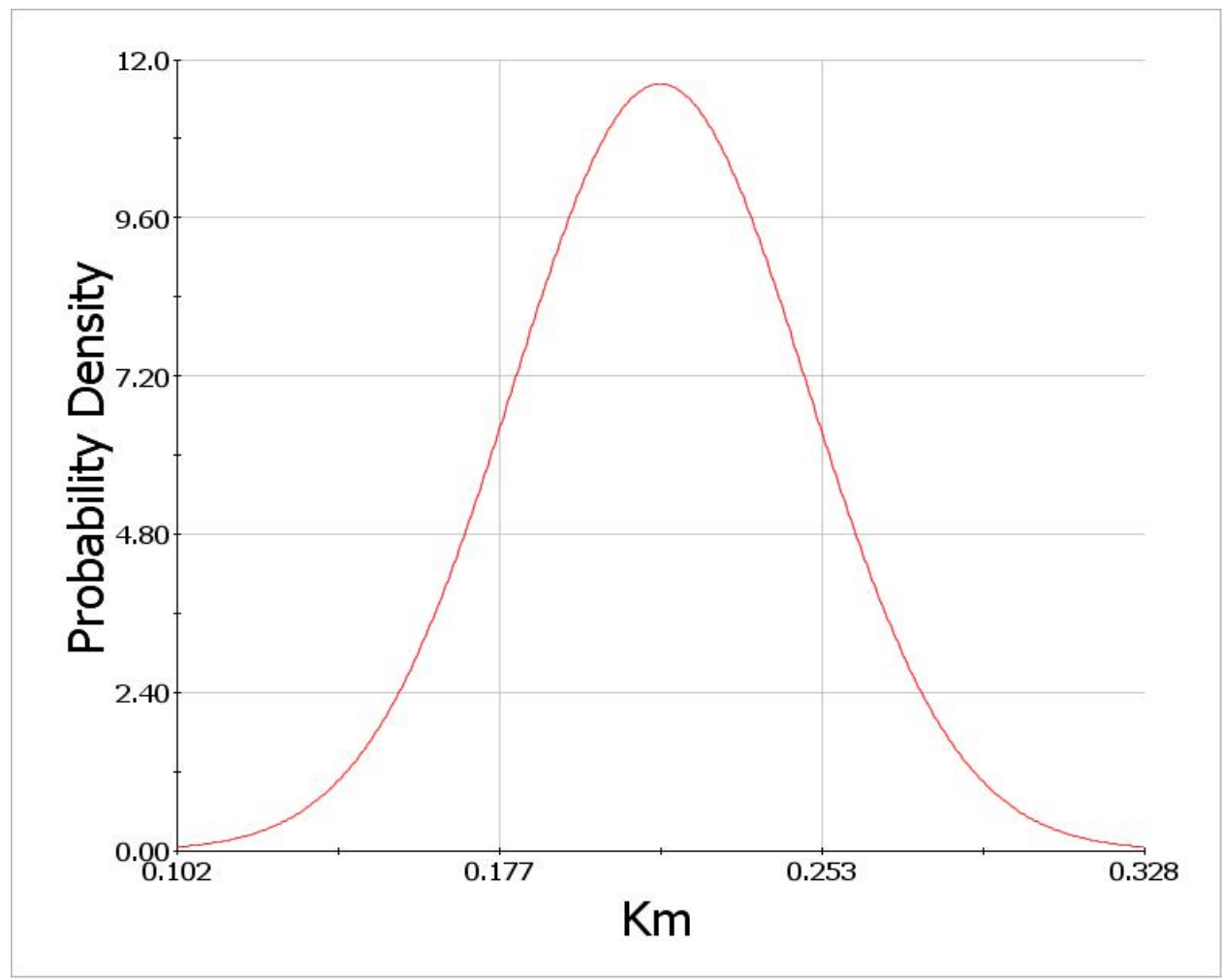

Figure 9 Probability density function for $\mathbf{K m}$

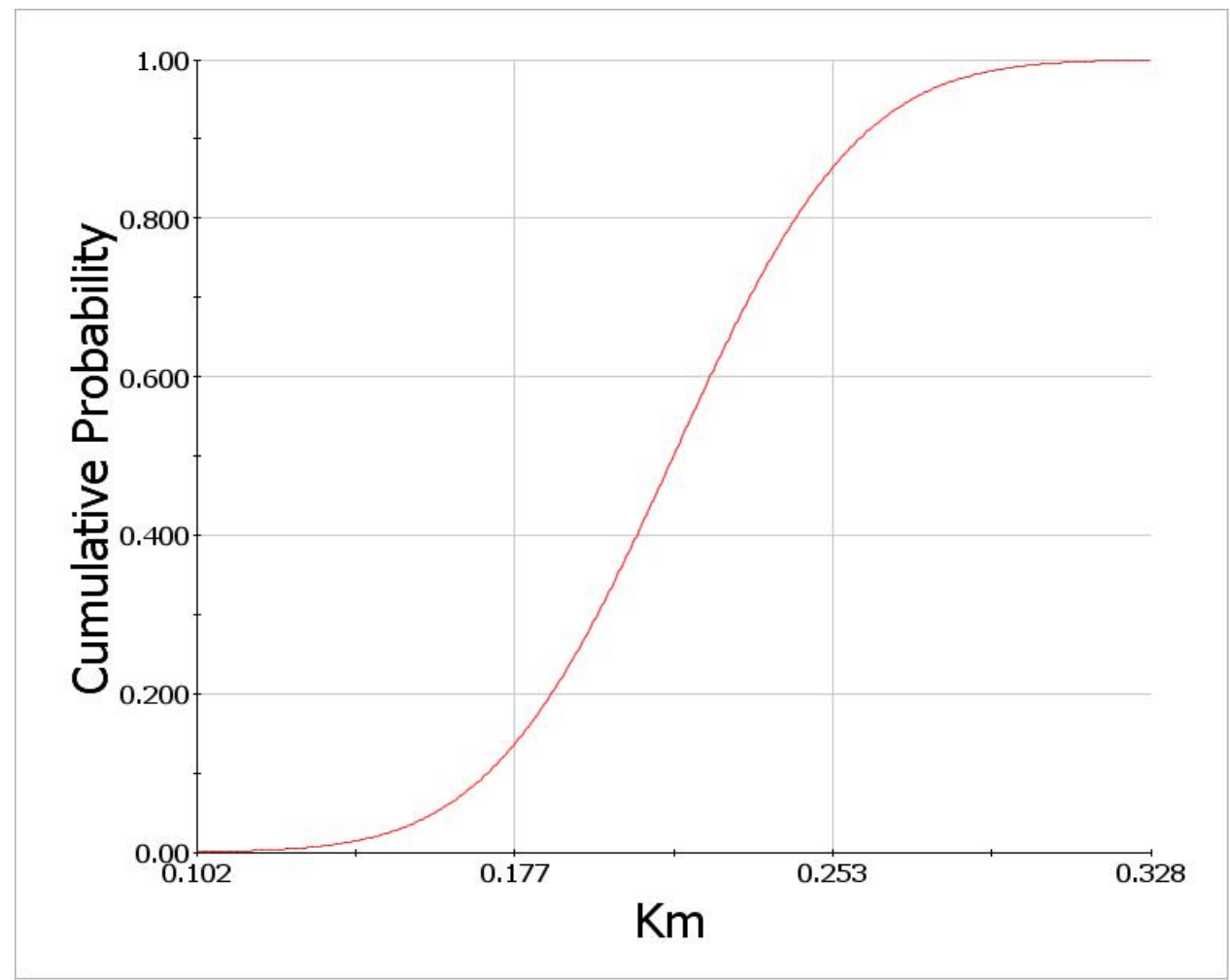

Figure 10 Cumulative density function for $\mathbf{K m}$ 


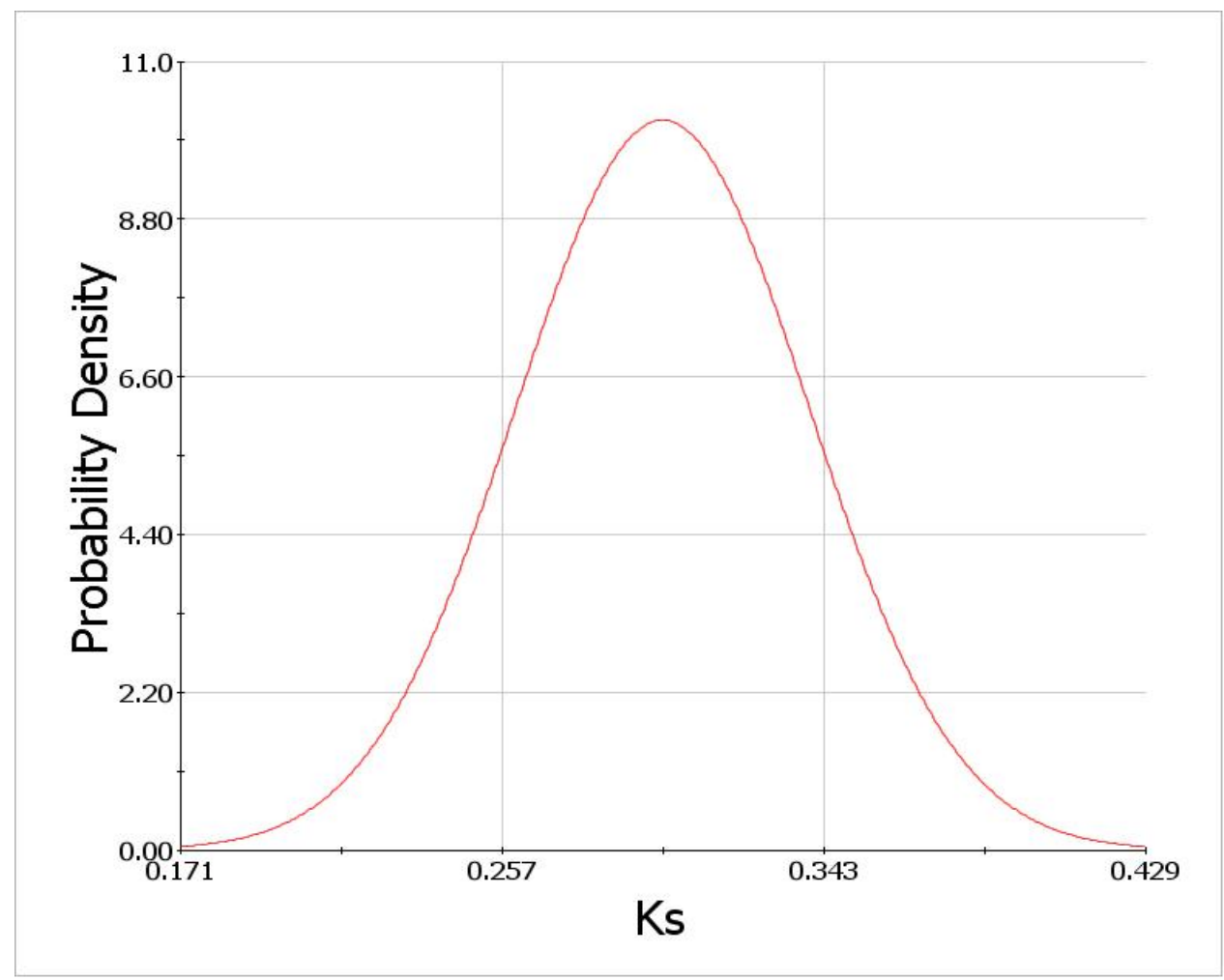

Figure 11 Probability density function for Ks

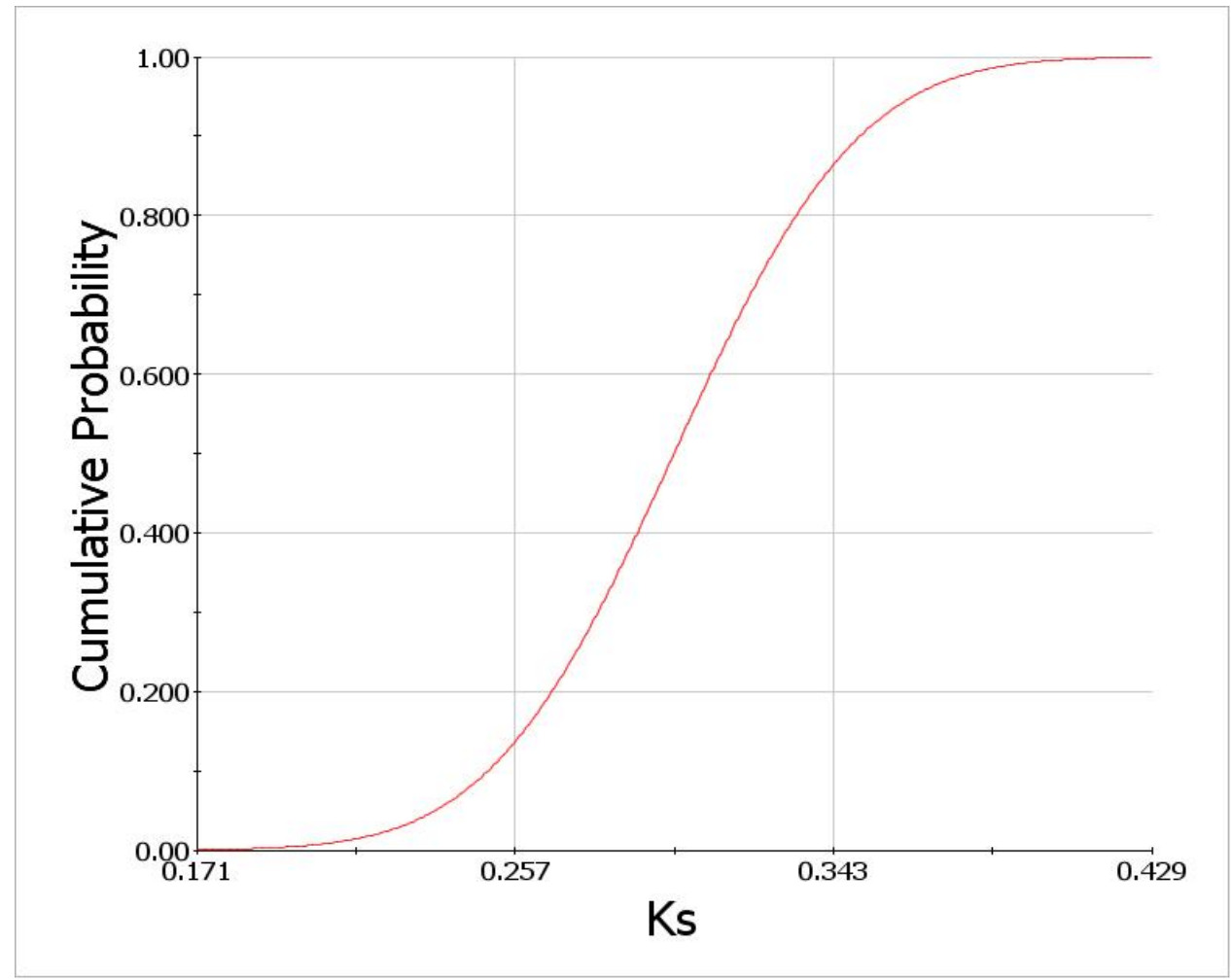

Figure 12 Cumulative density function for Ks 
These loss coefficients are then substituted in Eq. 3-28 to determine the sensitivity of the pressure ratio $\mathrm{N}$ to these coefficients. The rest of the variables are taken from the analytical model and assumed constants. Table 2 Deterministic Values for the used variables shows the values for each variable used in that equation.

Table 2 Deterministic Values for the used variables

\begin{tabular}{|l|l|}
\hline Variable & Value \\
\hline $\mathrm{R}$ & 0.27 \\
\hline $\mathrm{C}$ & 0.001225 \\
\hline $\mathrm{M}$ & 1.5733 \\
\hline $\mathrm{Kd}$ & 0.16 \\
\hline $\mathrm{Kp}$ & 0.14 \\
\hline Beta $(\beta)$ & 0 \\
\hline
\end{tabular}

After defining the variables, Standard Monte Carlo is used. This method uses repetition of randomly generated data to determine the probability density function for a given variable. The solution can be controlled either by specifying an error value or use sample size. The larger the sample size, the more accurate the results will be.

NESSUS reliability software from Southwest Research Institute was used to conduct the reliability model. NESSUS offers to find the sensitivity that each variable has to any changes in the input data. To do so, it uses the MPP value at each function and it records the data using a first order probability estimate. Probability analysis can also be used to find the relative importance of the particular variables by using sensitivity analysis. The procedure can be done by measuring the relative importance of the random variables based on the location of the MPP. At the MPP, $\mathrm{u}^{*}=\left(\mathrm{u} 1^{*}, \mathrm{u} 2^{*}, \ldots, \mathrm{un}{ }^{*}\right)$, the firstorder probability estimate is $\Phi(-\beta)$ where:

$$
\beta^{2}=u_{1}^{* 2}+u_{2}^{*^{2}}+\ldots+u_{n}^{* 2}
$$

The unit normal vector at the MPP at the surface is defined as: 


$$
\alpha=-\frac{\nabla g}{|\nabla g|}
$$

where $\mathrm{g}$ is the response function and $\alpha$ vector is positive in the direction of decreasing $\mathrm{g}$. The sensitivity factors are indicators of $\alpha$ vectors to the u-axes. Therefore, they are direction cosines of $\alpha$ and can be written as:

$$
\alpha_{1}=\frac{u_{i}^{*}}{\beta}
$$

The above equation satisfies the following rule:

$$
\alpha_{1}^{*}+\alpha_{2}^{*}+\ldots+\alpha_{n}^{*}=1
$$

which indicates that $\alpha_{i}^{2}$ is how much this variable contributes to the probability; the larger this value the more its contribution (importance).

The definition of sensitivity factors can be seen in the u-space

$$
\left|\alpha_{i}\right| \propto\left(\frac{\partial g}{\partial u_{i}}\right)_{u^{*}}
$$




\subsubsection{NUMERICAL MODEL}

The numerical analysis is conducted using CFD codes. The goal is to analyze each aspect of the ejector geometry and to correlate coherently any geometric parameter to a mathematical parameter. While experimental and pure correlative studies can make system specific predictions, there is a need for a model that can predict the impact of a geometric parameter in a more general way.

The ejectors were simulated to predict the flow behavior inside them. In the absence of important information needed to solve the numerical analysis, a simpler CFD model was conducted to predict the gas induction and then the flow behavior. A singlephase model was used to simulate gas induction and the behavior inside the ejectors. Using the mixture model with gas and liquid, with two different densities, is not applicable because knowing the slip velocity and relative velocity between the two phases is crucial, and this information is unknown. If the slip velocity is required, the bubble diameter has to be known. Using mixture model or EE model needs specific information to be used as an adjustable parameter to fit the simulation results to experimental results. In this work, it was decided that a single-phase model would be used to simulate induced gas and to capture the flow behavior of various geometries. This approach supposes that the driving force for the induced gas is imparted by the nozzle, which is the kinetic energy of the primary fluid, making this approach similar to the twophase gas-liquid ejector. The numerical analysis objectives are to develop a model to estimate the gas induction as a function of the primary fluid, measure the influence of the various geometric parameters on gas induction in an ejector nozzle, and to quantify the 
effect of the geometry on the flow behavior inside the ejectors. The impact of the geometries of the ejectors was investigated for developing a better understanding of the significance and sensitivity of the various geometric parameters. This approach and results will be valuable for designing better ejector configurations.

Three-dimensional steady-state analysis is carried out to simulate the water-gas twophase incompressible flow inside a water-gas jet pump. ANSYS version 16 CFD software package is used for the simulation. The mesh was developed using the ANSYS design modeler's meshing tools and the fluid flow was modelled using the FLUENT solver. The 3D model of the ejector pump, was imported into ANSYS as a STEP file, which is initially modelled in Solid Works. The solving method is pressure-velocity coupling. The realizable $\kappa-\varepsilon$ turbulence model is selected for two reasons:

1. The realizable $\kappa-\varepsilon$ model has a new formulation for the turbulent viscosity.

2. An improved transport equation for the dissipation rate, $\varepsilon$, has been derived from an exact equation for the transport of the mean-square vorticity fluctuation. while the standard near wall function is used in the near wall treatment. Boundary conditions are the pressure inlet for phase 1, water, and the outlet and pressure inlet for phase 2. Single-phase turbulent flow of two miscible fluids of different densities was simulated using the Reynold's averaged Navier-Stokes equations. The turbulent flow was simulated using the Realizable k- $\varepsilon$ model. The species equation was only solved for the secondary fluid, Ranade [57]. As the pressure inlet of water through the nozzle is known, the pressure inlet was used as the boundary condition for primary liquid. The suction chamber inlet was set to be 0 -gauge pressure due to the opening to atmospheric 
pressure and the outlet as well. Since, arbitrary fluid has been conducting, the slip velocity between the two phases has been disabled and lastly, the ejector was used standard wall-function.

In the FLUNET solver, second order has been set for the momentum, mass fraction, turbulent kinetic energy, and turbulent energy dissipation rate. In addition, a SIMPLE scheme for the pressure-velocity was enabled. To make the solution relaxes; its factor was set at 0.4 for momentum, turbulent kinetic energy and turbulent energy dissipation rate. The pressure was set at 0.3 for relaxation factor. Earlier modelling efforts using the EE or mixture models did not capture the gas-liquid dispersion in the ejector and simulated stratified flow. The experiments showed excellent mixing of gas and liquid in the ejector. In order to ensure mixing of primary and entrained flu-ids in the ejector, here we decided to treat the entrained fluid as a miscible fluid with the primary fluid. This will ensure complete mixing of primary and entrained fluids in the ejector. The use of miscible fluids of course completely ignores interphase drag. In order to mimic interphase drag exhibited by immiscible gas bubbles, the effective density of the entrained fluid had to be increased. It was therefore treated as an adjustable parameter. The density of this arbitrary entrained fluid was set as $998.2 \alpha(\mathrm{kg} / \mathrm{m} 3)$ where $\alpha$ is a dimensionless fitting parameter. 


\subsubsection{EXPERIMENTAL INVESTIGATION}

The experiments were divided into two parts,first with an ejector run in the analytical model providing empirical data. In the second part, nine ejectors were built with various values of geometric parameters carefully chosen from the published data and to ensure high efficiency. In the parameters provided in table Table 3, primary flow rate, $\mathrm{Q}_{\mathrm{p}}$, is the only input that can be controlled, thus, the maximum $\mathrm{Q}_{\mathrm{p}}$ has been selected. The minimum $\mathrm{Q}_{\mathrm{p}}$ differs from one ejector to another. For instance, in ejector 1, the minimum $\mathrm{Q}_{\mathrm{p}}$ was set with a fully opened bypass valve, and in ejector 3, the minimum $\mathrm{Q}_{\mathrm{p}}$ was set with a half closed bypass valve because water will not go through water will not go through a fully opened bypass valve. The experiments were repeated three times for each ejector.

Table 3 various values of geometric parameters

\begin{tabular}{|c|c|c|c|c|c|}
\hline $\begin{array}{l}\text { Ejector } \\
\text { number }\end{array}$ & $\mathrm{L} \mathrm{mm}$ & $\mathrm{s} \mathbf{~ m m}$ & $\mathrm{D} \mathrm{mm}$ & $\mathrm{d} \mathrm{mm}$ & $\begin{array}{c}\text { Diffuser } \\
\text { Angle } \\
\varnothing\end{array}$ \\
\hline 1 & 160 & 1.5 & 40 & 9.6 & 5 \\
\hline 2 & 160 & 1.5 & 40 & 12 & 5 \\
\hline 3 & 160 & 1.5 & 40 & 14 & 5 \\
\hline 4 & 200 & 1.5 & 40 & 9.6 & 5 \\
\hline 5 & 200 & 1.5 & 40 & 12 & 5 \\
\hline 6 & 200 & 1.5 & 40 & 14 & 5 \\
\hline 7 & 240 & 1.5 & 40 & 9.6 & 5 \\
\hline 8 & 240 & 1.5 & 40 & 12 & 5 \\
\hline 9 & 240 & 1.5 & 40 & 14 & 5 \\
\hline
\end{tabular}

Five data points have to be collected experimentally: primary flow rate, $Q_{p}$, the secondary flow rate, $\mathrm{Q}_{\mathrm{s}}$, air in this case, primary pressure, $\mathrm{P}_{\mathrm{p}}$, secondary pressure, $\mathrm{P}_{\mathrm{s}}$, and diffuser pressure, $\mathrm{P}_{\mathrm{d}}$. The test rig was constructed with the assistance of a senior capstone 
group. Once built, the sensors were calibrated, and an array of experiments were conducted with the test rig to examine each ejector operation. Data was recorded and analyzed to serve in the two parts of the experiments. The test rig contains two individual barrels, one connected to the secondary inlet and one connected to the diffuser outlet or discharge barrel of the ejector pump, with 2" ID PVC piping. A schematic diagram of the test rig is shown in Figure 13. A centrifugal pump, drawing from the bottom of the discharge barrel, ensures drawing liquid only, feeding motive flow.
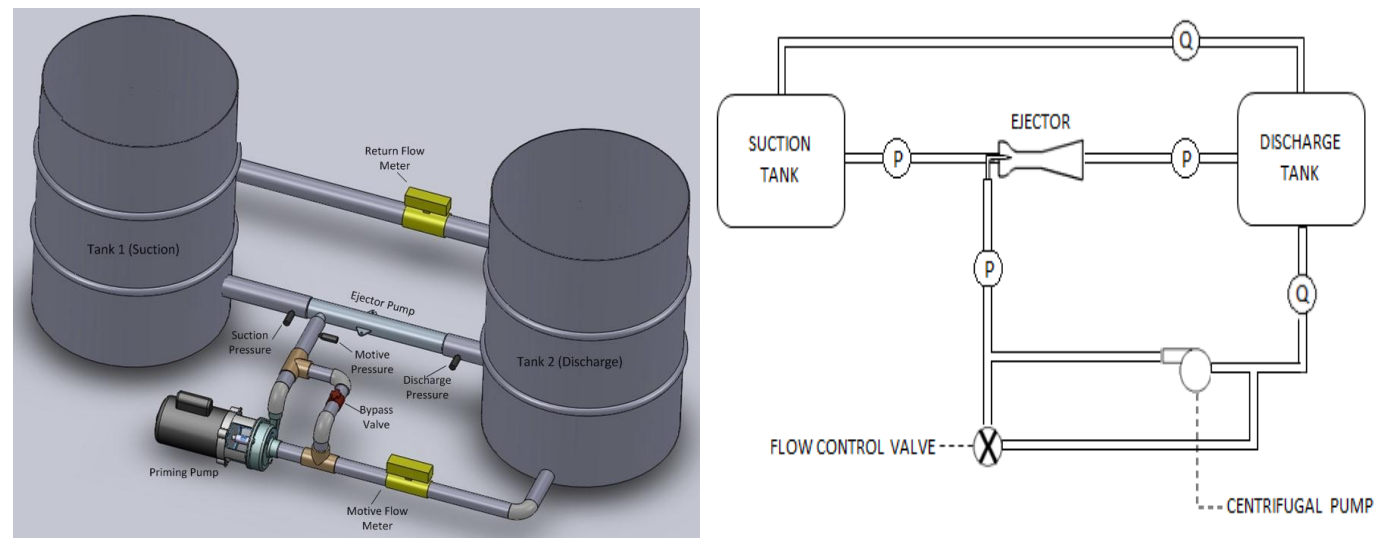

Figure 13 A schematic diagram of the test rig and A 3-D rendering of the test rig

The motive flow rate is an independent input that it could be changed from time to time as wished. The bypass valve is used to control the flow rate of the motive flow. In case of a fully closed valve, the highest motive flow rate occurs. In case of a fully open valve, the lowest motive flow rate occurs. Induced flow is drawn into the ejector from the suction barrel connected to the secondary inlet. The suction barrel is open to the atmosphere and maintains a constant level of available fluid by a return pipe angled from the discharge barrel back to the suction barrel in single-phase flow. In two-phase flow, the return valve is fully closed to prevent any liquid from running into the suction barrel. 
In two-phase flow, the induced fluid is air only. A 3-D rendering of the test rig is shown in Figure 13.

In order to evaluate the performance of both single-phase and two-phase ejector pumps by using Eq. 1-1 and Eq. 1-2 and then Eq. 1-3, five measurements are required: three pressures (primary (motive), secondary (suction), and discharge) and two flows (primary (motive) and secondary (suction)).

The pressure transducers are in the appropriate locations to detect the primary nozzle pressure, secondary inlet pressure, and discharge pressure. The primary flow buddle wheel meter is located right before the bypass valve. The secondary flow buddle wheel meter is located on the return from the discharge barrel to the suction barrel for single-phase flow only.

Due to the limits caused by the placement of the secondary flow meter, the scope of the data compiled from this test rig applies only to steady-state operation. A sixth data variable, the airflow rate through the ejector induced during two-phase operation, is required for the purpose of developing the analytical model. The method of measurement is discussed later.

Clear ejector pumps manufactured by 3-D Printer were used to enable observation of the two-phase flow. The clear ejector is a typical liquid ejector containing 
the four sections previously discussed: a primary nozzle, a secondary flow inlet, a constant-area mixing chamber, and a diffuser.

Nine clear ejectors were printed to investigate the effect of the geometry on the ejector performance. As mentioned, nine ejectors have been used in this work with nine different geometries. The only independent parameter, primary flow rate, is fixed at one level. Each experiment was repeated three times to ensure reproducing data for 27 experiments for all ejectors.

For safety purposes, water was used as the liquid phase of the system in place of jet fuel, and air was the gas phase. To begin each experiment, the discharge barrel was filled with running water to ensure water reached the centrifugal pump. The centrifugal pump was started with the bypass valve fully closed and the suction barrel valve was closed to circulate the water to prime the system. Once all of the air is displaced from the piping and ejector pump filled with water, the suction barrel valve was opened. The system is then given sufficient time to reach steady-state operation before data collection was initiated.

Each of the four variables was recorded with a data acquisition system on a computer via transducers and meters. National Instruments LabVIEW computer software interfaces with the data acquisition system and was used for data logging during the experiments. The pressure meters sent voltage outputs directly to the system, and then the system was calibrated to read the psig except when the secondary pressure, Ps, was 
calibrated to read the psia, the pressure that could fall below the atmospheric pressure. The flow meters sent frequencies to the transducers that were also calibrated to send voltage to the system and read as GPM. Eqs.3-54 and 3-58 describe that processes:

$$
\begin{gathered}
P_{p}=3.0029 v_{P_{p}}-0.0188 \\
P_{s}=5.9995 v_{P_{s}}-0.0164 \\
P_{d}=2.9952 v_{P_{d}}-0.0036 \\
Q_{p}=5 v_{Q_{p}} \\
Q_{s}=5 v_{Q_{s}}
\end{gathered}
$$

The resultant secondary pressure, in psig, is found by Eq. 3-59:

$$
P_{s}=\left(5.9995 V_{P_{s}}-0.0164\right)-P_{0}
$$

where $\mathrm{P}_{0}$ is the atmospheric pressure reading of the laboratory.

The data acquisition system averages data points every second for each of the four variables. Approximately 120 data points are recorded for each experiment at steady-state conditions. With two-phase conditions, a sixth data set must be included for the flow rate of the air induced in the secondary fluid. Here the trash bag method was employed. It is used by the HVAC industry and involves measuring the time required to fill a $50 \mathrm{lb}$ trash bag. Then the calculation for the airflow rate can be determined by using Eq. 3-60: 


$$
Q_{a}=\frac{V_{b a g}}{t}
$$

This strategy gives a measurement of volumetric airflow rate without depending on sampling a small amount of the flow and assuming uniformity. Error can be lessened by utilizing an unbending edge for the air to flow into the bag and by adjusting the sack to keep up a uniform shape after filling $[58,59]$. Because of the visual nature of this technique, there is some variation from person to person, though it is thought to be low.

For these experiments, the same person has been used to run the clock that times the filling of the sack. Error is acceptable within $10 \%[58,59]$. The trash bag technique, as connected to the two-phase discharge barrel, can be found in Figure 14.

As can be seen in the photo, the outlet barrel is tightened with a top cover and a fitting is attached to an opening in the top that decreases the range of actuated air that can leave the barrel. A plastic piece is connected to a standard, financially accessible trash bag that fits cozily into the fitting on the barrel, driving all air to go into the bag.

The waste bag is fixed along its edge, and a similar trash sack is used as a part of all the two-phase tests. The waste bag rig is not connected to the outlet barrel until the steady-state is achieved. At first, the waste bag is consistently adjusted to expel a reasonably expected amount of air. After that, it is permitted to fill uninhibited. The full trash bag opens into its final shape as seen. 

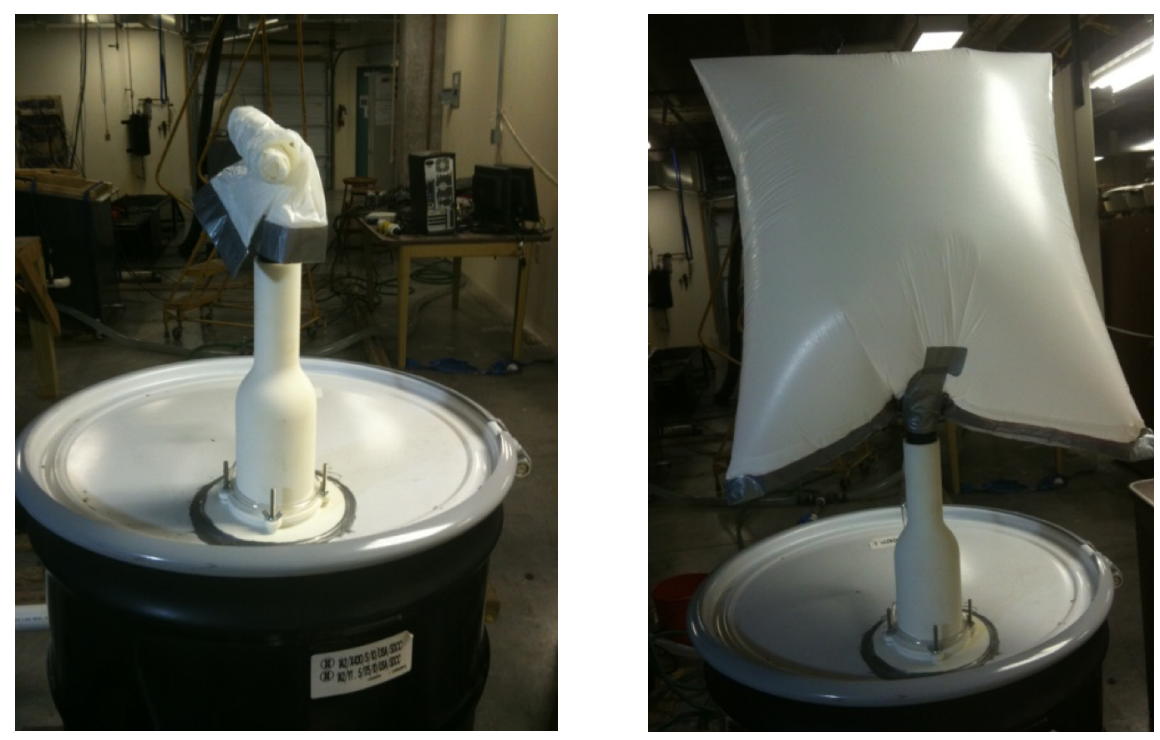

Figure 14 Visual of left empty and right full trash bag for airflow measurement

When information for all examinations is collected, investigation can start. An empirical model is created to improve the analytical model's ability to the forecast the entrained stream properties. Analysis also requires computing the performance characteristics seenin Chapter I using Eqs.1-1 - 1-3. A representative value of $N, M$ and $\eta$ for each single-phase and two-phase test are used to align the analytical model.

\subsubsection{ERROR ANALYSIS}

The sensors are found as exhibited in "Mechanical Measurements" by Beckwith. [60]. The precision of the analytical model depends on those error equations. The sensor error starts with understanding the aggregate error in the voltage readings, which is a function of both the accuracy and inclination error as seen in Eq. 3-61: 


$$
u_{v_{i}}=\left(\text { Precision Error }^{2}+\text { Bias Error }^{2}\right)^{1 / 2}
$$

where $i$ is each individual sensor including primary, secondary, and discharge pressure sensors, and primary and secondary flow meters. Precision error accounts for fluctuations in the voltage signal sent from the sensor. Bias error is a function of accuracy of the device's calibration and dimensional tolerances. Precision error is calculated by Eq. 3-62, and bias error is calculated by Eq. 3-63:

$$
\begin{gathered}
\text { Precision Error }=\frac{\sigma_{e} Z_{c / 2}}{\sqrt{n}} \\
\text { Bias Error }=\text { Reading (Gain Error })+ \text { Range }(\text { Offset Error })
\end{gathered}
$$

where $\sigma_{e}$ is the standard deviation of the sensor voltage readings, $z_{c / 2}$ is the value from the students t-distribution for a $95 \%$ confidence level, and $n$ is the number of readings taken. Both gain error and offset error are values based on the voltage range of the individual sensor and available in the datasheet for the specific data acquisition system used.

The uncertainty in each measured value is then propagated from the total uncertainty in the voltage measurement. To do so, the total voltage uncertainty from Eq. 3-61 is multiplied by the derivative of the voltage conversion equation for each individual sensor, particularly the derivatives of Eqs. 3-54-3-58 Equations 3-64 and 3-65 represent the total error for the different data readings: 


$$
\begin{aligned}
& u_{P_{j}}=u_{v_{i}} \frac{\partial P_{j}}{\partial V_{P_{j}}} \\
& u_{Q_{I}}=u_{V_{k}} \frac{\partial Q_{I}}{\partial V_{Q_{l}}}
\end{aligned}
$$

where $j$ is the pressure sensor variable (primary, secondary, or discharge) and $I$ is the flow meter variable (primary or secondary). The uncertainty must be propagated again to find the voltage of the dependent variables: $N, M$, and $\eta$ :

$$
\begin{gathered}
u_{N}=\left[\left(u_{P_{P}} \frac{\partial N}{\partial P_{P}}\right)^{2}+\left(u_{P_{s}} \frac{\partial N}{\partial P_{s}}\right)^{2}+\left(u_{P_{d}} \frac{\partial N}{\partial P_{d}}\right)^{2}\right]^{1 / 2} \\
u_{M}=\left[\left(u_{Q_{p}} \frac{\partial M}{\partial Q_{p}}\right)^{2}+\left(u_{Q_{s}} \frac{\partial M}{\partial Q_{s}}\right)^{2}\right]^{1 / 2} \\
u_{\eta}=\left[\left(u_{N} \frac{\partial \eta}{\partial N}\right)^{2}+\left(u_{M} \frac{\partial \eta}{\partial M}\right)^{2}\right]^{1 / 2}
\end{gathered}
$$

With this error analysis, all uncertainties must be independent of each other and have the same probability of occurring [60]. 


\subsubsection{MATRIX EXPERIMENT FOR VARIOUS GEOMETRIC PARAMETERS}

It was interesting to determine the effect of the two geometric parameters: The length of mixing chamber, $\mathrm{L}$, and the diameter of nozzle, $\mathrm{d}$, on the efficiency of the ejector. Three levels for each parameter were chosen to cover the range of interest.

The factors and their chosen levels are listed in Table 4. They define the experimental region or the region of interest. The reason for this is to determine the best setting for each parameter, so that the efficiency is maximized.

Table 4 the factors and their chosen levels

\begin{tabular}{|c|c|c|c|}
\hline \multirow{2}{*}{ Factor } & \multicolumn{3}{|c|}{ Levels } \\
\cline { 2 - 4 } & 1 & 2 & 3 \\
\hline $\mathrm{L}$ & 160 & 200 & 240 \\
\hline $\mathrm{d}$ & 9.6 & 12 & 14 \\
\hline
\end{tabular}

The matrix experiment is shown in Table 5. It consists of nine individual experiments that correspond to nine rows. The two columns of the matrix are the two factors as specified in the table. The data in the matrix are the levels of factors. Thus, experiment 1 is to be tested with each factor at the first level. Referring to Table 4, it can be seen that the factor levels for experiment 1 are $160 \mathrm{~mm}$, and $9.6 \mathrm{~mm}$. The matrix experiment of the table is the standard orthogonal array L9 of the Taguchi and Wu. The full range of the matrix experiment can be seen in Table 6

Table 5 matrix experiment

\begin{tabular}{|c|c|c|c|}
\hline \multirow{2}{*}{ Exp. No. } & \multicolumn{2}{|c|}{ Column Number and Factor assigned } & Efficiency \\
\cline { 2 - 4 } & $1 \mathrm{~L}$ & $2 \mathrm{~d}$ & (output) \\
\hline 1 & 1 & 1 & $\eta_{1}$ \\
\hline 2 & 1 & 2 & $\mathrm{H}_{2}$ \\
\hline 3 & 1 & 3 & $\mathrm{H}_{3}$ \\
\hline 4 & 2 & 1 & $\mathrm{H}_{4}$ \\
\hline 5 & 2 & 2 & $\mathrm{H}_{5}$ \\
\hline 6 & 2 & 3 & $\mathrm{H}_{6}$ \\
\hline 7 & 3 & 1 & $\mathrm{H}_{7}$ \\
\hline 8 & 3 & 2 & $\mathrm{H}_{8}$ \\
\hline 9 & 3 & 3 & $\mathrm{H}_{9}$ \\
\hline
\end{tabular}


Table 6 orthogonal array $L_{9}$ for the full range of the various geometries

\begin{tabular}{|c|c|c|c|}
\hline \multirow{2}{*}{ Exp. No. } & \multicolumn{2}{|c|}{ Column Number and Factor assigned } & \multirow{2}{*}{ Efficiency } \\
\cline { 2 - 3 } & $1 \mathrm{~L}$ & $2 \mathrm{~d}$ & \\
\hline 1 & 160 & 9.6 & 10.015 \\
\hline 2 & 160 & 12 & 9.259 \\
\hline 3 & 160 & 14 & 7.721 \\
\hline 4 & 200 & 9.6 & 13.45 \\
\hline 5 & 200 & 12 & 9.37 \\
\hline 6 & 200 & 14 & 7.886 \\
\hline 7 & 240 & 9.6 & 14.76 \\
\hline 8 & 240 & 12 & 9.915 \\
\hline 9 & 240 & 14 & 7.974 \\
\hline
\end{tabular}

Table 6 shows the full region of interest with corresponding efficiency. After producing this table, the nine ejectors listed in Table 7 can be designed. All the geometric parameters have been chosen accordingly from published studies to maximize the outputs and efficiencies of the selected geometries.

Table 7 geometric parameters for all nine ejectors

\begin{tabular}{|c|c|c|c|c|c|c|c|}
\hline Group & No. & $\mathrm{L}(\mathrm{mm})$ & $\mathrm{d}(\mathrm{mm})$ & $\mathrm{D}(\mathrm{mm})$ & $\mathrm{L} / \mathrm{D}$ & $\mathrm{d} / \mathrm{D}$ & $\mathrm{s} / \mathrm{D}$ \\
\hline A & 1 & 160 & 9.6 & 40 & 4 & 0.24 & 0.0375 \\
\hline B & 2 & 160 & 12 & 40 & 4 & 0.3 & 0.0375 \\
\hline C & 3 & 160 & 14 & 40 & 4 & 0.35 & 0.0375 \\
\hline A & 4 & 200 & 9.6 & 40 & 5 & 0.24 & 0.0375 \\
\hline B & 5 & 200 & 12 & 40 & 5 & 0.3 & 0.0375 \\
\hline C & 6 & 200 & 14 & 40 & 5 & 0.35 & 0.0375 \\
\hline A & 7 & 240 & 9.6 & 40 & 6 & 0.24 & 0.0375 \\
\hline B & 8 & 240 & 12 & 40 & 6 & 0.3 & 0.0375 \\
\hline C & 9 & 240 & 14 & 40 & 6 & 0.35 & 0.0375 \\
\hline
\end{tabular}



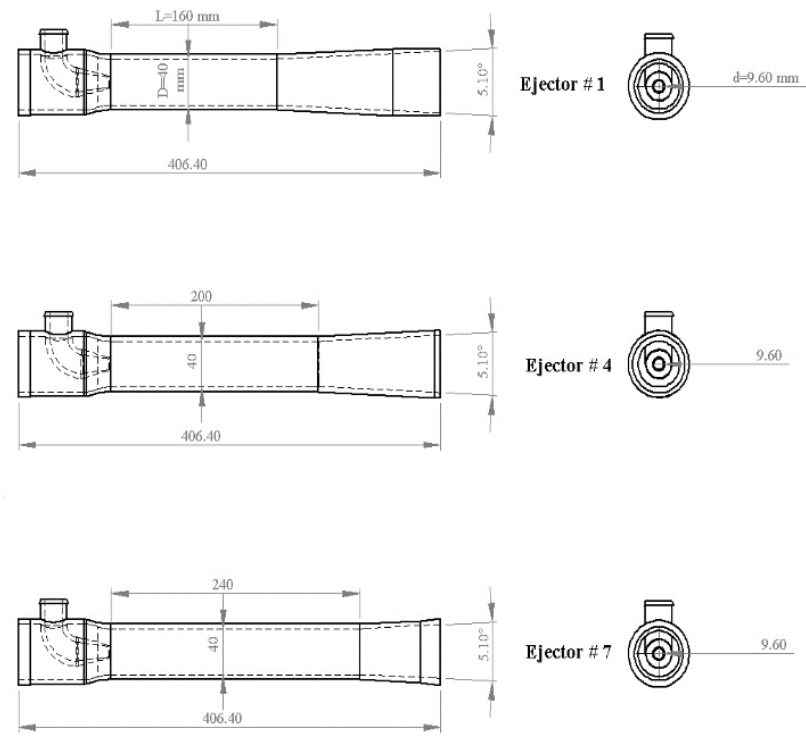

Figure 15 geometric parameters for group A
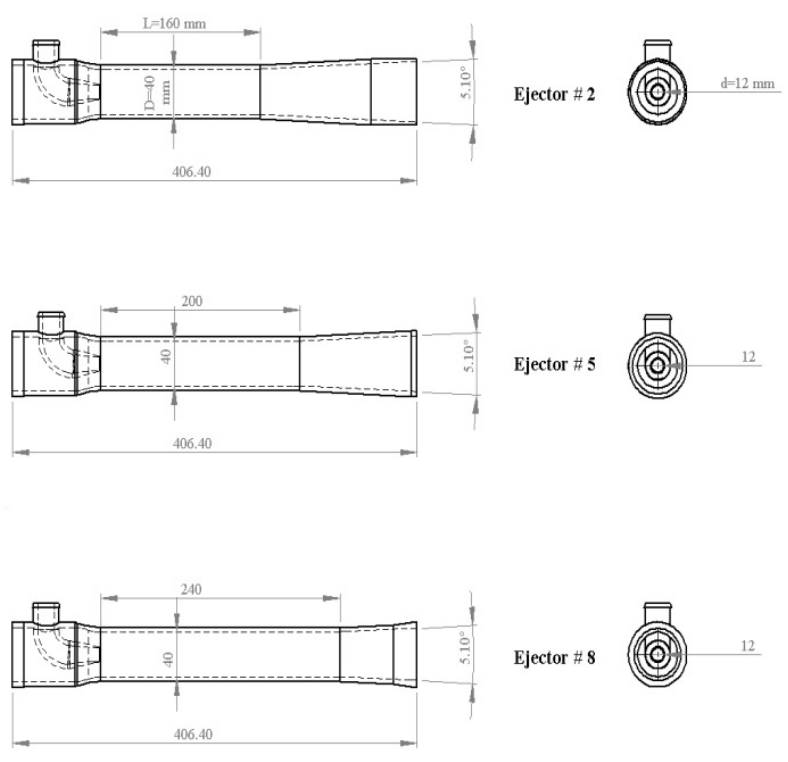

Figure 16 geometric parameters for group B 

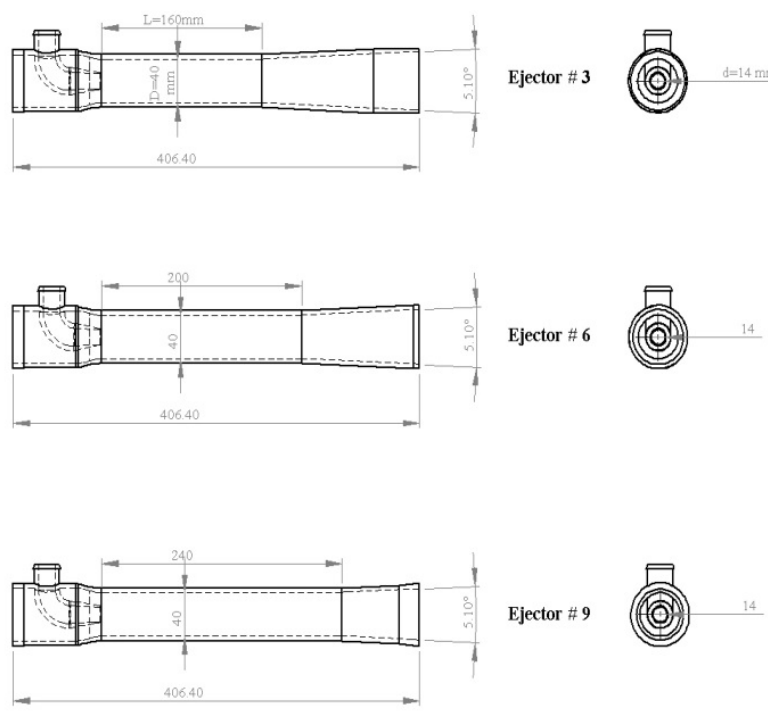

Figure 17 geometric parameters for group C 


\section{CHAPTER IV}

\subsection{RESULTS AND DISCUSSIONS}

\subsubsection{ANALYTICAL MODEL RESULTS}

The analytical model predicts the four parameters necessary to compute the performance of the system. They are the secondary pressure, the two-phase flow ratio, the pressure ratio, and the efficiency. As aforementioned, the loss factors are the key to computing the efficiency analytically, and they have to be calculated via the analytical model. A review of the literature was made for the loss factors, with only three papers addressing the two-phase flow inside the ejector : Petrie et al.[61], Jiao et al.[20], and Noronha et al.[21, 22].

Some researchers, consider the loss factor in the mixing chamber and diffuser to be an loss factor, $\mathrm{K}_{\mathrm{md}}$, when they have applied Eq. 3-28. Out of many researchers, only Jiao et al. set a range for $\mathrm{K}_{\mathrm{md}}$ over a set of experiments.

Table 8 the comparison with literature for the loss factors

\begin{tabular}{|c|c|c|c|c|c|}
\hline Source & $\mathbf{K}_{\mathbf{p}}$ & $\mathbf{K}_{\mathbf{s}}$ & $\mathbf{K}_{\mathbf{m}}$ & $\mathbf{K}_{\mathbf{d}}$ & $\mathbf{K}_{\mathbf{m d}}$ \\
\hline Gosline \& O'Brien [3] & 0.15 & 0.00 & 0.28 & 0.10 & 0.38 \\
\hline Cunningham [62] & 0.10 & 0.00 & -- & -- & 0.30 \\
\hline Sanger [9] & 0.14 & 0.04 & 0.10 & 0.10 & 0.20 \\
\hline Sanger [9] & 0.09 & 0.08 & 0.10 & 0.10 & 0.20 \\
\hline Petrie et al. [61] & 0.03 & 0.00 & -- & -- & 0.20 \\
\hline Jiao et al. [20] & 0.04 & 0.00 & -- & -- & $0.10-0.50$ \\
\hline Noronha et al. [21, 22] & 0.10 & 0.00 & -- & -- & 0.19 \\
\hline This work & 0.14 & $0.21-0.34$ & $0.11-0.25$ & $0.00-$ & $0.16-0.41$ \\
\hline
\end{tabular}


In addition, loss factors in the secondary tube were recorded as a zero value. That is far from realistic physics [21,22]. Since zero is a value, it might be replaced with an finite value in order to compute the loss factor in the secondary tube [8].

A valueless secondary inlet loss factor is convenient when the secondary tube has gas only [15] unlike our experiments.

Table 8 shows that the published loss factors are consistent with the one that was calculated in this work. A range is adopted for the loss factors in this work due to the calculations that have been made for them. All the researchers use empirical data for the loss factors, yet this work calculates the loss factors.

Marini et al.'s work discovered that the diffuser loss factors could become insignificant for low discharge flow [11]. The range of the loss factors that was found is logical and gives precise results. The ability of an analytical model to produce a characteristic curve for both single-phase and two-phase flow is crucial.

The analytical model produced the characteristic curves for single-phase flow in the first stages of the work. It includes the repetitions for each individual experiment linked with estimated error.

The characteristic curve should be studied carefully to identify any unusual curves that may show that the analytical model does not work. There is a minor curvature in the slope that presents the pressure ratio, and it depends on the area ratio that is an 
input in the analytical model [9]. Moreover, close to the mid-point where the high efficiency is, all the data points are plotted under the normal operation [9].
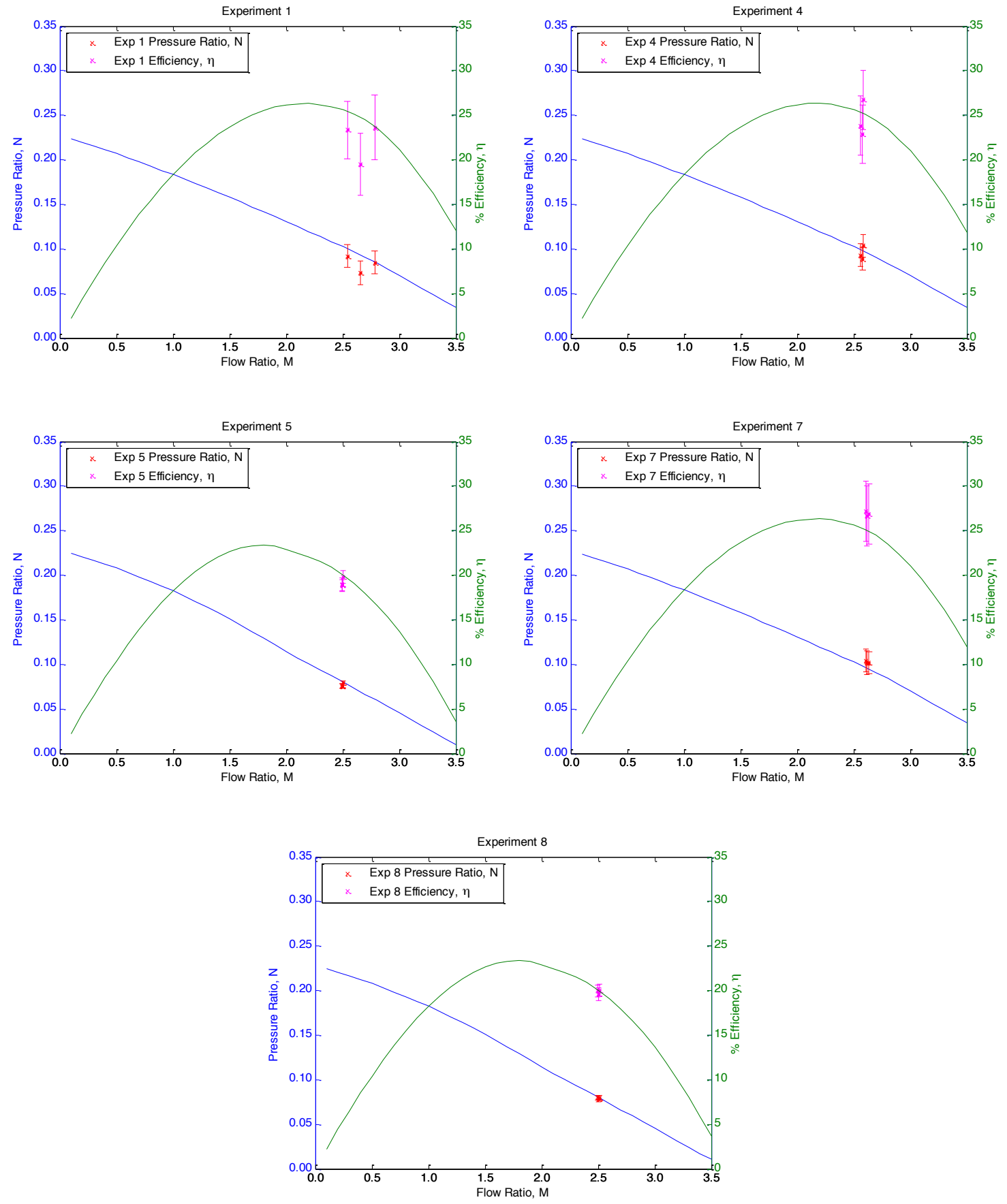

Figure 18 Analytical model characteristic curves for single-phase experiments 
The plotted data on the characteristic curve gives a wide view of the analytical model's ability versus the experimental data. All experimental data falls within the curve except one datum as shown in Figure 18. As mentioned, the error is involved in the analytical model and it is normal range.

The error fluctuates considerably between the five experiments because it is a function of the actual sensor readings, and he lowest primary flow rates get especially high error rates. Yet, when the flow rate increases, the error decreases. The variability between the repetitions of Experiment 1 is the only obvious outlier. The repetitions between the other four single-phase experiments show strong agreement. With low motive flow rate and low available fluid head, which is the lowest of the ejector operations, there is variation in ejector performance that could be explained by the sensors limitations for low readings. In addition, there is not good agreement between one repetition of Experiment 1 and the analytical model's prediction that indicates this may be an outlier. Now, the performance of the analytical model is ready to be considered over the whole range of ejector operations, including both single-phase and two-phase flow.

For single-phase performance, predicting the pressure ratio, presented in Figure 19, and efficiency, as shown in Figure 20, is important. For two-phase performance, the third ratio, which is flow ratio, is also important due to the differences in densities between the primary fluid, water, and secondary fluid and air, as shown in Figure 21, and a prediction of secondary pressure presented in Figure 22. 
Better agreement appears between the empirical data and the analytical data of the pressure ratio for the two-phase experiments than in the single-phase experiments. This relates to lower error for the two-phase experiments because most were operated at the higher motive flow rates. The highest level of error happens for the single-phase experiments with the lowest motive flow rate. With sequential, the same thing happens for efficiency. For the single-phase experiments, there is no error coupled with the flow ratio because flow ratio is an input into the model. The error for the efficiency is the same as the error for the pressure ratio which both are dependent variables. For the twophase experiments, the average of the single-phase experiments is the predicted flow ratio input into the analytical model. The final flow ratio for the two-phase experiments is an output of the analytical model after calculating the quality for the induced air in the empirical model.

Figure 21 shows some error in the prediction of the two-phase flow ratio, albeit very slight. Experiment 3, which is operated at the highest motive flow rate and the lowest available fluid head, shows the largest disagreement because the highest induced air and the lowest flow ratio occurs here.

Lastly, as mentioned earlier, the secondary pressure for two-phase flow is calculated by comparing the predicted data with the empirical data. Experiment 6 shows a weak agreement, while the rest has a good agreement. 

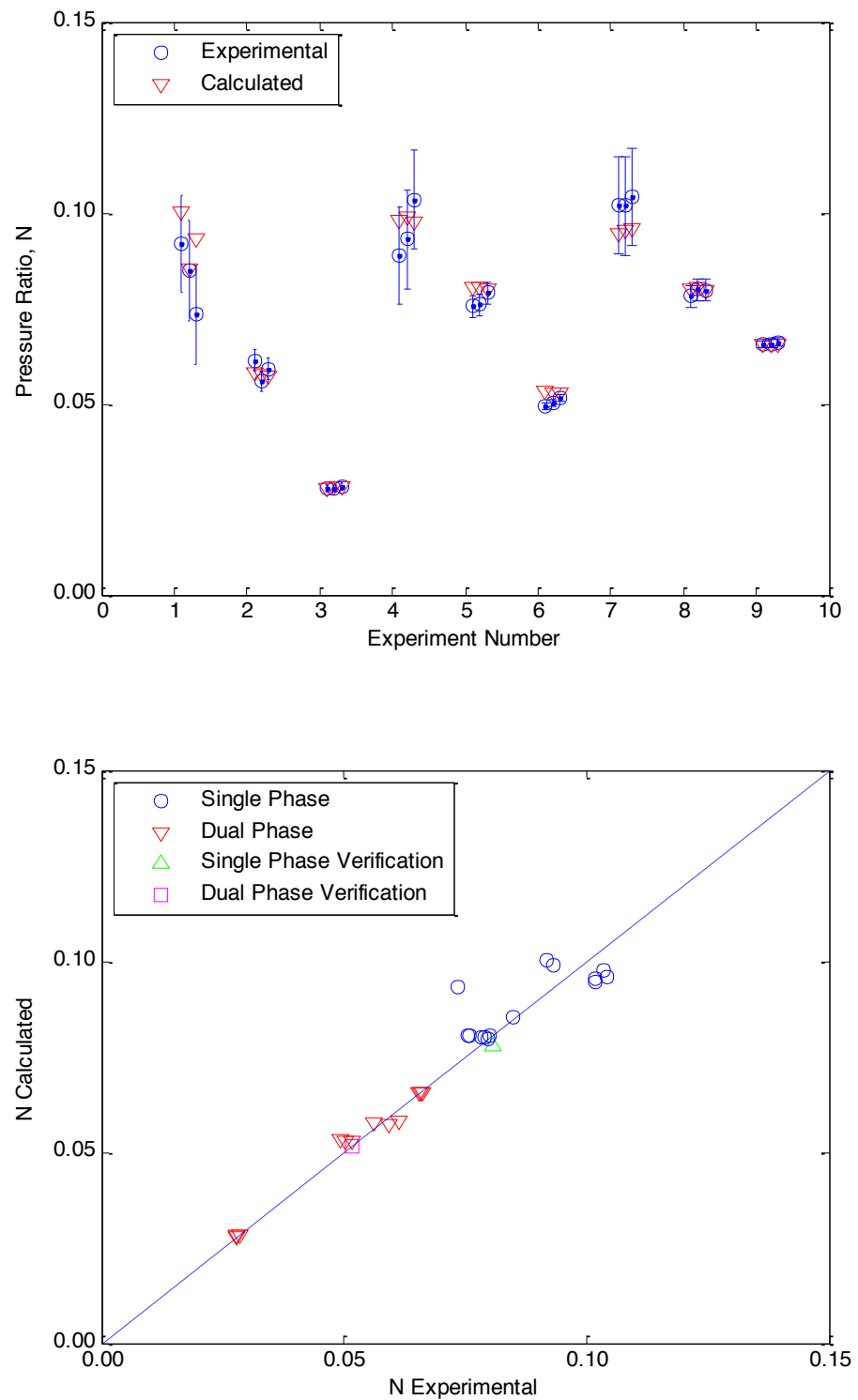

Figure 19 Analytical model prediction of pressure ratio 

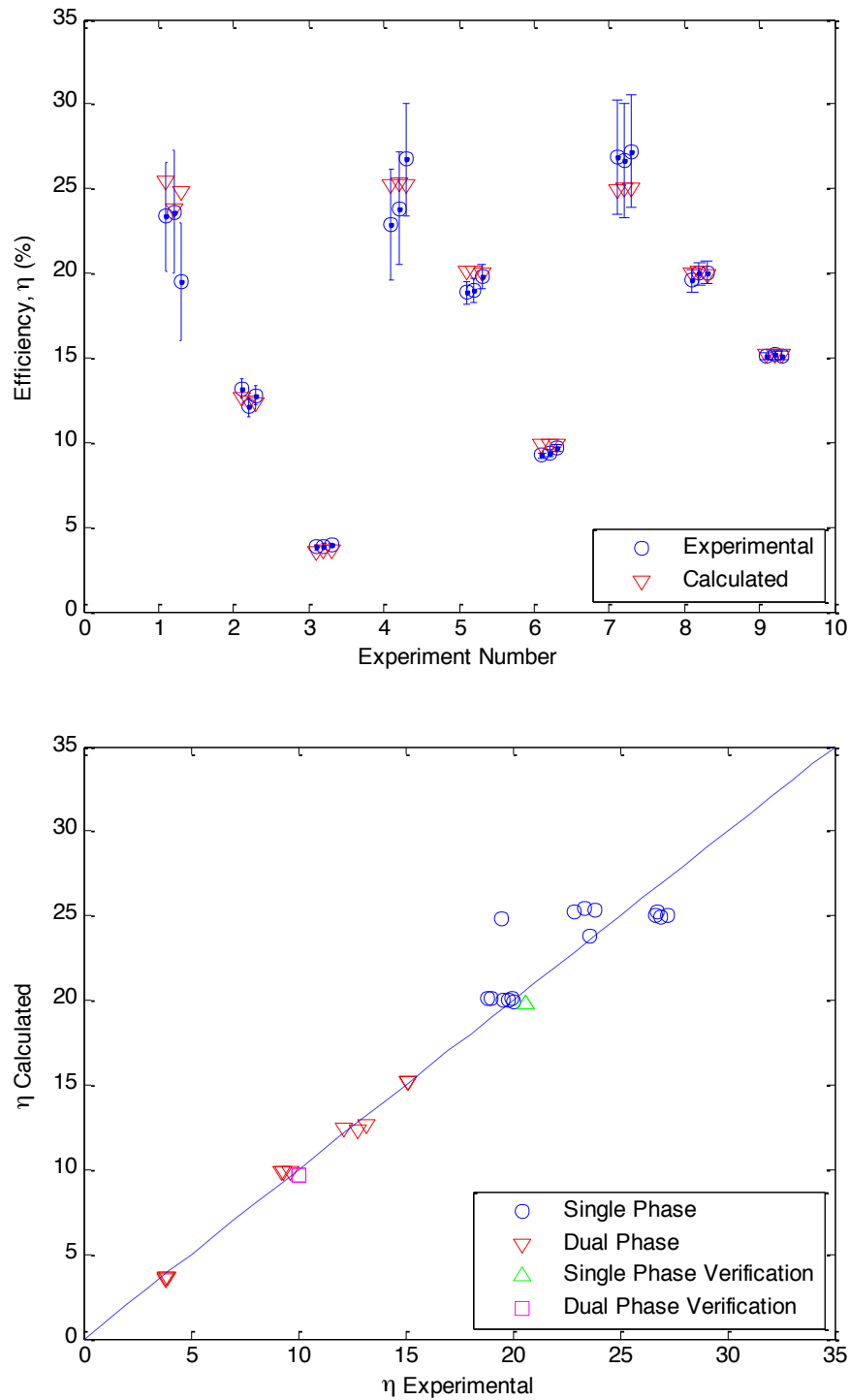

Figure 20 Analytical model prediction of efficiency 

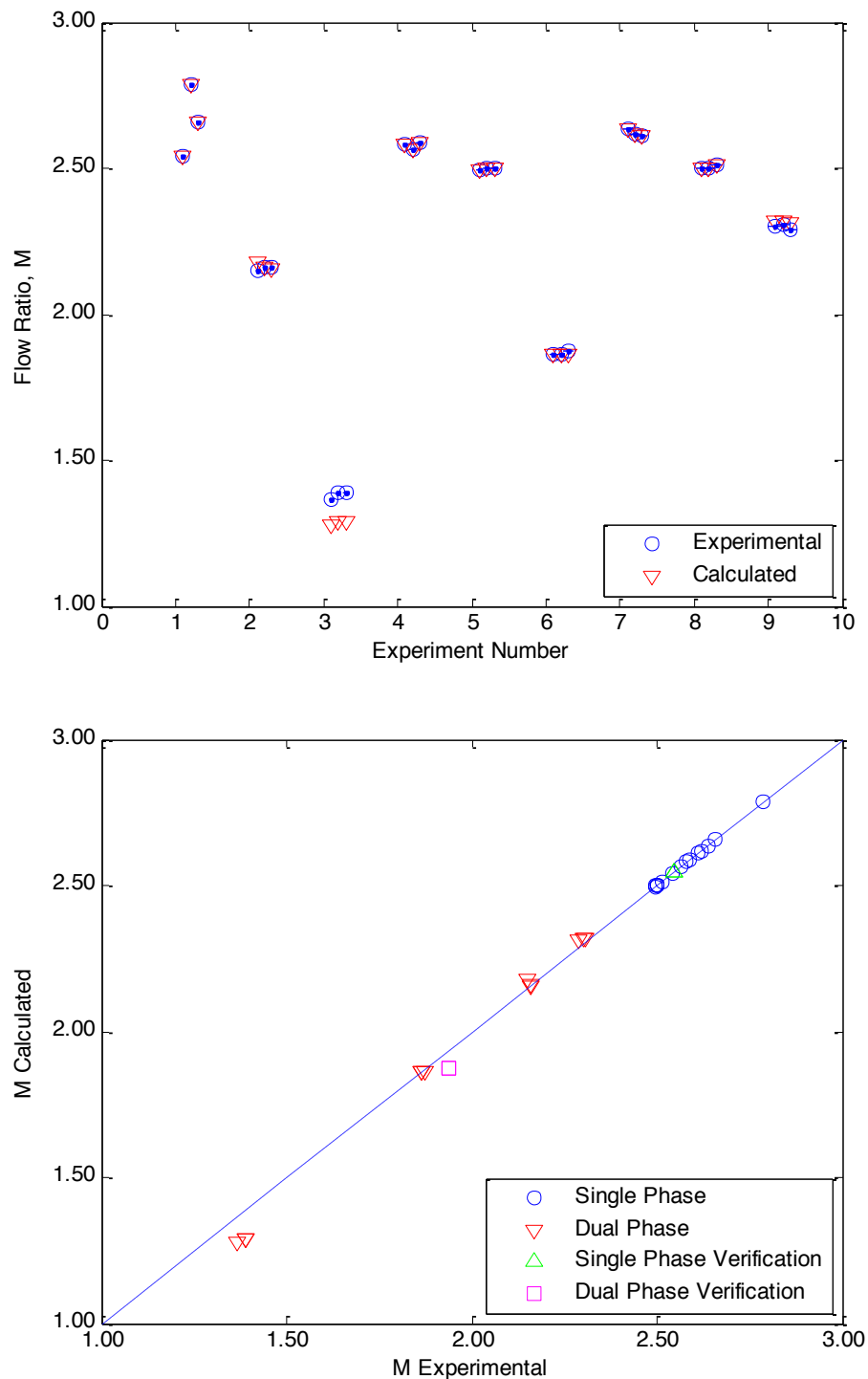

Figure 21 Analytical model prediction of flow ratio 

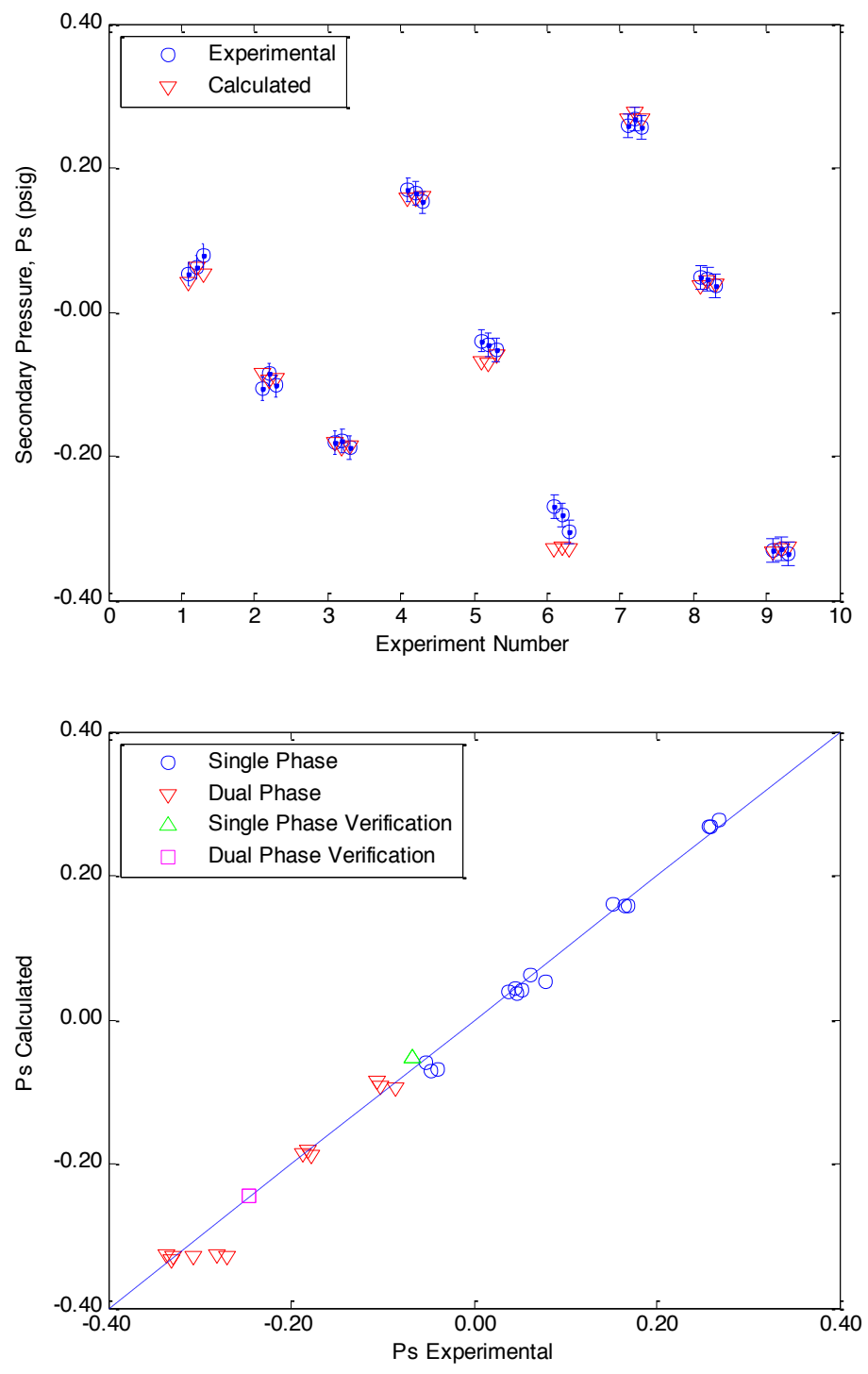

Figure 22 Analytical model prediction of secondary pressure

What it has been mentioned, it is summarized in Table 9 and Table 10, as the percent error and the mean square error have been calculated. 
Table 9 Analytical model results (percent error)

\begin{tabular}{|c|c|c|c|c|}
\hline Model Phase & $\mathbf{P}_{\mathbf{s}}$ & $\mathbf{N}$ & $\mathbf{M}$ & $\mathbf{\eta}$ \\
\hline Single & 16.94 & 6.49 & -- & 6.48 \\
\hline Two & 7.93 & 2.61 & 2.14 & 3.89 \\
\hline Overall & 12.94 & 4.76 & 2.14 & 5.33 \\
\hline
\end{tabular}

Table 10 Analytical model results (mean square error)

\begin{tabular}{|c|c|c|c|c|}
\hline Model Phase & $\mathbf{P}_{\mathbf{s}}$ & $\mathbf{N}$ & $\mathbf{M}$ & $\mathbf{\eta}$ \\
\hline Single & 0.014 & 0.007 & -- & 1.941 \\
\hline Two & 0.024 & 0.002 & 0.051 & 0.369 \\
\hline Overall & 0.019 & 0.006 & 0.051 & 1.468 \\
\hline
\end{tabular}

\subsubsection{MODEL VERIFICATION}

The results of the two validation experiments further proves that the developed analytical model is a reliable and accurate method of predicting ejector performance using ejector geometry and flow conditions. The specific results of the individual performance parameters determined by the validation experiments are included in Table 12. Similar to the error results of the standard array of experiments, the error results for

Table 11 Analytical model verification results (percent error)

\begin{tabular}{|c|c|c|c|c|}
\hline Model Phase & $\mathbf{P}_{\mathbf{s}}$ & $\mathbf{N}$ & $\mathbf{M}$ & $\mathbf{\eta}$ \\
\hline Single & 20.15 & 3.59 & -- & 3.55 \\
\hline Two & 0.69 & 0.39 & 3.30 & 3.49 \\
\hline Overall & 10.42 & 1.99 & 3.30 & 3.52 \\
\hline
\end{tabular}

Table 12 Analytical model verification results (mean square error)

\begin{tabular}{|c|c|c|c|c|}
\hline Model Phase & $\mathbf{P}_{\mathbf{s}}$ & $\mathbf{N}$ & $\mathbf{M}$ & $\mathbf{\eta}$ \\
\hline Single & 0.014 & 0.003 & -- & 0.730 \\
\hline Two & 0.002 & 0.000 & 0.064 & 0.350 \\
\hline Overall & 0.010 & 0.002 & 0.064 & 0.572 \\
\hline
\end{tabular}

the validation experiments are provided in Table 11 and Table 12. 
Analytical model results for the prediction of the performance parameters of the verification experiments are consistent with the results of the original experiments for both the single-phase and two-phase flows. This shows very strong model performance, repeatable at data points contained within the examined experimental data set.

Final model performance consideration is given to comparing the newly developed model to previously published two-phase models in the literature. Three models are readily available with specific published results, particularly the root mean square error of the pressure ratio prediction. Although specific data that could be run through the model is not available, the root mean square error for the data set contained can be determined and is presented in Table 13 with the other models' root mean square error.

Table 13 Comparison of published two-phase model pressure ratio prediction results

\begin{tabular}{|c|c|}
\hline Source & Root Mean Square Error \\
\hline Petrie et al. [61] & 0.401 \\
\hline Jiao et al. [20] & 0.255 \\
\hline Noronha et al. [21, 22] & 0.224 \\
\hline This work & 0.006 \\
\hline
\end{tabular}

The model developed through this work demonstrates significant improvement over previous models, reducing the root mean square error to less than $10 \%$ of the previous best value. This is a significant improvement and shows the benefit of calculating the loss coefficients based on the geometry and flow conditions contained within the ejector rather than fitting empirical data. Constant loss coefficients across a 
range of empirical data may not adequately consider conditions as they vary between experimental parameters.

\subsubsection{UNCERTAINTY MODEL:}

This section shows the results for the Monte Carlo method discussed earlier. The output of the NESSUS software [56], using Monte Carlo method can solve for the cumulative probability, Figure 23, probabilistic sensitivity factors, Figure 24, and sensitivity levels, Figure 25. A cumulative probability graph shows the relationship between the pressure ratio $\mathrm{N}$ and the probability of occurrence. For example, there is $10 \%$ chance that the pressure ratio $\mathrm{N}$ is 0.041 using this model and almost $99 \%$ chance that it is 0.075 . This probability will change if the random variables are changed. Probabilistic sensitivity factor can determine the sensitivity of the pressure ratio $\mathrm{N}$ to each of the random variables used (loss coefficients).

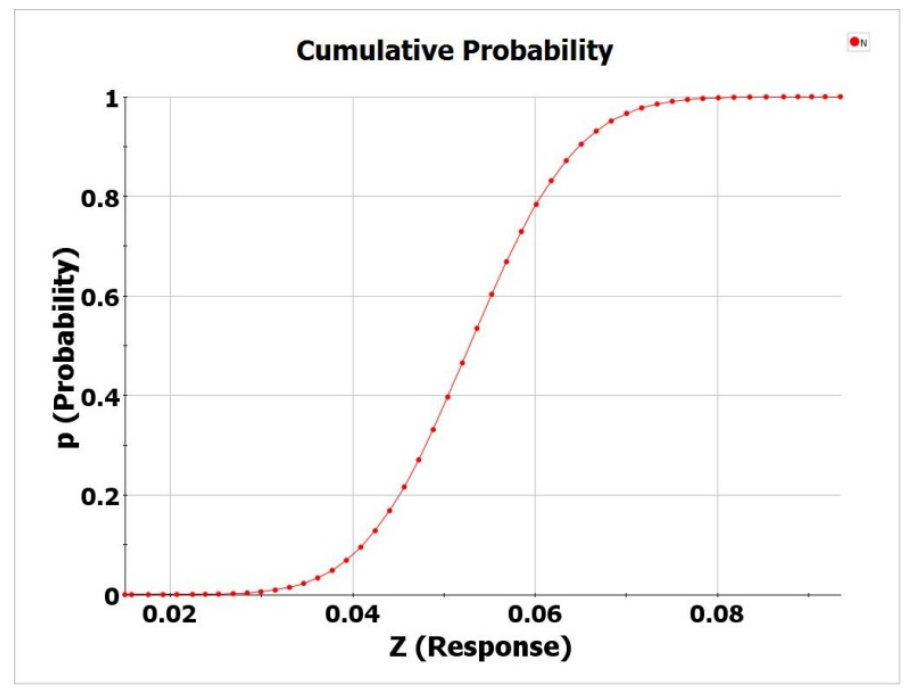

Figure 23 Cumulative probability for the pressure ratio $\mathbf{N}$ 


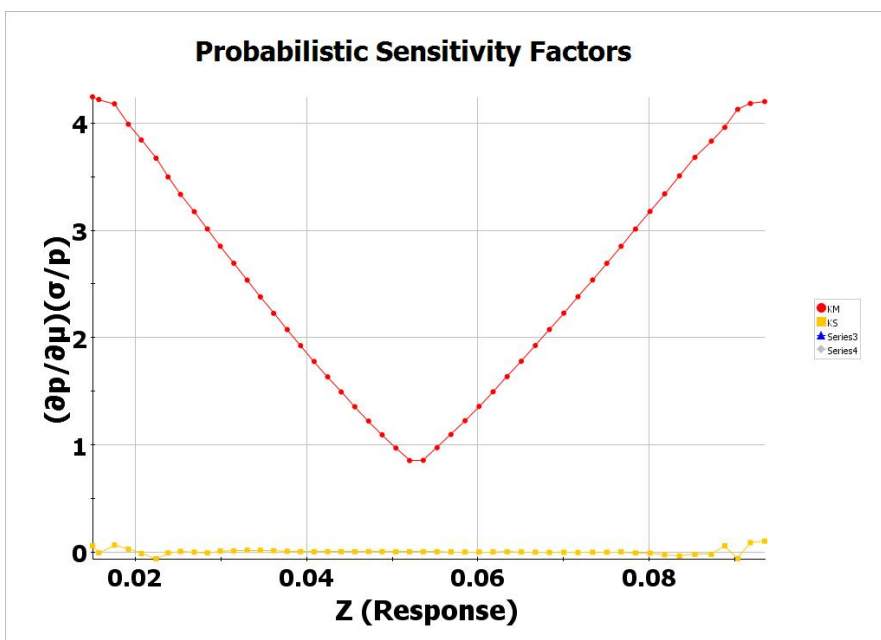

Figure 24 Probabilistic sensitivity factors

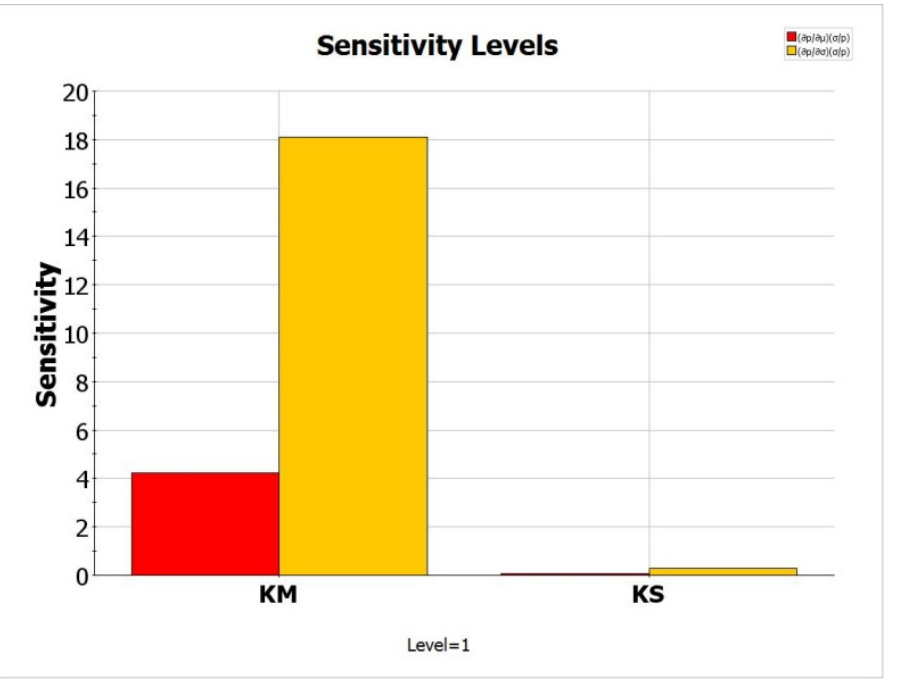

Figure 25 Sensitivity levels 


\subsubsection{NUMERICAL}

The model was solved for the velocity and pressure across the ejector. The solution of these equations provides detailed results on velocity, pressures, and extent of secondary fluid inside the ejector. Simulated velocity, pressure, and volume fraction of primary phase in the form of contour plots are shown in Figure 26-Figure 34.

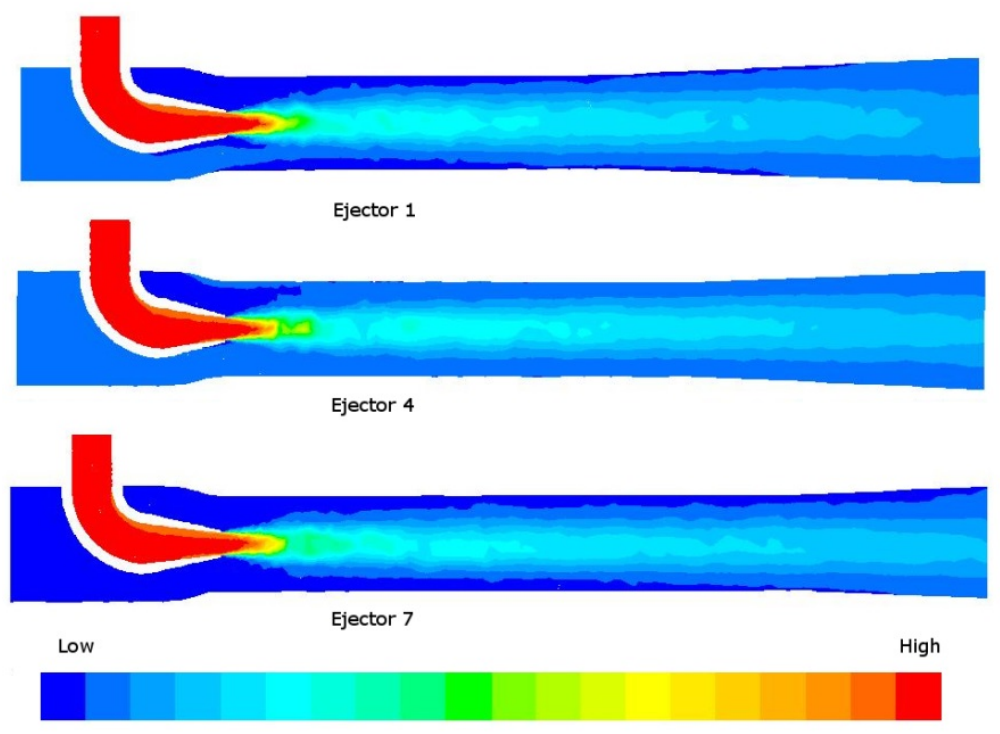

Figure 26 Pressure contour plots of various geometries
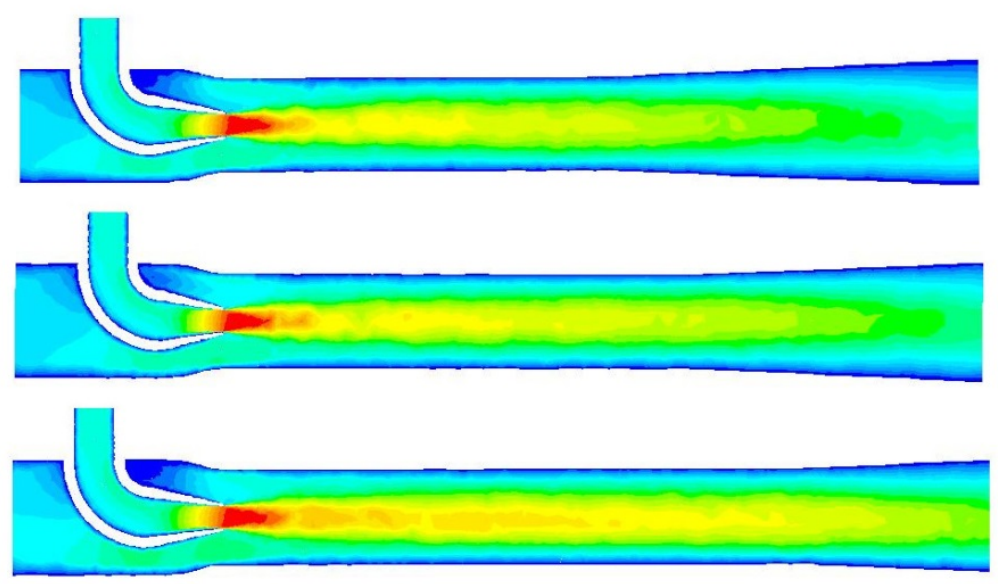

Low High

Figure 27 Velocity contour plots of various geometries 


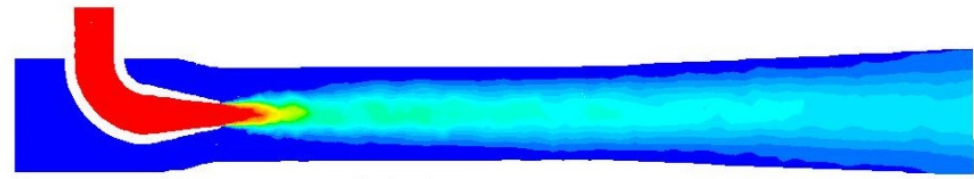

Ejector 1

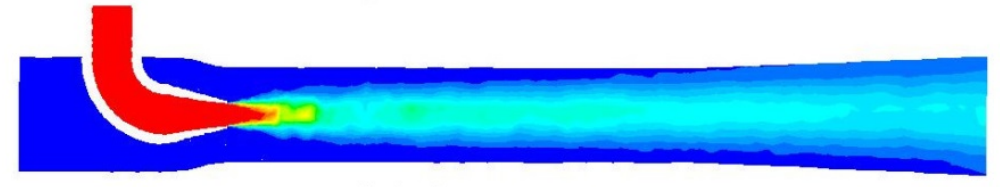

Ejector 4

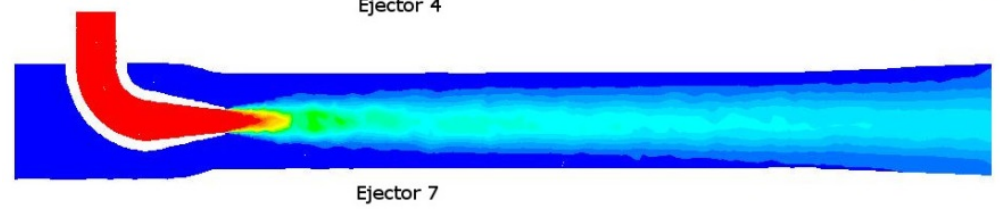

Gas

Liquid

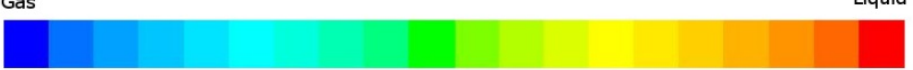

Figure 28 Volume fractions of the primary phase contour plots of various geometries

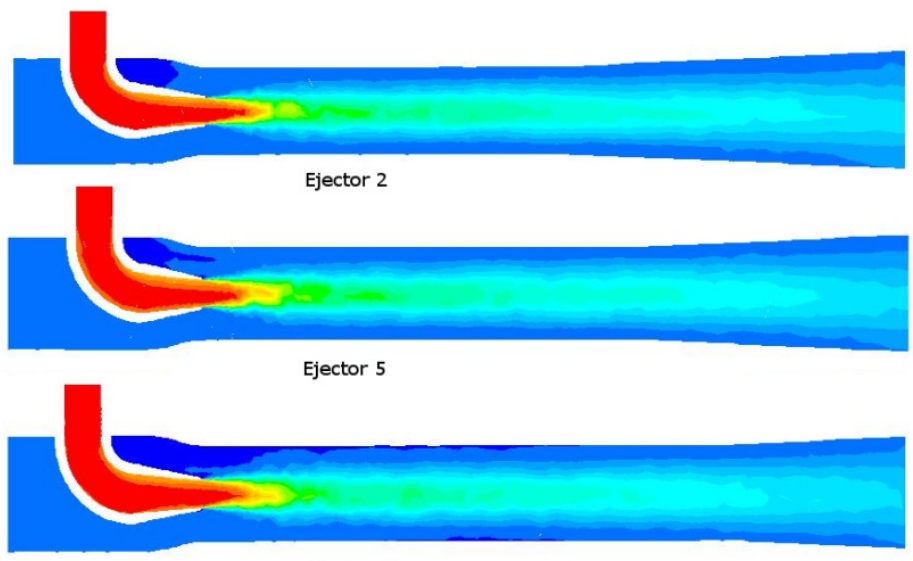

Ejector 8

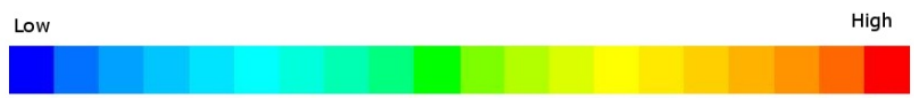

Figure 29 Pressure contour plots of various geometries 


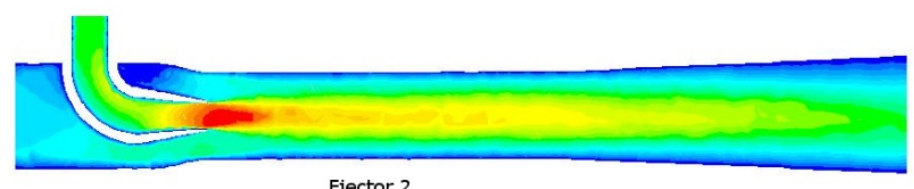

Ejector 2
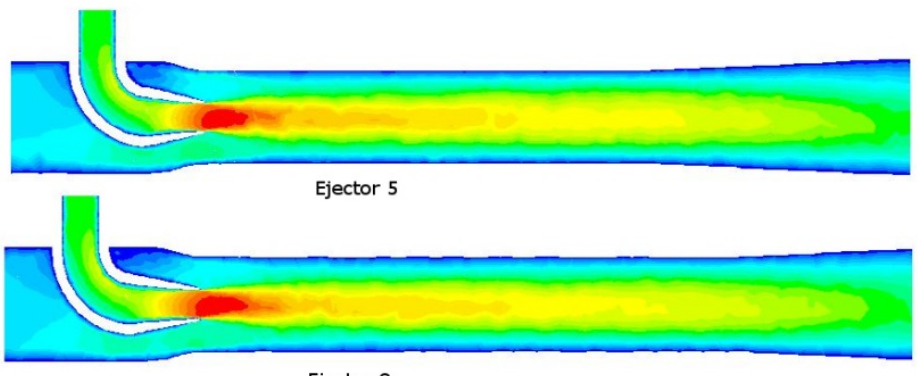

Ejector 8

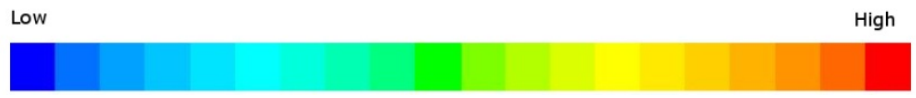

Figure 30 Velocity contour plots of various geometries

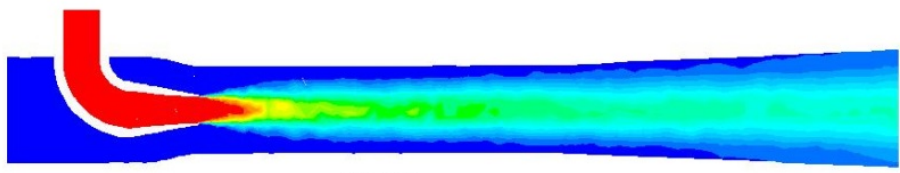

Ejector 2

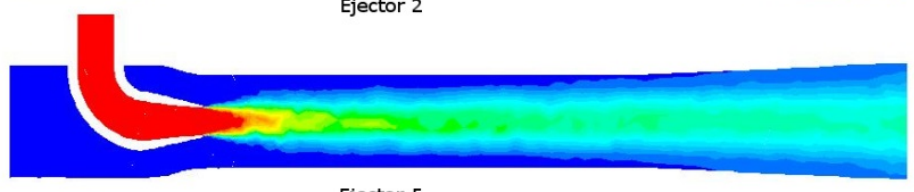

Ejector 5

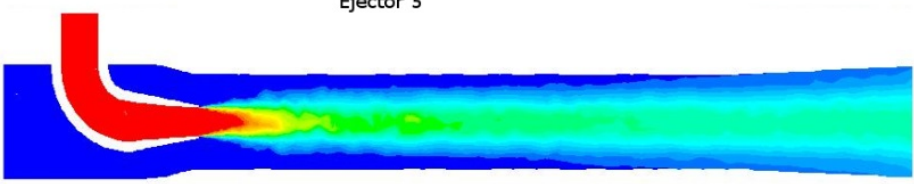

Ejector 8

Gas

Liquid

Figure 31 Volume fractions of the primary phase contour plots of various geometries 


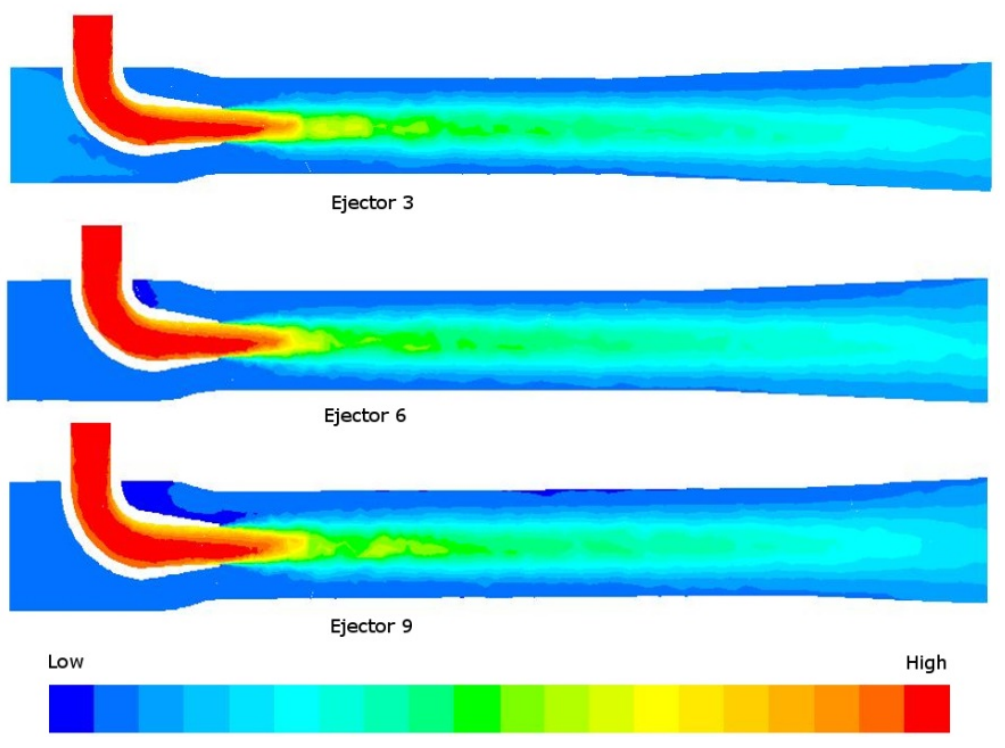

Figure 32 Pressure contour plots of various geometries
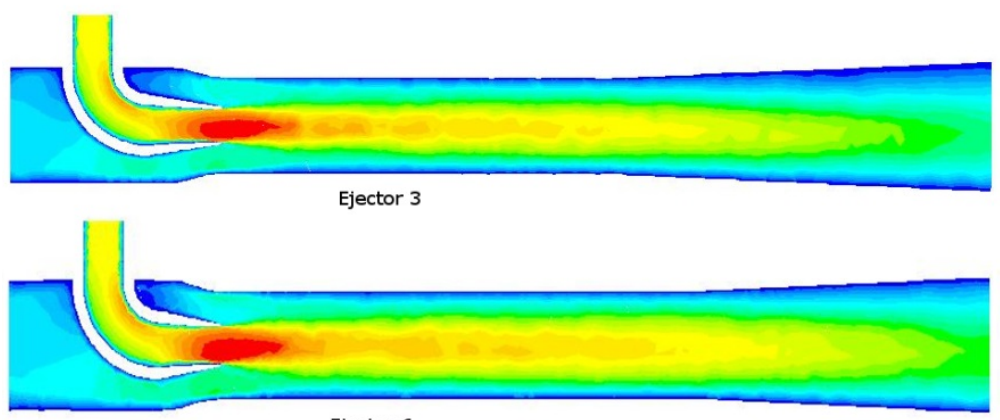

Ejector 6
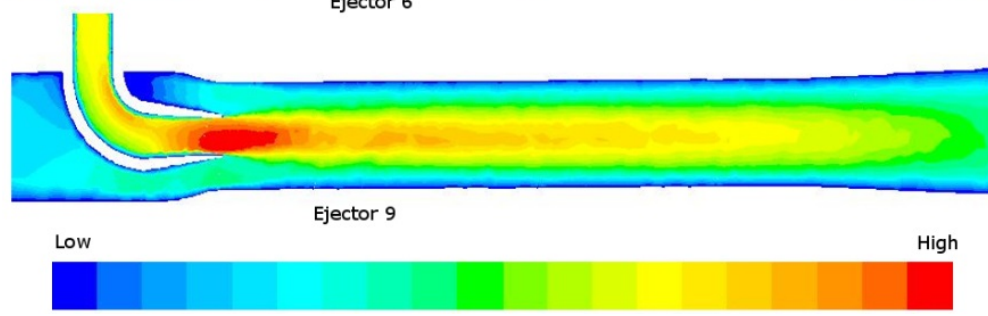

Figure 33 Velocity contour plots of various geometries 


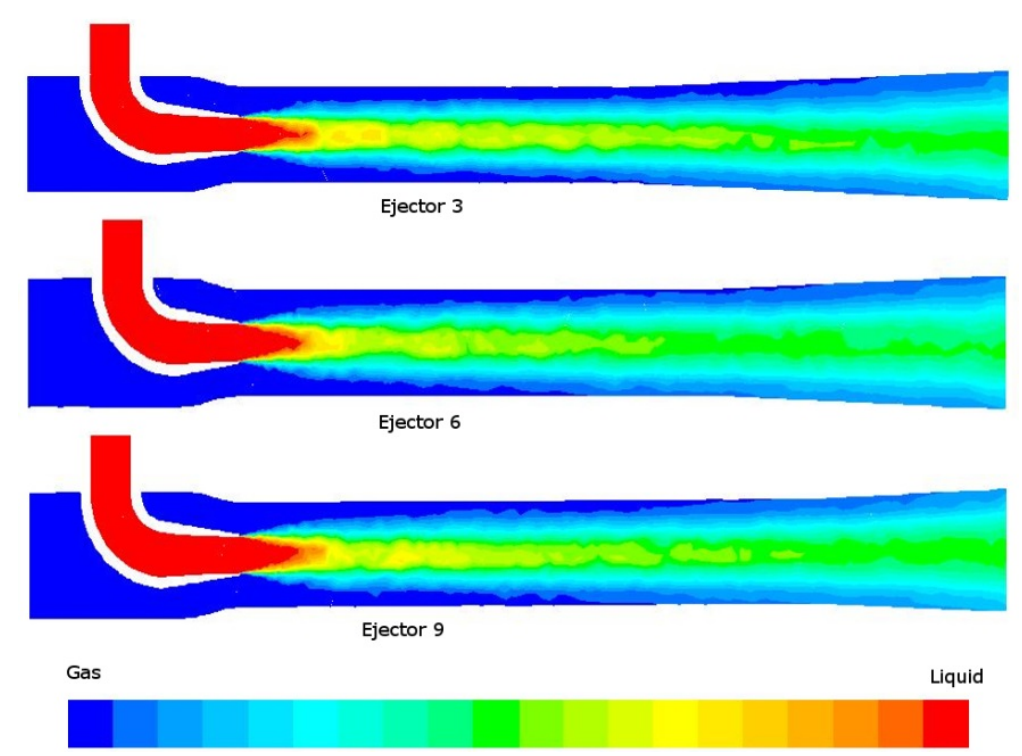

Figure 34 Volume fractions of the primary phase contour plots of various geometries

The primary fluid creates a vacuum region as seen in the pressure contours. The gas is induced to enter the mixing chamber and partially mix with the primary fluid. Because the ejector follows Bernoulli's principle, which states that "pressure is inversely proportional to velocity, " the basic assumptions that the driving force for the induced gas is a power imparted by the liquid is reinforced. However, the fluids slowly diffuse and become a mixture, as can be seen in the contours of volume fraction. This envelope does not depend upon the velocity and is a constant for all the flow rates, i.e., when the flow rate is changed the actual values of velocity will change, but not the shape of the envelope. The lowest pressure region in the whole ejector geometry is at the secondary inlet and the highest-pressure region is in the liquid nozzle exit, which is expected. The resultant flow and pressure in the ejector depends upon the geometry of the ejector. The results were grouped to better visualize them. They have been divided upon the $\mathrm{d}$, the diameter of the nozzle. For example, ejectors 1, 4, and 7 have identical geometries with the only exception being the mixing tube length. It has been noted that the most important 
parameter is the $\mathrm{d}$. The first group that has the high efficiency and high gas induction has been illustrated in Figure 26-Figure 28.

Nine ejectors have been built to examine the impact of different geometries on the behavior of ejectors. At this point, most attention has been placed on the behavior of the flow. The parameters such as mixing tube length, $\mathrm{L}$, and nozzle exist diameter, $\mathrm{d}$, were studied computationally. The experimental data was used to capture reliable behavior as seen in Table 14.

Table 14 nine ejectors experimental results

\begin{tabular}{|c|c|c|c|c|c|}
\hline No. & $\mathrm{L}(\mathrm{mm})$ & $\mathrm{d}(\mathrm{mm})$ & $\mathrm{M}$ & $\mathrm{N}$ & Efficiency \\
\hline 1 & 160 & 9.6 & 4.714 & 0.021 & 10.015 \\
\hline 2 & 160 & 12 & 3.125 & 0.03 & 9.259 \\
\hline 3 & 160 & 14 & 2.413 & 0.032 & 7.721 \\
\hline 4 & 200 & 9.6 & 4.719 & 0.029 & 13.459 \\
\hline 5 & 200 & 12 & 3.303 & 0.028 & 9.37 \\
\hline 6 & 200 & 14 & 2.446 & 0.032 & 7.886 \\
\hline 7 & 240 & 9.6 & 5.185 & 0.028 & 14.763 \\
\hline 8 & 240 & 12 & 3.131 & 0.032 & 9.915 \\
\hline 9 & 240 & 14 & 2.418 & 0.033 & 7.974 \\
\hline
\end{tabular}

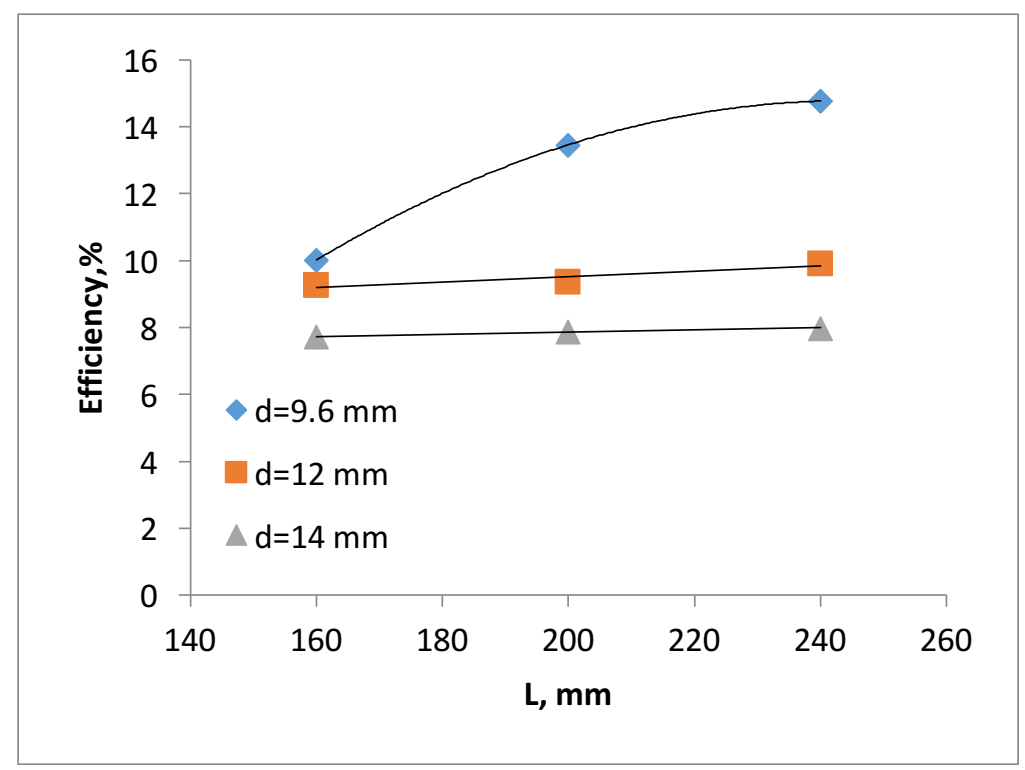

Figure 35 the impact of the mixing chamber length, L, and the nozzle diameter, $d$. 
As seen in the table, ejectors are divided into three groups based on the similarity of their mixing tube length, L. Group A, 1-4-7, has the high efficiency associated with the lowest d, group B, 2-5-8, and group C, 3-6-9. As shown, in all three groups, the high efficiency occurs with the lowest d. It is thought that the gas induction depends upon kinetic energy used by the primary flow to drive gas, which has low density in the direction of the mixing flow. In addition, the high efficiency in all groups happens with the high flow ratio, $\mathrm{M}$ and lowest pressure ratio, $\mathrm{N}$, which is consistent with the ejector pump characteristic curve. Moreover, the best group in all three combinations is Group A, $d=9.6 \mathrm{~mm}$. Figure 35 plots readings from the table to be more easily visualized.

Table 15 the impact of geometric parameter with using fitting parameter, $\alpha$, on gas induction

\begin{tabular}{|c|c|c|c|c|c|c|c|c|}
\hline No. & $\begin{array}{c}\mathrm{L} \\
(\mathrm{mm})\end{array}$ & $\begin{array}{c}\mathrm{D} \\
(\mathrm{mm})\end{array}$ & $\mathrm{L} / \mathrm{D}$ & $\begin{array}{c}\mathrm{d} \\
(\mathrm{mm})\end{array}$ & $\mathrm{d} / \mathrm{D}$ & $\begin{array}{c}\text { Experiment } \\
\left(\mathrm{m}^{3} / \mathrm{s}\right)\end{array}$ & $\begin{array}{c}\text { Simulation } \\
\left(\mathrm{m}^{3} / \mathrm{s}\right)\end{array}$ & $\alpha$ \\
\hline 1 & 160 & 40 & 4 & 9.6 & 0.24 & 0.0063 & 0.0063 & 0.4 \\
\hline 2 & 160 & 40 & 4 & 12 & 0.3 & 0.0061 & 0.0061 & 0.498 \\
\hline 3 & 160 & 40 & 4 & 14 & 0.35 & 0.0056 & 0.0056 & 0.6 \\
\hline 4 & 200 & 40 & 5 & 9.6 & 0.24 & 0.0063 & 0.0063 & 0.356 \\
\hline 5 & 200 & 40 & 5 & 12 & 0.3 & 0.0063 & 0.0063 & 0.4 \\
\hline 6 & 200 & 40 & 5 & 14 & 0.35 & 0.0059 & 0.0059 & 0.45 \\
\hline 7 & 240 & 40 & 6 & 9.6 & 0.24 & 0.0069 & 0.0069 & 0.239 \\
\hline 8 & 240 & 40 & 6 & 12 & 0.3 & 0.0061 & 0.0061 & 0.376 \\
\hline 9 & 240 & 40 & 6 & 14 & 0.35 & 0.0058 & 0.0058 & 0.4 \\
\hline
\end{tabular}

Using the fitting parameter, $\alpha$, shows excellent agreement between experimental results and simulation results as seen in Table 15. This excellent match comes from changing $\alpha$ to find a best match on gas induction for each ejector. 
The increasing in $\mathrm{L}$ will decrease in $\alpha$. It was discovered that ejector 7 has the lowest $\alpha$ among all ejectors and the highest induced gas as well. The same trend happens in all groups as seen in Figure 36-Figure 38.

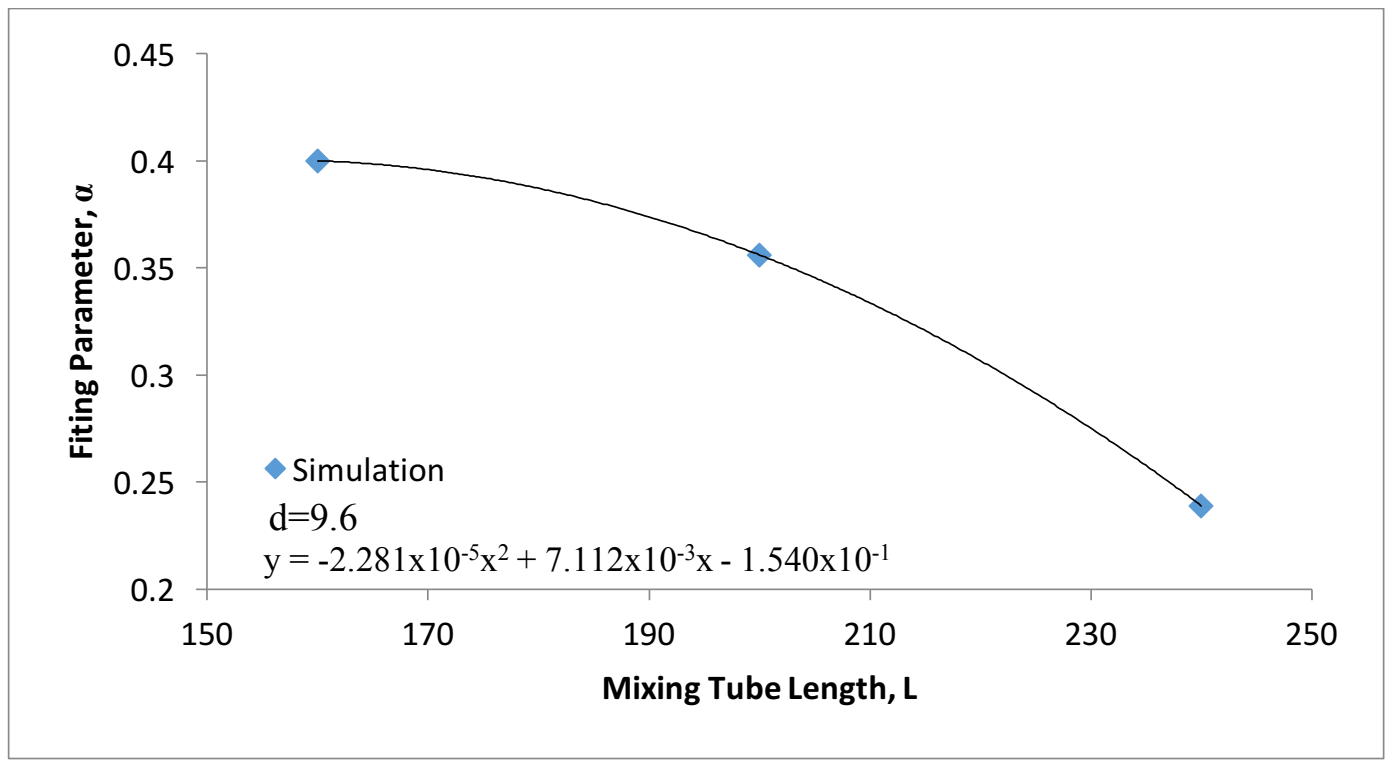

Figure 36 Group A; Variation of $\alpha$ with different Mixing tube length and constant nozzle diameter, d

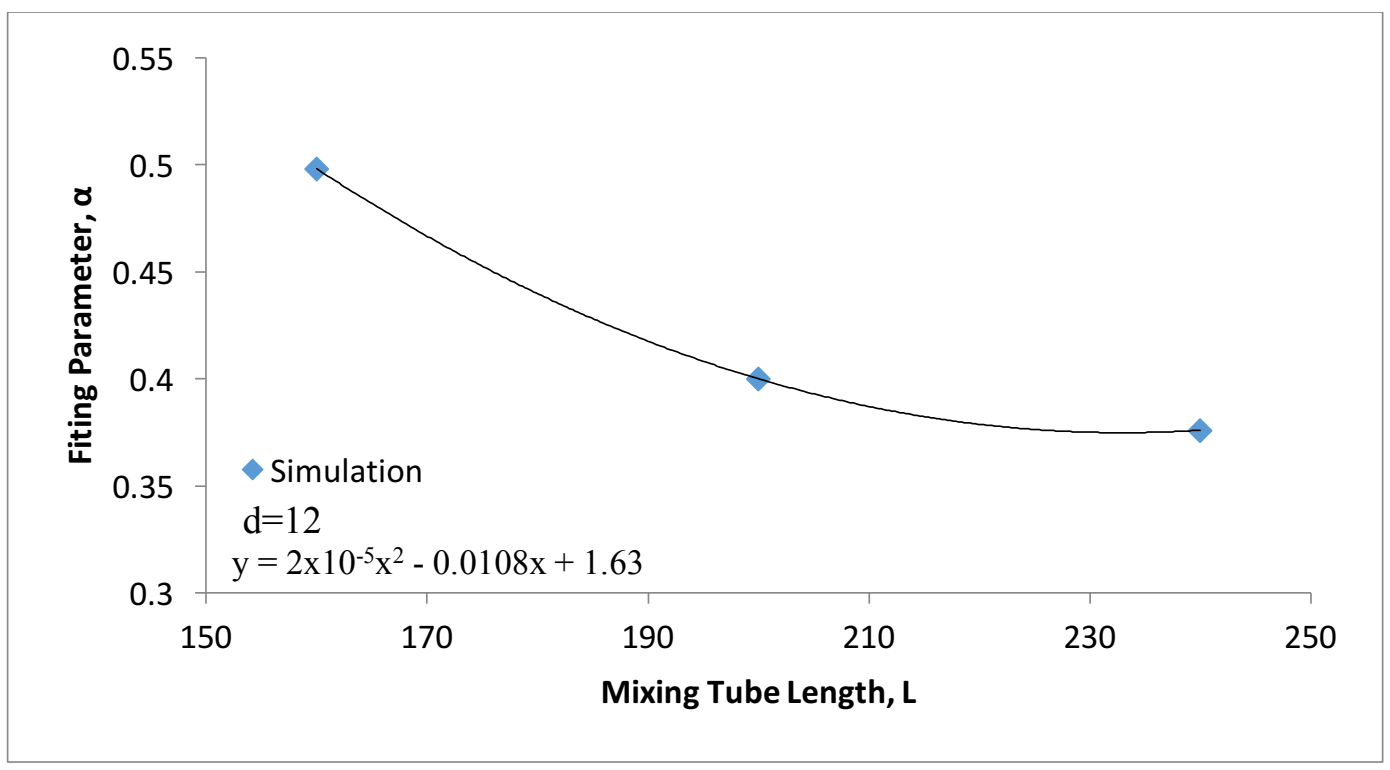

Figure 37 Group B; Variation of $\alpha$ with different Mixing tube length and constant nozzle diameter, d 


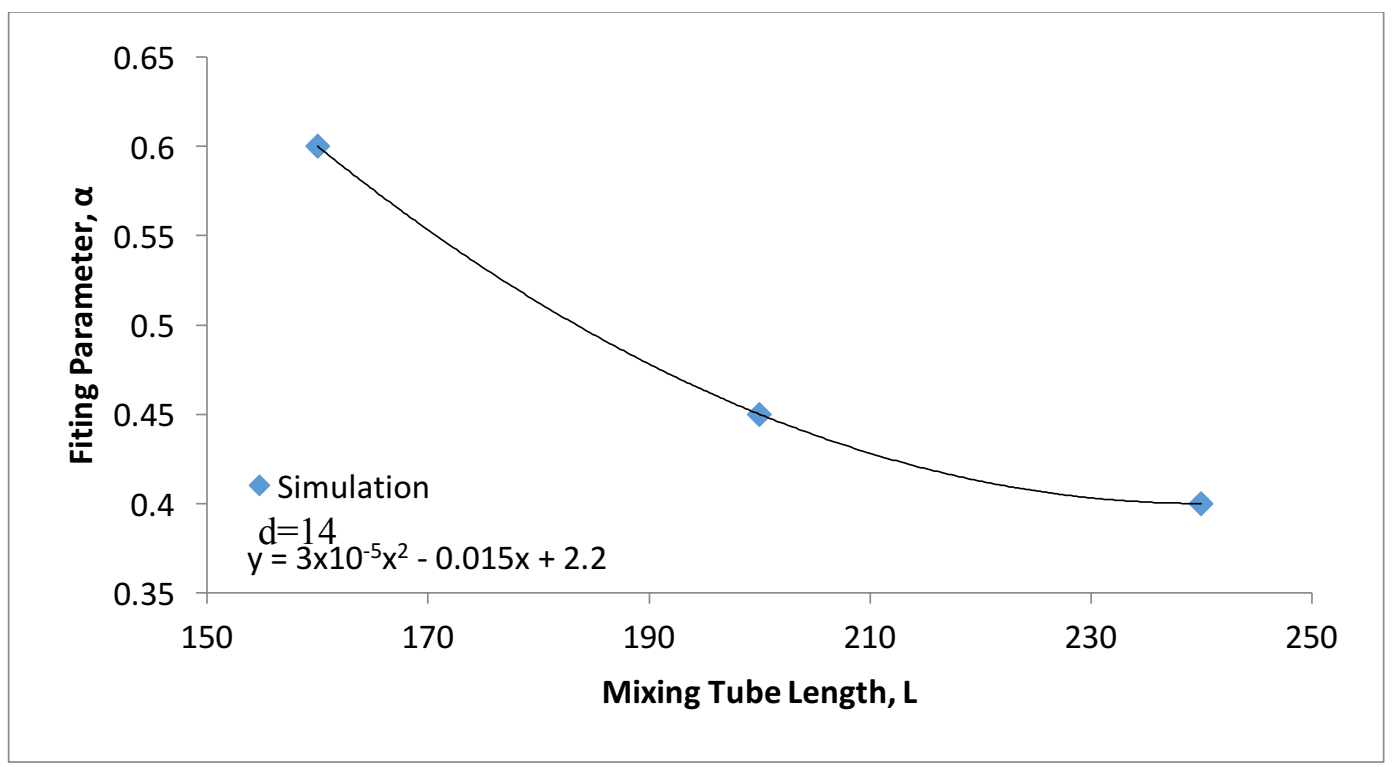

Figure 38 Group C; Variation of $\alpha$ with different Mixing tube length and constant nozzle diameter, d

The numerical results, also, show the impact of variation of geometers on the gas induction. The categories mentioned earlier used a fixed $d$ and changing $L$. In order to address the results in a new perspective, fixing $L$ and changing $d$ is necessary. Thus, the new groups were L1, 1-2-3, L2, 4-5-6, and L3, 7-8-9. As seen in Figure 39-Figure 41.

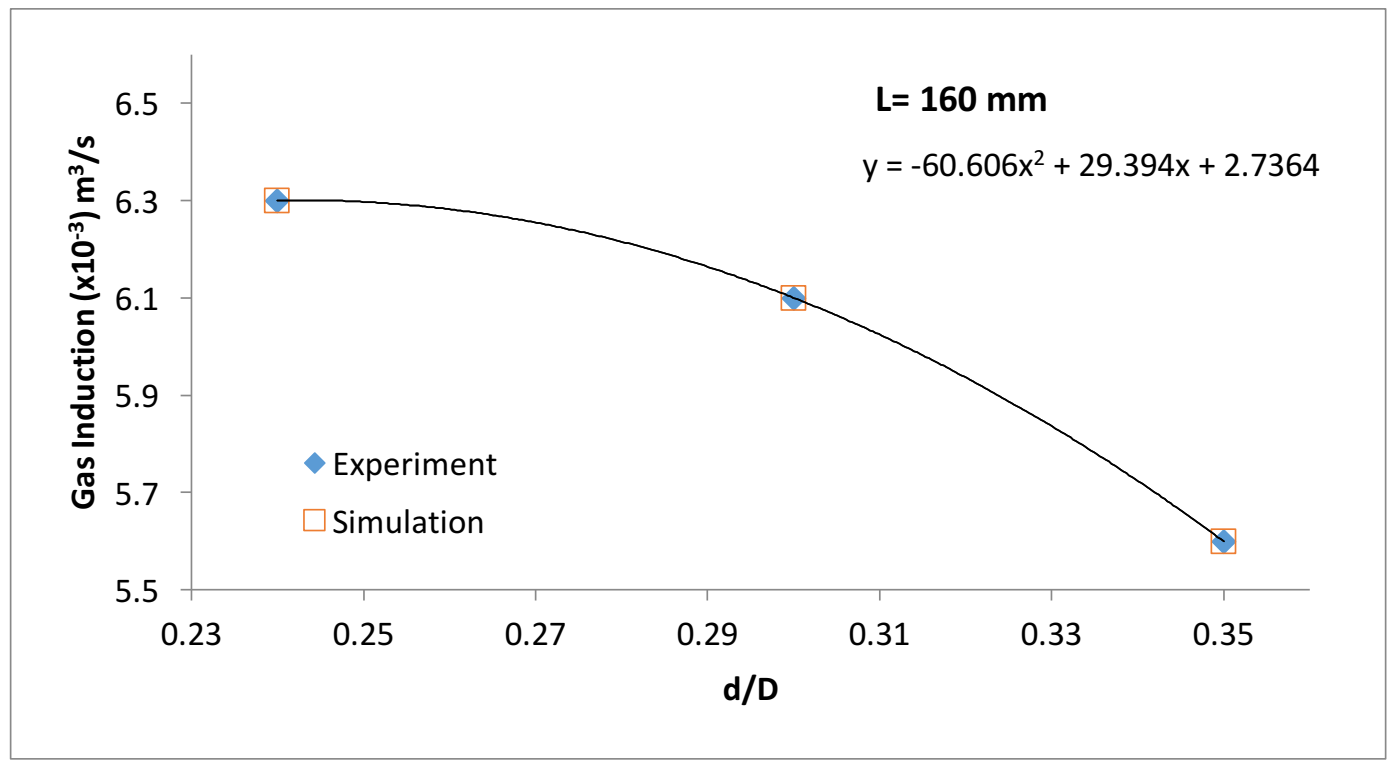

Figure 39 Group L1; Variation of gas induction with different nozzle diameter, $d$ and constant Mixing tube length, $\mathrm{L}$ 


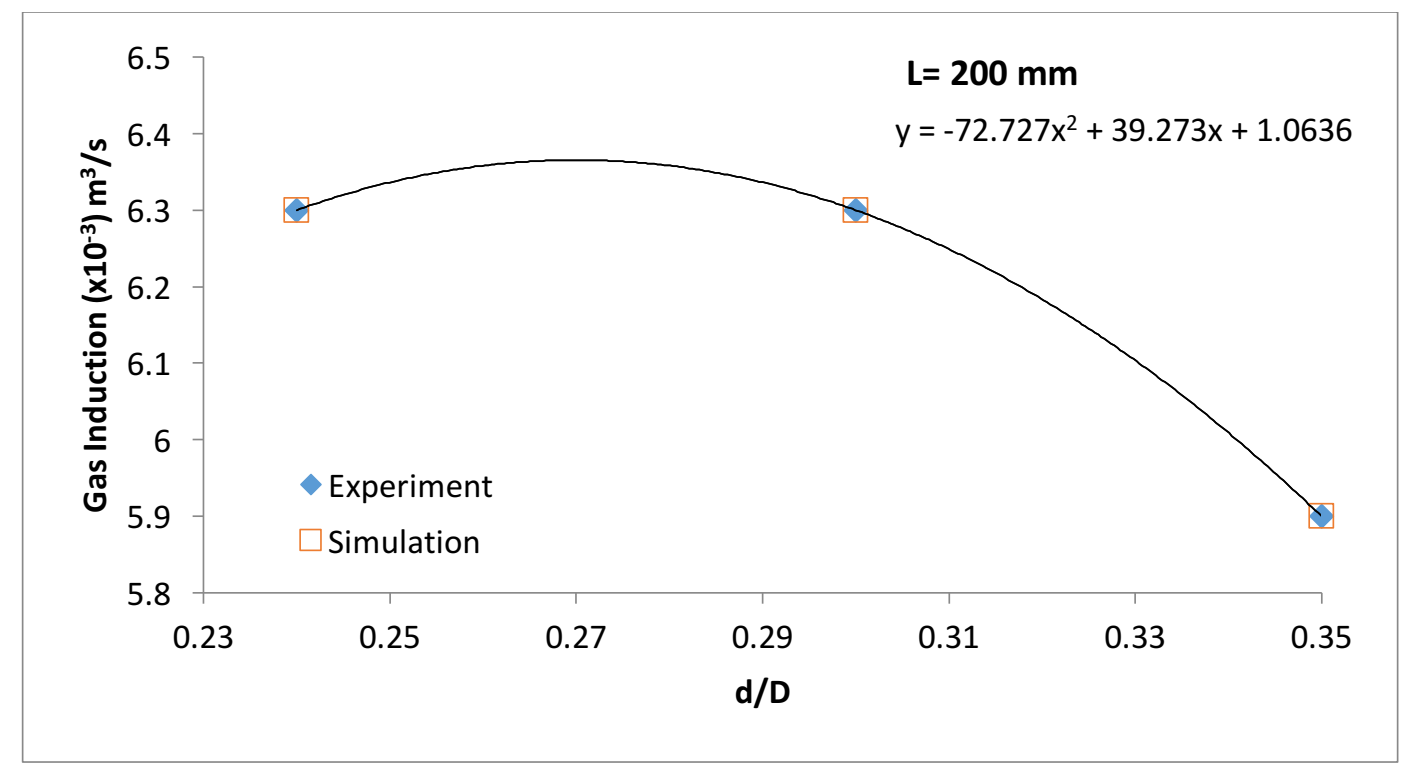

Figure 40 Group L2; Variation of gas induction with different nozzle diameter, $d$ and constant Mixing tube length, $\mathrm{L}$

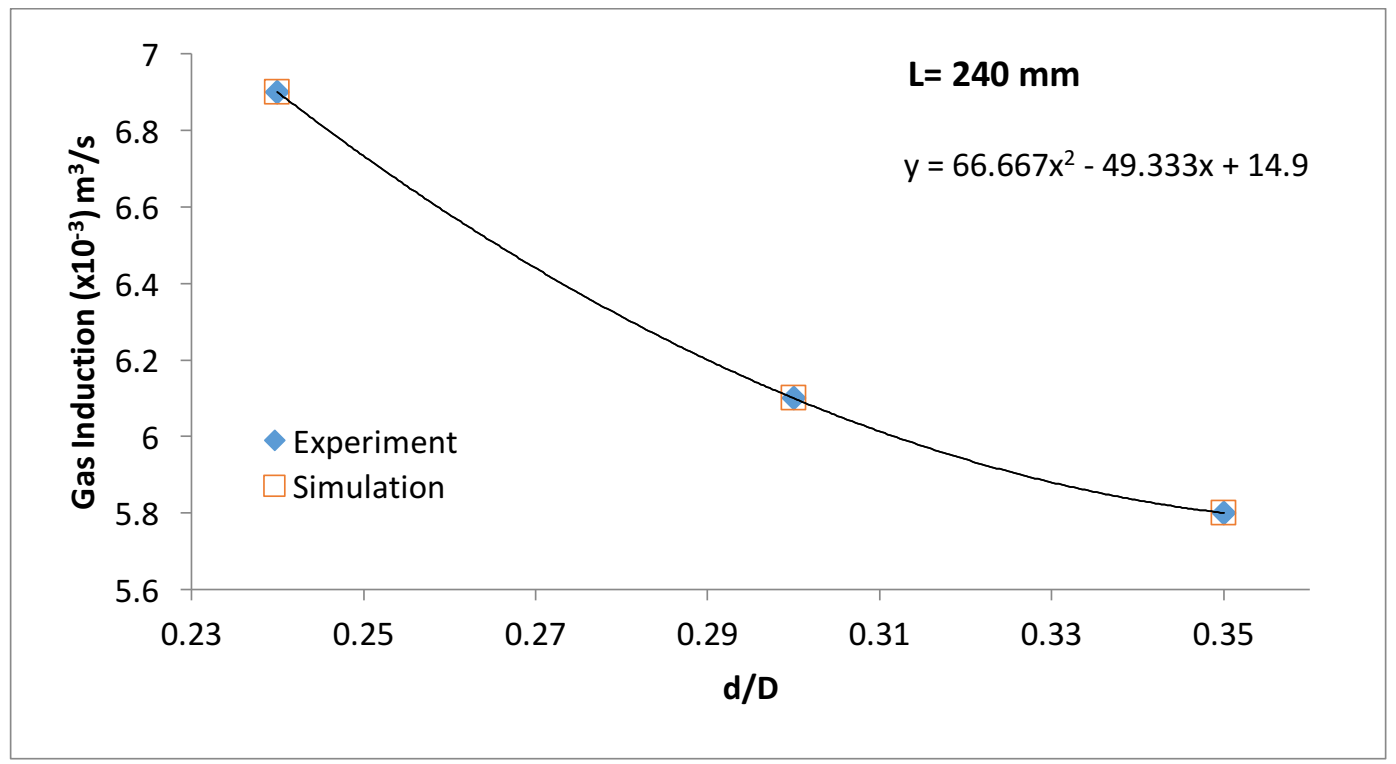

Figure 41 Group L3; Variation of gas induction with different nozzle diameter, $d$ and constant Mixing tube length, $\mathrm{L}$ 


\subsubsection{EXPERIMENTAL}

Data from all 27 experiments and the two additional validation experiments was compiled and analyzed. The results of the experiments were studied to determine the impact of the induced fluid stream comprised of both water and air. An empirical model was subsequently developed to predict the quality of the induced stream as a function of the primary flow rate and the available secondary fluid height.

Two-phase flow, when the liquid level in the inlet barrel is below the bell mouth, was found in half of the experiments. Here, the ejector sucks $100 \%$ air into the system and it mixes with the primary fluid which is water and, because of the two different densities, makes turbulence. It was seen that this turbulence in the mixing chamber loses most of its energy as shown in Figure 42, and that when air is induced, the flow ratio is decreased. Low flow ratio happens due to the different densities of the two fluids. The air is only $0.12 \%$ of the density of water and there were high quantities of air transported to the outlet barrel by the primary fluid, water. At low primary flow rate, the flow ratio is going to be higher and vice versa- when primary flow rate is high, the flow ratio is low.

The rest of experiments were single-phase as shown in Figure 43. When there is no air induction due to the water height level in inlet barrel, the flow ratio is high and single-phase flow occurs. All the data on the Y-axis is with no airflow. However, it is seen from the Figure 44 that when the airflow rate increases, the corresponding flow ratio decreases. This is not unexpected when one looks at the flow ratio equation. 
In the same manner, Figure 45 shows that the pressure ratio with two-phase flow is less than the one is found with single-phase. That is due to the vacuum that happens in secondary pressure because it is below the atmospheric pressure which is negative. It can be seen that efficiency is reduced due to that.

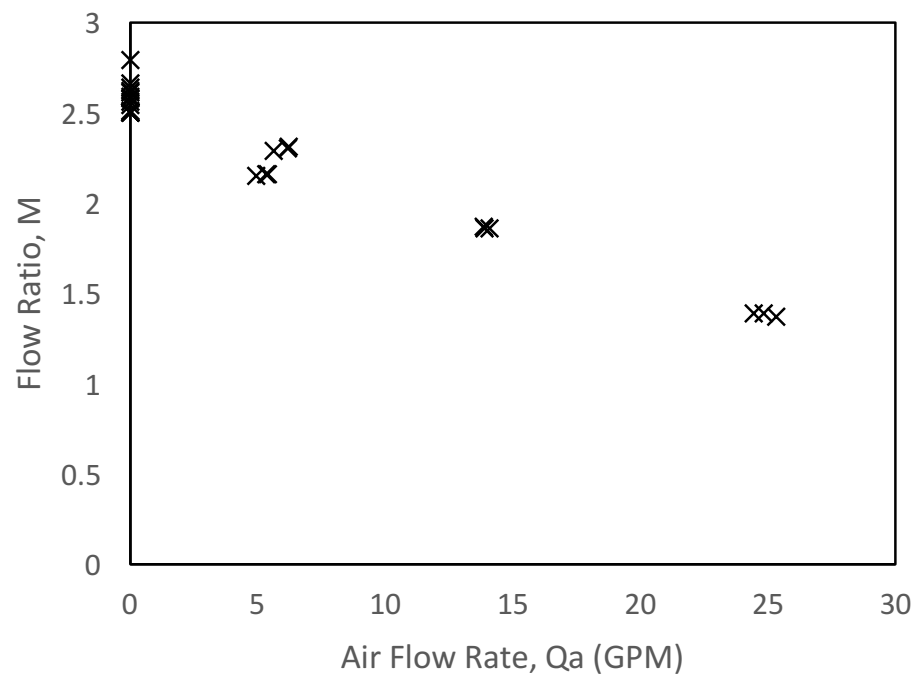

Figure 42 Flow ratio versus airflow rate

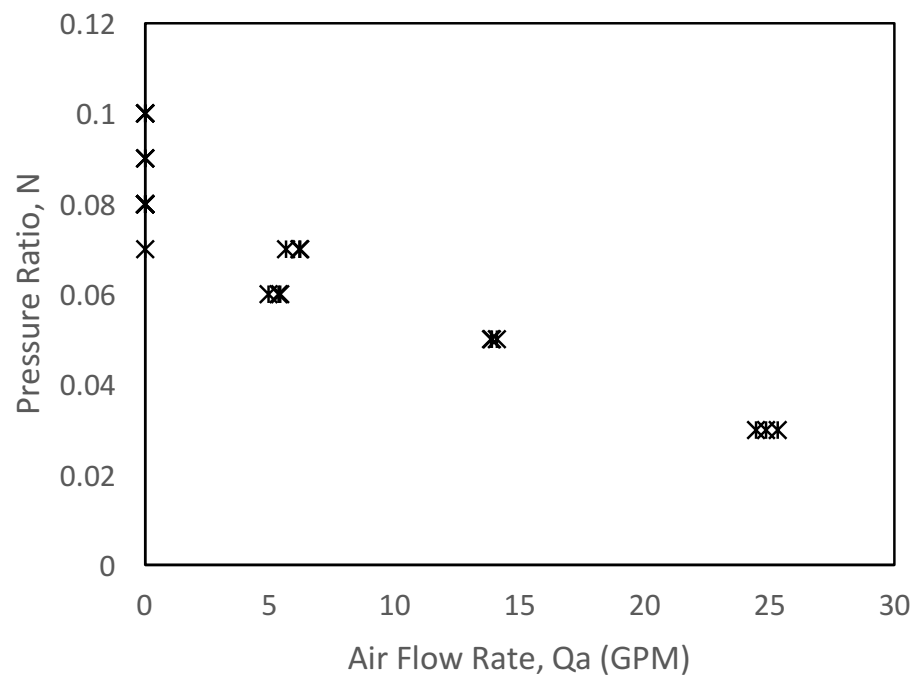

Figure 43 Pressure ratio versus air flow rate 
Figure 46 shows the dependency of primary pressure, $\mathrm{Pp}$, on the primary flow rate, Qp. Because higher flow rates result in high pressure it was expected that the diffuser pressure, Pd, was between these. The pressure balance is shown in Figure 47. The primary pressure is the highest pressure due to the primary fluid that has been delivered by the centrifugal pump. In contrast, the secondary pressure is the lowest pressure due to the fall below the atmospheric pressure at the inlet barrel.

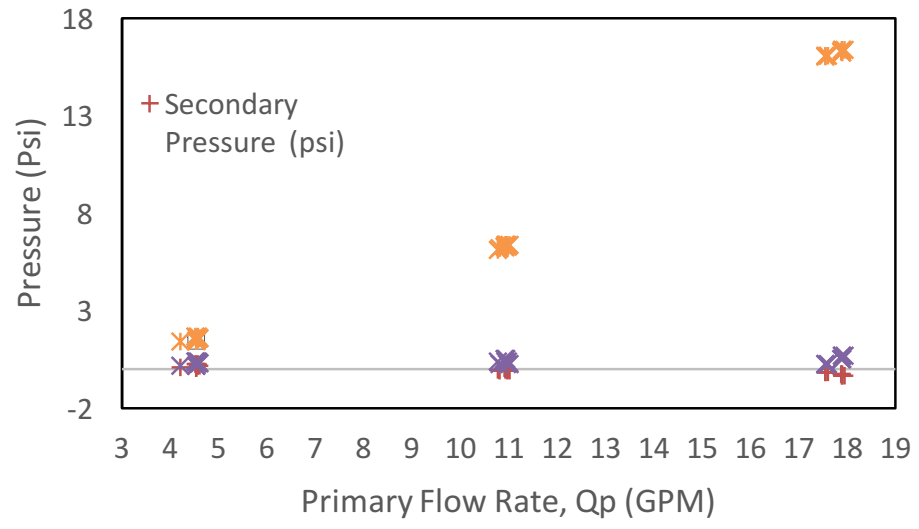

Figure 44 Pressure versus primary flow rate 


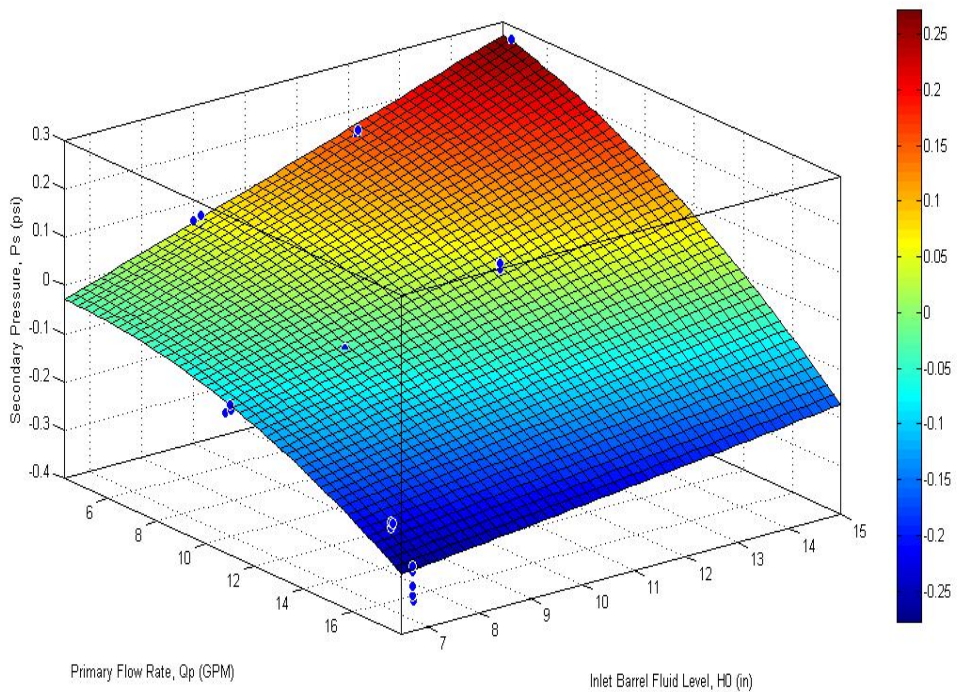

Figure 45 Secondary pressure as a function of primary flow rate and inlet barrel fluid

The secondary pressure is dependent on two independent aspects; the primary flow rate and the available fluid head in the inlet barrel. This relationship is shown in Figure 45 . When primary flow rate is high, much more fluid is induced, which makes the pressure decrease below 0 psi. All of these factors cause the pressure ratio to decrease with the increase of the air flow rate. When higher flow rate is provided and lower inlet barrel water height happens in sequence, the pressure ratio increase of the secondary flow is slight as the secondary pressure decreases. The increase in the primary pressure significantly increases the pressure drop of the primary flow and the pressure ratio. The decrease of the flow ratio and the pressure ratio cause a large decrease in the efficiency of the ejector pump during two-phase flow. This is shown in Figure 46. 


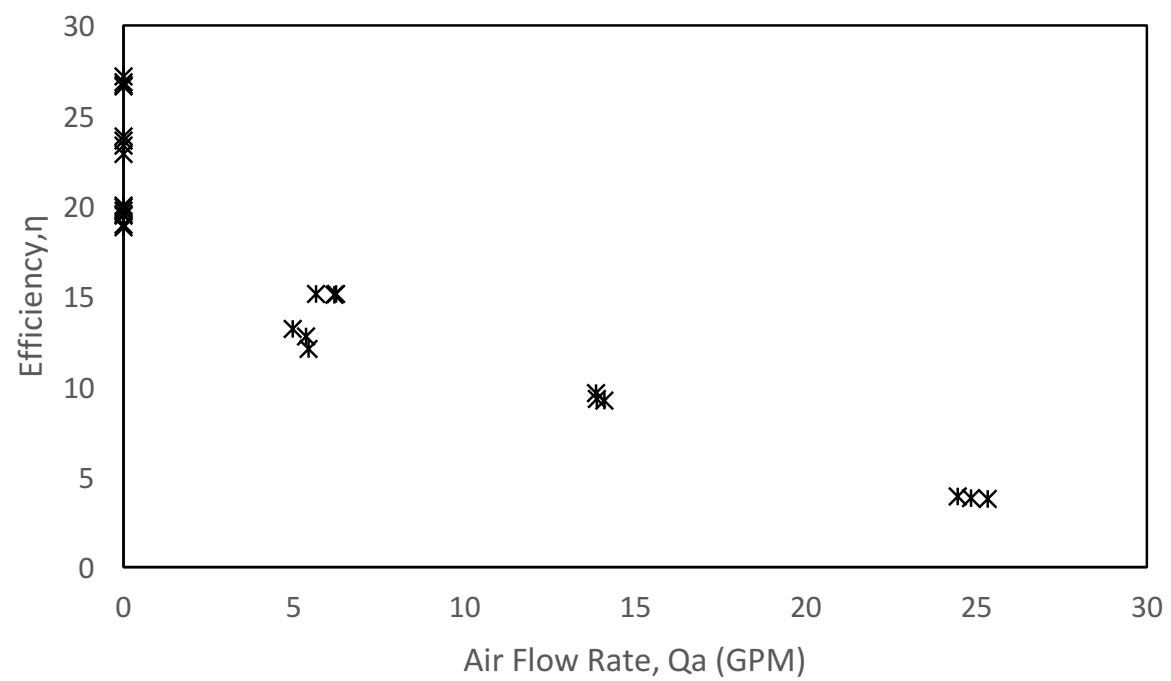

Figure 46 Efficiency versus air flow rate

The maximum ejector efficiency can be seen at a low motive flow rate and a high level of available fluid. After collecting and analyzing all the data, the estimated error linked with each sensor data measurement is determined by Eqs.64-3-65and is presented in Table 16.

Table 16 Error associated with data variables

\begin{tabular}{|c|c|}
\hline Principal Measured Variable & Estimated Error \\
\hline Motive Pressure & $\pm 0.19 \mathrm{psig}$ \\
\hline Secondary Pressure & $\pm 1.61 \mathrm{psig}$ \\
\hline Discharge Pressure & $\pm 0.16 \mathrm{psig}$ \\
\hline Motive Flow Rate & $\pm 0.10 \mathrm{GPM}$ \\
\hline Secondary Flow Rate & $\pm 0.10 \mathrm{GPM}$ \\
\hline
\end{tabular}

The estimated error is low for all five sensors, yet the secondary pressure transducer is greater than the others are. This is because the secondary pressure sensor outputs pressure in psia versus psig and uses an additional sensor to make the conversion to psig. The error is presented in conjunction with the analytical model results. The 
ejector used for examining two-phase performance was manufactured from clear acrylic plastic.

During doing the experiments, it was found that the change in fluid height is the same for a certain level of primary flow rate, regardless of the available fluid in the inlet barrel. Due to that, more experimental work is needed to predict the quality of the secondary flow stream when two-phase conditions occur, and it will be necessary to use an empirical model to examine an analytical model. Some data was taken at different primary flow rates not included in the experimental matrix to get a better look at the relationship and is shown in Figure 47:

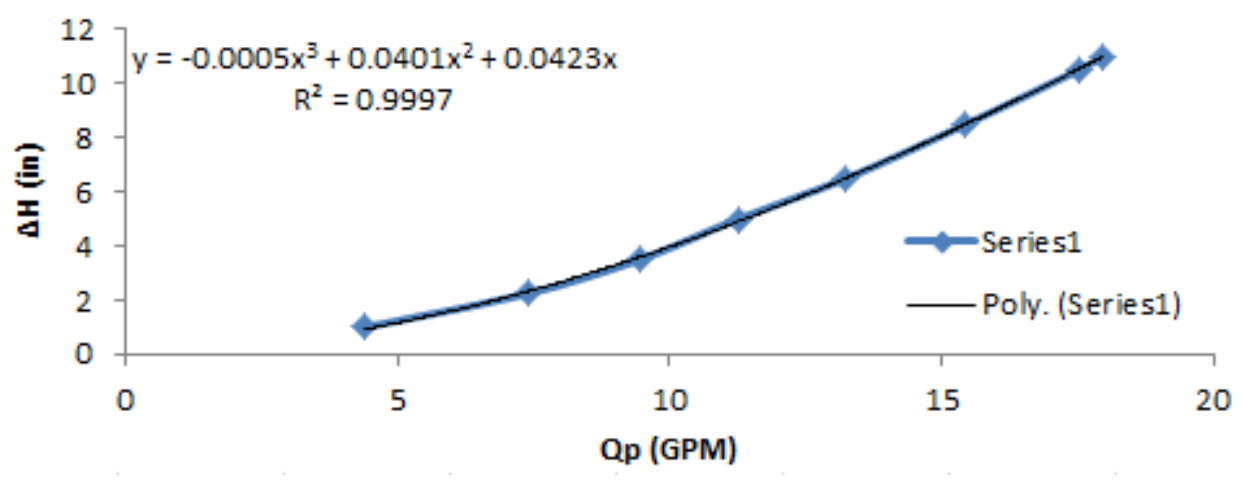

Figure 47 Empirical relationship for $\Delta H$ as a function of $Q p$ 
Once the change in the inlet barrel available fluid height is determined, the fluid level that occurs while the system is running is known, and the actual quality of the air entrained in the secondary fluid is determined from the empirical model shown in Figure 48. The empirical model is a function of two independent variables, the motive flow rate and the available fluid height at the inlet barrel. These two measurements determine the flow rate of air in the induced fluid stream. Using those two models to determine the induced air flow rate, the empirical models are accurate within 5.55\%. The model

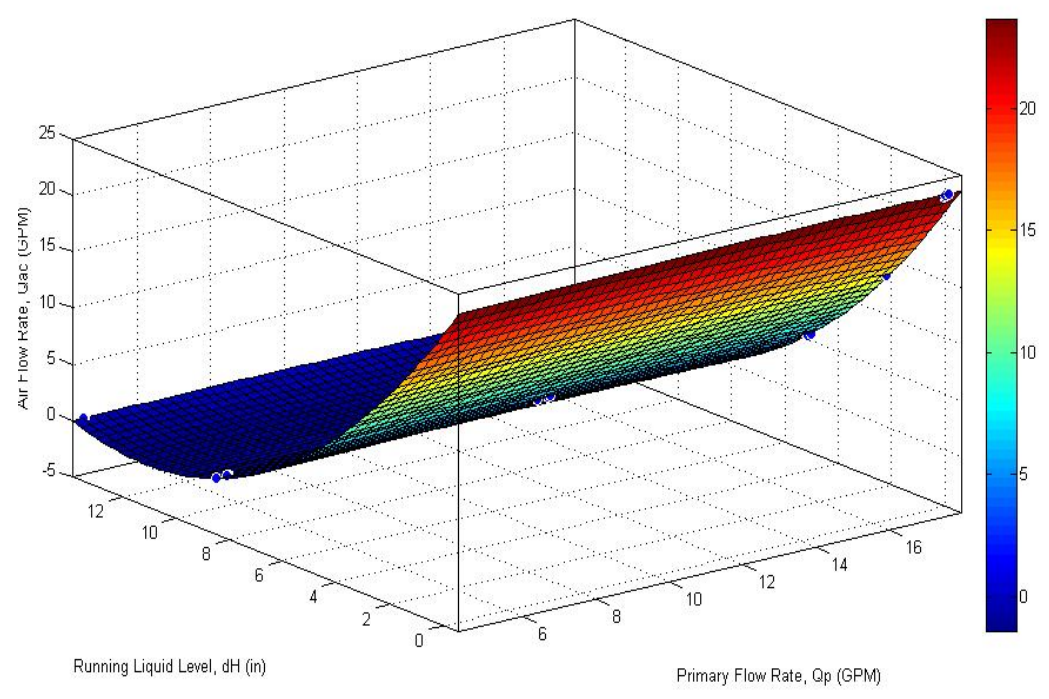

Figure 48 Empirical model for volumetric flow rate of induced air

predicts the airflow rate of the two-phase verification experiment with $3.46 \%$ accuracy. 


\section{CHAPTER V}

\subsection{CONCLUSION}

The present work is a continuation of a project started with support from Boeing Company for improving the efficiency of ejectors used in the Fuel System for large aircraft [50]. The results of the presented research have addressed many of the deficiencies in our original work. Improvements include refining the analytical models with more accurate parameters estimations, including uncertainties that were never included in any previous models, and development of cost and time efficient numerical simulation of the flow behavior inside the ejectors. Both analytical and numerical models were verified experimentally in the present work.

The following specific conclusions can be drawn from the present work:

1. An integrated modeling approach was developed for understanding two-phase flow inside ejector pumps.

2. The introduced approach involves analytical, experimental and numerical modeling methods which will help in optimization of performance of the ejectors in terms of energy utilization, and delivered flow rate.

3. The developed analytical model extends the single-phase flow model for predicting behavior and performance of ejectors to two-phase flow models.

4. Uncertainty, ignored in previously developed analytical models, is introduced in the present model in order to improve its prediction accuracy to address the analytical loss coefficients, Km and Ks. 
5. A numerical simulation modeling method using computational fluid dynamics is developed to address cases that difficult to predict analytically or expensive experimentally.

6. Comprehensive experimental investigation was conducted using a specifically built fluid transportation system to verify analytical and numerical predictions.

7. All results indicate that increasing the mixing chamber length and decreasing the nozzle diameter would result in increasing flow efficiency. 


\section{REFERENCES}

[1]ESDU 85032, 1985, "Ejectors and Jet Pumps. Design and Performance for Incompressible Liquid Flow," Engineering Sciences Data Unit.

[2]Jianyong Chen, Sad Jarall, Hans Havtun, Björn Palm. (2015). A review on versatile ejector applications in refrigeration systems, Renew. Sustain. Energy Rev. 49 67-90.

[3]Gosline, J. E., and O'Brien, M. P., 1933, "The Water Jet Pump," University of California Publications in Engineering, 3, pp. 167-190.

[4]BHRA (Association), and Institution of Chemical Engineers (Great Britain). 1972, Jet Pumps and Ejectors Proceedings of a Symposium on Jet Pumps and Ejectors, British Hydromechanics Research Association, Fluid Engineering, Cranfield, England.

[5]Coles, N. G., and BHRA (Association), 1975, Proceedings of the Second Symposium on Jet Pumps \& Ejectors and Gas Lift Techniques, 1975, Cambridge, BHRA Fluid Engineering, Cranfield.

[6]Seddon, J., and Dyke, M., 1964, Ejectors and Mixing of Streams, Royal Aircraft Establishment.

[7]Bonnington, S. T., King, A. L., and Hemmings, J. A. G., 1976, Jet Pumps and Ejectors : A State of the Art Review and Bibliography, BHRA Fluid Engineering, Cranfield.

[8]Cunningham, R. G., 1975, "Liquid Jet Pump Modelling: Effects of Axial Dimensions on Theory-Experiment Agreement," Proc. Second Symposium on Jet Pumps and Ejectors, BHRA Fluid Engineering, pp. F1-1-F1-15.

[9]Sanger, N. L., 1970, "An Experimental Investigation of Several Low-Area-Ratio Water Jet Pumps," Journal of Basic Engineering, 92(1), pp. 11-19.

[10]Cunningham, R. G., Hansen, A. G., and Na, T. Y., 1970, "Jet Pump Cavitation," Journal of Basic Engineering, 92(3), pp. 483-492.

[11]Marini, M., Massardo, A., Satta, A., and Geraci, M., 1992, "Low Area Ratio Aircraft Fuel Jet- Pump Performances with and without Cavitation," Journal of Fluids Engineering, 114(4), pp. 626-631. 
[12]Kentfield, J. A. C., and Barnes, R. W., 1972, "The Prediction of the Optimum Performance of Ejectors," Proc. The Institution of Mechanical Engineers, pp. 671681.

[13]Mikhail, S., and Abdou, H. A. M., 2005, "Two-Phase Flow in Jet Pumps for Different Liquids," Journal of Fluids Engineering, 127(5), pp. 1038-1042.

[14]Cunningham, R. G., 1974, "Gas Compression with the Liquid Jet Pump," Journal of Fluids Engineering, 96(3), pp. 203-215.

[15]Cunningham, R. G., and Dopkin, R. J., 1974, "Jet Breakup and Mixing Throat Lengths for the Liquid Jet Gas Pump," Journal of Fluids Engineering, 96(3), pp. 216226.

[16]Hongqi, L., "Liquid Gas Two Phase Flow Theory of Jet Pump," Proc. International Conference on the Physical Modelling of Multi-Phase Flow, pp. 439-451.

[17]Elbel Stefan, Lawrence Neal. (2016) Review of recent developments in advanced ejector technology, Int. J. Refrig. 62 1-18.

[18]Khennich Mohammed, Galanis Nicolas, Sorin, Mikhail. (2016). Effects of design conditions and irreversibilities on the dimensions of ejectors in refrigeration systems, Appl. Energy 179 1020-1031.

[19]M.M. Rashidi, O.A. Bég, A. Habibzadeh. (2012). First and second law analysis of an ejector expansion Joule-Thomson cryogenic refrigeration cycle, Int. J. Energy Res. 36 231-240.

[20]Jiao, B., Blais, R., and Schmidt, Z., 1990, "Efficiency and Pressure Recovery in Hydraulic Jet Pumping of Two-Phase Gas/Liquid Mixtures," SPE Production Engineering, 5(4), pp. 361-364.

[21]Noronha, F. A. F., França, F. A., and Alhanati, F. J. S., 1997, "Improved Two-Phase Model for Hydraulic Jet Pumps," Proc. Production Operations Symposium, Society of Petroleum Engineers, pp. 333-340.

[22]Noronha, F. A. F., Franca, F. A., and Alhanati, F. J. S., 1998, "Improved Two-Phase Model for Hydraulic Jet Pumps," SPE Journal, 3(3), pp. 227-231.

[23]Cunningham, R. G., 1995, "Liquid Jet Pumps for Two-Phase Flows," Journal of Fluids Engineering, 117(2), pp. 309-316. 
[24]Lear, W. E., Parker, G. M., and Sherif, S. A., 2002, "Analysis of Two-Phase Ejectors with Fabri Choking," Proceedings of the Institution of Mechanical Engineers, Part C: Journal of Mechanical Engineering Science, 216(5), pp. 607-621.

[25]Balamurugan, S., Gaikar, V., and Patwardhan, A., 2006, "Hydrodynamic Characteristics of Gas-Liquid Ejectors," Chemical Engineering Research and Design, 84(12), pp. 1166-1179.

[26]Karassik, I. J., Messina, J. P., Cooper, P., and Heald, C. C., 2008, Pump Handbook, McGraw-Hill, New York, NY, Chap. 7.

[27]Hatzlavramidis, D. T., 1991, "Modelling and Design of Jet Pumps," SPE Production Engineering, 6(4), pp. 413-419.

[28]Kumar, R. S., Kumaraswamy, S., Mani, A., 2007, "Experimental Investigations on a Two-Phase Jet Pump Used in Desalination Systems," Desalination, Vol. 204, pp. 437-447.

[29]Neto, I. E. L., Porto, R. M., 2004, "Performance of Low-Cost Ejectors," Journal of Irrigation and Drainage Engineering, Vol. 130, No. 2, pp. 122-128.

[30]Chamlong, P., Takayama, S., Aoki, K., Nakayama, Y., 2002, "Numerical Prediction on the Optimum Mixing Throat Length for Drive Nozzle Position of the Central Jet Pump," Proceedings of 10th International Symposium on Flow Visualization, F0328, pp.1-6, Kyoto, Japan.

[31]Mikhail, S., Abdou, H. A. M., 2005, "Two-Phase Flow in Jet Pumps for Different Liquids," Journal of Fluids Engineering, Vol. 127, pp.1038-1042.

[32]Samad, A., Nizamuddin, M., 2013, "Flow Analyses Inside Jet Pumps Used for Oil Wells," International Journal of Fluid Machinery and Systems, Vol. 6, No. 1, pp. 110.

[33]Afzal Husain, Arihant Sonawat, Sarath Mohan and Abdus Samad, "Energy Efficient Design of a Jet Pump by Ensemble of Surrogates and Evolutionary Approach", International Journal of Fluid Machinery and Systems, Vol. 9, No. 3, July-September 2016 (9.3 (2016): 265-276).

[34]Bin, A.K., 1993. Gas entrainment by plunging liquid jets. Chem.Eng. Sci. 48, 3585. 
[35]Bhutada, S.R., Pangarkar, V.G., 1987. Gas induction and hold-up characteristics of liquid jet loop reactors. Chem. Eng.Commun. 61, 239.

[36]Fadavi, A., Chisti, Y., 2005. Gas-liquid mass transfer in novel forced circulation loop reactor. Chem. Eng. J. 112, 73.

[37]Havelka, P., Linek, V., Sinkule, J., Zaheadnik, J., Fialova, M., 1997.Effect of the ejector configuration on the gas suction rate andgas hold up in the ejector loop reactors. Chem. Eng. Sci. 52,1701.

[38]Acharjee, D.K., Bhat, P.A., Mitra, A.K., Roy, A.N., 1975. Studies onmomentum transfer in vertical liquid jet ejectors. Indian J.Technol. 13, 205.

[39]Bhutada, S.R., Pangarkar, V.G., 1989. Solid suspension and mixingcharacteristics of liquid jet loop reactors. Chem. Eng. Sci. 44,2384.

[40]Dutta, N.N., Raghavan, K.V., 1997. Mass transfer andhydrodynamic characteristics of loop reactors with down flowliquid jet ejector. Chem. Eng. J. 36, 111.

[41]Bhutada, S.R., 1989. Design of Liquid Jet Loop Reactors, Ph.D.(Tech) Thesis. University of Mumbai.

[42]Ben Brahim, A., Prevost, M., Bugarel, R., 1984. Momentumtransfer in a vertical down flow liquid jet ejector: case ofself-gas aspiration and emulsion flow. J. Multiph. Flow. 10, 79.

[43]Bhat, P.A., Mitra, A.K., Roy, A.N., 1972. Momentum transfer in ahorizontal jet liquid jet ejector. Can. J. Chem. Eng. 50, 313.

[44]Yadav, R.L., Patwardhan, A.W., 2008. Design aspects of ejectors:effect of suction I chamber geometry. Chem. Eng. Sci. 63, 3886.

[45]Kim, M.I., Kim, O.S., Lee, D.H., Kim, S.D., 2007. Numerical andexperimental investigations of gas-liquid dispersion in anejector. Chem. Eng. Sci. 62, 7133.

[46]Kim, O.G., Lee, Y., Lee, D.H., 2009. Hydrodynamic characteristicsof a horizontal flow ejector in a rectangular chamber. KoreanJ. Chem. Eng. 26, 288.

[47]Utomo, T., Jin, Z., Rahman, Msq., Jeong, H., Chung, H., 2008.Investigation on hydrodynamics and mass transfercharacteristics of a gas-liquid ejector using three dimensionalCFD modelling. J. Mech. Sci. Technol. 22, 1821.

[48]Kandakure, M.T., Gaikar, V.G., Patwardhan, A.W., 2005.Hydrodynamic aspects of ejectors. Chem. Eng. Sci. 60, 6391. 
[49]Sharma, D. V., Patwardhan, A. W., \& Ranade, V. V. (2017). Estimation of gas induction in jet loop reactors: Influence of nozzle designs. Chemical Engineering Research and Design, 125, 24-34.

[50]E. Elmore, K. Almutairi, B. Hussain, A. El-Gizawy (2016). Development of analytical model for predicting dual-phase ejector performance, Proc. Of the ASME 2016 international Mechaincal Engineering congress \& Exposition, , Phinex, AZ, CD8pages.

[51]Huang, B. J., Chang, J. M., Wang, C. P., and Petrenko, V. A., 1999, "A 1-D Analysis of Ejector Performance," International Journal of Refrigeration, 22 (1999), pp. 354364.

[52]Faghri, A., and Zhang, Y., 2006, Transport Phenomena in Multiphase Systems, Elsevier, Burlington, MA, 2006.

[53]Crane Co. Engineering Division., 2010, Flow of Fluids through Valves, Fittings and Pipe, Crane, Stamford, CT.

[54]Miller, D. S., 1971, Internal Flow: A Guide to Losses in Pipe and Duct Systems, British Hydromechanics Research Association, Cranfield.

[55]Neve, R. S., 1991, "Diffuser Performance in Two-Phase Jet Pumps," International Journal of Multiphase Flow, 17(2), pp. 267-272.

[56]Southwest Research Institute. NESSUS Theoretical Manual, Austin, Texas, June 2014.

[57] Ranade, V.V., 2002. Computational Flow Modeling for ChemicalReactor Engineering, 1st edition. Academic Press, California,p. 41.

[58]Walker, I. S., and Wray, C. P., 2003, "Evaluation of Flow Capture Techniques for Measuring Hvac Grille Airflows," Lawrence Berkeley National Laboratory. Berkeley, CA. LBNL-51520.

[59]Walker, I. S., Wray, C. P., Guillot, C., and Masson, S., 2003, "Evaluation of Commercially Available Techniques and Development of Simplified Methods for Measuring Grille Airflows in Hvac Systems,"Lawrence Berkeley National Laboratory. Berkeley, CA. LBNL-51551. 
[60]Beckwith, T. G., Marangoni, R. D., and Lienhard, J. H., 2007, "Mechanical Measurements," Pearson Prentice Hall, Upper Saddle River, N.J., pp. 71-82.

[61]Petrie, H. L., Wilson, P. M., and Smart, E. E., 1983, "Jet Pumping Oil Wells: Part I. Design Theory, Hardware Options and Application Considerations," World Oil, 197(6), pp. 51-56.

[62]Cunningham, R. G., 1957, "Jet Pump Theory and Performance with Fluids of High Viscosity," Trans. ASME, 79, pp. 1807-1820. 


\section{VITA}

Khalid Almutairi was born and raised in Jeddah, Saudi Arabia. Before attending the University of Missouri- Columbia, he attended the Riyadh College of Technology, Riyadh, where he earned a Bachelor's of Mechanical Engineering, with Highest Distinction, in 2006.

Starting in 2011, he began attending the University of Missouri- Columbia, working as a research assistant and receiving a Master's of Science in Mechanical, and Aerospace Engineering in 2012.

While at University of Missouri he has been a logistical organizer for the King Abdulaziz University Six-Week Internship Program. 